\title{
TRITIUM RETENTION IN TFTR
}

\section{Prepared by the D-T Materials Physics Collaboration}

Edited by

H. F. Dylla

Plasma Physics Laboratory, Princeton University

P.0. Box 451

Princeton, NJ 08543

and

K. L. Wilson

Sandia National Laboratories

P.0. Box 969

Livermore, Ca 94550

\section{ABSTRACT}

This report discusses the materials physics related to D-T operation in TFTR. Research activities are described pertaining to basic studies of hydrogenic retention in graphite, hydrogen recycling phenomena, first-wall and Iimiter conditioning, surface analysis of TFTR first-wall components, and estimates of the tritium inventory.

\section{DISCLAIMER}

This repart was prepared as an account of work sponsored by an agency of the United States Goverament. Neither the United States Government nor any agency thereof, nor any of their employees, makes any warranty, express or implied, or assumes any legal liability or responsibility for the accuracy, completeness, or usefulness of any information, apparatus, product, or process diselosed, or represents that its we would not inftinge privately owned rights. Referance herein to any specific commercial product, process, or service by trade name, trademark, manufacturer, or etherwise does not necessarily constitute or imply its endorsement, recom. mendaliot, or favoring by the United States Gove:nment or any agency therenf. The views and opinions of authors expressed herein do not necessarily state or reflect those of the United Stated Government or any agency thereof.

Joint Report prepared by Princeton Plasma Physics Laboratory (Report No. PPPL-2523) and Sandia National Laboratories (Report No. SAND-88-8212). This work was supported by U.S. DoE Contract Nos, DE-ACO2-76-CHO-3073 (PRPL) DE-ACOA-76DP00789 (Sandia). 
COATRIBUTORS: DT-MATERIALS PHYSICS COLLABORATION

$\begin{array}{ll}\text { A. Bastasz } & \text { (SNLL) } \\ \text { D. Brice } & \text { (SNLA) } \\ \text { J. Brooks } & \text { (ANL) } \\ \text { D. Buchenauer } & \text { (SNLL) } \\ \text { R. Causey* } & \text { (SNLL) } \\ \text { R. Llausing } & \text { (ORNL) } \\ \text { B. Doyle* } & \text { (SNLA) } \\ \text { H. F. Dylla } & \text { (PPPL) } \\ \text { A. Ehrhardt } & \text { (PPPL) } \\ \text { R. Fleming } & \text { (PPPL) } \\ \text { A. Haasz } & \text { (Univ. of Toronto) } \\ \text { Y. Hirooka } & \text { (UCLA) } \\ \text { H. Hsu } & \text { (SNLL) } \\ \text { S. Kilpatrick } & \text { (PFPL) } \\ \text { P. Lakarche } & \text { (PPPL) } \\ \text { W. Langer } & \text { (PPPL) } \\ \text { R. Langley } & \text { (ORNL) } \\ \text { S. Lee } & \text { (SNLA) } \\ \text { D. Manos } & \text { (PPPL) } \\ \text { R. McGrath* } & \text { (SNLA) } \\ \text { B. Mills } & \text { (SNLL) } \\ \text { R. Nygren } & \text { (UCLA) } \\ \text { A. Pontau* } & \text { (SNLL) } \\ \text { M. Ulrickson* } & \text { (PPPL) } \\ \text { H. Hanpler } & \text { (SNLA) } \\ \text { J. Whitley } & \text { (SNLA) } \\ \text { K. Wilsont } & \text { (SNLL) } \\ \text { K. Wright } & \text { (PPPL) } \\ \text { * Working Group Chairmen } \\ \end{array}$


TABLE OF CONTENTS

1.0 INTRODUCTION

PACE

2.0 TFTR D-T CONFIGURATION AND PROPOSED OPERATIONAL SCENARIO

2. 1 First-wall Configuration

2.2 Tritium Fueling and Recovery

2.3 Constraints to D-T Experimental Operations

3.0 LABORATORY MEASUREMENTS OF D-T RETENTION

3.1 Tritium Retention and Removal from Graphite and Codeposited Layers of Carbon and Tritium

3.2 Tritium Retention in TFTR Neutral Beam Lines and Copper Beam Dumps

4.0 IN-SITU MEASUREMENTS OF D-T RETENTION IN TETR

4. 1 Intraduction

4.2 Wall Loading and Particle Balance

4.3 Edge Probe Measurements

4.4 Surface Coupons

4.5 Planned Experiments

5.0 SUAFACE AND BULK ANALYSIS OF EIRST-WALL

SAMPLES REMOVED EROM TFTR

5.1 Introduction

5.2 Experimental

5.3 Results

5.4 Discussion

5.5 Conclusions

$\begin{array}{lll}6.0 & \text { MODELING OF D-T RETENTION } & \mathbf{8 7}\end{array}$

$\begin{array}{lll}6.1 & \text { Introduction } & 87\end{array}$

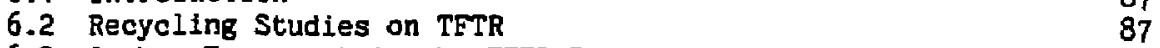

6.3 Carbon Transport in the TFTR Edge Region 90

6.4 MEASTRI: A Hybrid Analytical/Monte Carlo Code 93

6.5 Preliminary Results of the Redep/MEASTRI Model 94

6.6 The FDTD Model 95

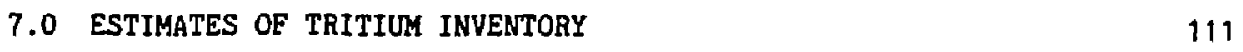

7.1 Introduction 111

7.2 Estimate of TFTR Tritium Inventory by Component 112

7.3 Estimate of Tritium Inventory From Particle Balance 116

$\begin{array}{lll}7.4 \text { Conclisions } & 117\end{array}$

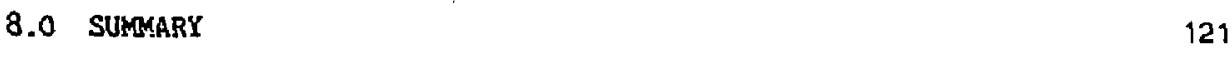

$\begin{array}{llr}9.0 & \text { BIBLIOGRAPHY } & 124\end{array}$ 


\subsection{INTRODUCTION}

During 1990-91, the last planned phase of TFTR operation will be dedicated to a limited series $(100-300)$ of full power ( $\geq 30 \mathrm{MW}$ ) D-T discharges. This phase of the TETR project has the scientific goal of demonstrating the plasma conditions of energy breakeven $(Q=1)$, and technical goals of demonstrating the tritium fueling of a magnetic fusion device. An important part of the latter goal is the analysis of the required tritium inventory.

The in-vessel tritium inventory is of great concern because of the limited on-site tritium inventory $(5 \mathrm{~g})$ for the TFTR project, and the goal of minimizing the fraction of vessel inventory that could be considered at risk during an accidental breach of the vacuum vessel. In order to guantify the constraints imposed by a $5 \mathrm{~g}$ limit to the on-site inventory and assess the consequences of posed accidents, estimates of the tritium inventory within the vessel during operational periods are necessary. A majority of the tritium inventory remaining in the vessel will be codeposited with carbon eroded from the graphite first-wall.

Tritium inventory estimates have been made for the TFTR vessel based on in-situ measurements of deuterium particle balance, measurements of hydrogen isotope (deuterium and tritium) retention in the graphite tiles and wall coupons removed from TETR, and laboratory studies and modeling of hydrogen isotope plasma interactions with graphite. An extensive data base has been gathered which is useful not only for predicting the in-vessel tritium inventory, but also for providing guidance on plasma operational techniques that minimize tritium inventory. The data base and analysis supporting the TETR tritium inventory estimates are contained in this report, which was prepared by the D-T Materials Physics Collaboration involving Princeton Plasma Physics Laboratory, Sandia National Laboratories, Oak Ridge National Laboratory, Argonne National Laboratory, the University of California (at Los Angeles), and the University of Toronto.

This report summarizes the research activities of the D-T Materials Physics Collaboration since it was chartered in October 1986 to prepare tritium inventory estimates for TFTR. As part of this effort five working groups were established under the topics of: 1) laboratory simulations; 2) in-sitù measurements (in TFTR); 3) post-run surface analysis; 4) modeling; and 5) tritium inventory. The interests and output fron these working groups have broadened from the original goal of inventory estimates to include many topics of concern for the aperation of tokamaks with graphite first-wall structures. These ancillary topics include basic measurements and analysis of hydrogen retention in graphite, particle control and recycling phenomena in 
TFTR, redeposition of first-wall materials, and tritium release rates with ion bombardment (glow discharge cleaning) and air exposure.

The organization of this report is keyed to the working groups. Section 2.0 presents a summary of the items from the TFTR D-T Plan [1] that form the basic working assumptions on the D-T discharge scenario, D-T fueling rates, and operational constraints for the 1990-91 D-T experiments in TFTR. Section 3.0 presents measurements from laboratory simulations of the relevant hydrogen-carbon interactions, including retention measurements as a function of graphite temperature, simulations of tokamak first-wall conditioning and isotope exchange, and tritium adsorption-desorption phenomena on neutral beam component materials. Section 4.0 presents in-situ studies on TFTR, including particle balance measurements and edge-plasma characterization with electrostatic probes and $H_{a}$ emission measurements. Section 5.0 presents extensive data from the surface analysis of first-wall and limiter samples removed after the 1985-87 operations period on TFTR. These measurements include three-dimensional profiles of the retalned deuterium and preliminary measurements of the small quantity $(\sim 0.15 \mathrm{Ci})$ of retained tritium that was generated during the run by $D-D$ fusion reactions. Section 6.0 describes the first phase of an extensive modeling effort that involves the marriage of several solid-state and edge-plasma computer codes. The eventual goal of the modeling effort is to predict the temporal and spatial dependence of tritium retention and recycling.

Section 7.0 presents the tritium Inventory estimates for TFTR consistent with the D-T discharge scenario described in Sec. 2.0. The inventory is estimated by two methods: One method is an inventory itemized by first-wall components based primarily on the deuterium retention measurements given in Sec. 3.0. The second estimation method is based on particle balance measurements in TFTR and yislds an approximate prediction for the shot-to-shot dependence of the inventory. A brief summary of the working group results is given in Sec. 8.0 followed by a bibliography (Sec. 9.0) of the recent publications generated by the colidooration.

H. F. Dylia

K. L. Wilson

Co-Chairmen

D-T Materials Physics Collaboration

April 1988

\section{REFERENCE}

[i] TFTA D-T Plan, Princeton Plasma Physics Laboratory Internal Report No. DTSD-R-5 (May 1988). 
2.0 TETR D-T CONFIGURATION AND PROPOSED OPERATIONAL SCENARIO

\section{1 First-Wall Configuration}

During the 1985-87 operations period, the first-wall structure of TFTR (See Fig. 2.1) consisted of a water-cooled, toroidal bumper limiter, a cooled, moveable limiter, and cooled, protective armor to shield the vaculum vessel from neutral beam shinethrough [1]. In addition, there were Inconel and stainless steel bellows cover plates to protect the vacuum vessel bellows $[2,3]$, and the Zr/Al Surface Pumping System [4] which provided enhanced pumping in the torus and also served to protect the bellows. The bumper limiter and protective armor have the same basic construction of cooled Inconel-718 backing plates supporting POCO ${ }^{\mathrm{TM}}$ graphite (grade AXF-5Q) tiles [5]. FOCo ${ }^{\mathrm{TM}}$ graphite was chosen as the best substrate for a $\mathrm{TiC}$ coating [6]. The protective armor tiles are coated with $20 \mu \mathrm{m}$ of $\mathrm{TiC}$ while the bumper limiter tiles are uncoated.

To further extend the plasina heating capabilities of TFTA, a pair of ICRF antennas capable of handling $7 \mathrm{MW}$ of injected power were installed on the device late in 1987. The plasma-facing surfaces of these antennas are protected with carbon tiles. In addition, two poloidal ring limiters $[7,8]$ were installed on the outer midplane, toroidally upstream and downstream of the RF antennas, as further protection. These RF antenna-limiters replaced the TFTh moveable limiter. The surface pumping system was also removed. The first-wall structure of the device is now complete as envisioned through the final stage of D-T operation scheduled for 1990-91.

\subsection{Tritium Fueling and Recovery}

The envisioned plasma scenario for the TFTR D-T phase is the enhanced confinement, neutral-beam-fueled mode, otherwise referred to as the "supershot" mode $[9,: 0]$. In this mode practically all the plasma fueling is provided by the four neutral beans, two operated with deuterium and two operated with tritium. The estimated fueling rates are given in Table 2.1. Because of the relative inefficiency of the beamline, only a small fraction ( $5 \%)$ of the tritium input to the beamlines appears as high energy tritons in the torus.

All gas handling during the D-T phase will occur in a cycle which eliminates atmospheric venting of exhaust gases [11], During H-D operations of TFTR, exhaust gases from the torus vacuum pumping and neutral beam vacuum punping systems are routed to the stack vent. With D-T plasma operations, all vacuum exhausts (which are dominated by the periodic regeneration of the neutral beam eryopanels) will be routed to the Plasma Exhaust Tank (PET). The PET is an explosion-proof tank having a maximum capacity of 475,000 torr 
liters. Following cessation of an experimental run, exhaust gases from the PET will be transferred to approved shipping containers for shipment to and processing by one of the national tritium handling facilities. Plasma operations will be constrained to maximum (H,D,T) gas loads of approximately $1 / 3$ capacity of the DET in order to minimize the number of shipping containers that are required per operational cycle.

\subsection{Constraints to D-T Experimental Operations}

A number of technical and administrative constraints limit the planned experimental operations of TFTR during the D-T phase. These constraints as presently defined are:

1) 40-week operations period for the D-T phase (Sept. 1990 - June 1991).

2) Maximum D-T neutron fluence of $1.5 \times 10^{19}$ per discharge and $3 \times 10^{21}$ for the entire D-T run.

3) A limit of 2.5 \& of tritium loaded onto a hot uranium-tritide storage canister (U-bed) in the Tritium Storage and Delivery System (TSDS) [12].

4) Maximum on-site tritium inventory of $5 \mathrm{~g}$.

5) Maximum Plasma Exhaust Tank (PET) capacity of 475,000 torr-liters.

A self-consistent operational scenaric which satisfies these constraints is presented in this section. The upper limit to the $D-T$ neutron fluence (constraint 2) limits the maximum number of high-Q D-T discharges to approximately 300. However, the remaining four constraints will most likely limit the high-Q discharges to the range of 50-100, while allowing a somewhat larger number, 200-300, of low-Q D-T discharges.

The tritium fueling efficiency of the neutral beam injectors will allow a relatively small number of Tritium Neutral Beam (TNB) shots per $2.5 \mathrm{~g}$ loading of the U-beds in the Tritium Storage and Delivery System (TSDS). Table 1.6 shows that 672 torr-liters, or $2.3 \mathrm{kCi}$ of tritium, are reguired to fuel a single 6-source TWB shot. For each $2.5 \mathrm{~g}$ loading of the TSDS an overhead of $0.8 \mathrm{~B}$ is estimated for piping and storage volume inventories between the TSDS and the TNB [11]. Therefore, each U-bed loading will allow a maximum of 8 TNB shots. Most of the deuterium and tritium input to the neutral beams will be deposited onto the NB cryopanels, as will the plasma exhaust following the cessation of a discharge. After 8 TNB shots, the gas inventory on the NB 
cryopanels will be recovered by regenerating the He panels and transferring the desorbed gases to the Plasma Exhaust Tank (PET). The total quantity of gas transferred will depend on the total quantity of gas input to the system and the recovery efficiency. In addition to the $\mathrm{D}_{2}$ loading ( 840 torr-Iiters) and $\mathrm{T}_{2}$ loading ( 672 torr-liters) for the 8 TWB shots, the dominant input gas load will come from the neutral beam conditioning required to ensure a reliable 8-shot TNB run. For the proposed high-Q TNB run scenarto (see Table 2.2), approximately 150,000 torr-liters of exhaust gas are generated during a 3-shift period, Vessel conditioning and NB conditioning prior to the TNB operation and an additional $5 \mathrm{NB}$ conditioning shots (in $\mathrm{D}_{2}$ ) precede each of the TNB-plasma shots. Seven additional shifts are estimated to be required to process the effluent gases: transfer to the PET, unload to shipping containers, assay tritium zontent, and transfer to the designated exchange point to pick up a new $2.5 \mathrm{~g}$ tritlum shipment. Any change in the assumptions which generates a larger gas load, e.g., more conditioning shots, will increase the cycle time by increasing the number of shipping containers which must be handled to unload the PET.

If less than $6 \mathrm{NB}$ sources are run on tritium, then the number of TNB shots per U-bed loading cycle can be increased. A scenario where the run is unconstrained by tritium (and is, therefore, constrained by gas-handling requirements) is a TNB run with 1-6 sources operating with trace tritium (1\% $T / D$ ) levels. This small isotopic mixture of tritium in deuterium will not affect the beamline optics; however, the tritium will be useful for diagnostic purposes. This scenario could be run for 23 shots at which point slightly more than 300,000 torr-liters of exhaust gas (or $64 \%$ of the PET capacity) would have been generated. Operation of one or more NB sources with pure tritium will fall between the limiting cases represented by this scenario and the Table 2.2 TNB scenario.

The number of times these operations cycles could be repeated depends on the tritium inventory constraint (4) and the length of the operations period constraint (1). If tritium were completely recoverable from the vessel and neutral beamline vacuum systems (i.e., if the inventory were negligible), then the number of repeat cycles for the 8-shot TNB scenario would be constrained first by the limited time period for the D-T phase and then by the total neutron fluence.

A strawman scenario for the 40 -week $D-T$ phase is given in Table 2.3. The run starts with 4 weeks of vessel conditioning followed by 6 weeks of D-D and 18 T-D operation. Week 11 is then devoted to TNB testing. A second full parameter D-D run is then scheduled for the next 6 weeks which can include more $18 \mathrm{~T}-\mathrm{D}$ operation and $\mathrm{T}$-ohmic plasma studies. Following a 2-week break, the remaining 18 weeks comprise the low-Q, medium-Q and high-Q experiments with weekly cycles sjmilar to the TNB scenario of Table 2.2. 
REFERENCES

[1] J. L. Cecchi, J. Nucl. Mater. 93/94 (1980) 28.

[2] P. Winkler et al., in Proc, 9th Sym. on Engineering Problems of Fusion Research, Chicagc, October, 1981 (IEEE, New York, 1982), p. 1383.

[3] P. Winkler et al., ob. cit, p. 1387.

[4] J. L. Cecchi and R. J. Knize, J. Vac. ScI. Technol. A2 (1984) 1214.

[5] POCO is a registered trademark of POCO Graphite Corporation.

[6] M. Ulrickson, J. Vac. Sci. Technol. 18 (1981) 1037.

[7] G. W. Labik et al., in Proc. 12th Sym. on Fusion Engineering, Monterey, 1987 , in press.

[8] R. Ritter and M. Ulrickson, ob. cit.

[9] J. D. Strachan et al., Phys. Rev. Lett. 58 (1987) 1004.

[10] R. 3. Goldston et al., in Proc. 11th Intern. Conf. on PIama Physics and Controlled Nuclear Fusion Research, Kyoto, 1987. (IAEA, Vienna, 1987) Paper No. IAEA-CN-471A-II-1.

[11] TFTR D-T Plan, Princeton Plasma Physics Laboratory Internal Report No. DTSD-R-5 (May 1988).

[12] J. T. G111 et al., J. Vac. Sei. Technol. Al (1983) B56. 
TABLE 2.1

SULFARY OF ESTIMATED GAS FLOWS: HIGH POWER DISCHARGES

TORUS FUELING REQUIREMENT

INJECTION SYSTEM INPUT

(torr-liters/discharge)

(torr-liters/discharge)

GIS

$\mathrm{NBI}^{3}$

$\mathrm{NBI}^{4}$

MODE

$6 \mathrm{D}_{2}$ Sources $\quad 6 \mathrm{~T}_{2}$ Sources

High density ${ }^{1}$

gas-fueled $\mathrm{OH}$

with NBI

Low density ${ }^{2}$

3

gas-fueled OH

with NBI

40
66

840

672

$(2.3 \mathrm{kCi})$

66

840

672

1) Assumes OH target plasma density of $6 \times 10^{19} \mathrm{~m}-3$

2) Assumes OH target plasma density of $1 \times 10^{19} \mathrm{~m}^{-3}$

3) Assumes 12 sources injecting into torus for 2s; $60 \mathrm{~A}$ \& $120 \mathrm{keV} / \mathrm{source}$ at $0.8 / 0.15 / 0.05$ species mix

4) Assumes 20 torr-1/s $* 5.6 \mathrm{~s}=112$ tarr-1 per $\mathrm{T}_{2}$ source and 25 tor $r-1 / \mathrm{s} * 5.6 \mathrm{~s}=140$ torr -1 per $\mathrm{D}_{2}$ source

GIS: Gas Injection System

NBI: Neutral Beam Injection 
TABLE 2.2

\section{TRITIOM NEUYTRAL BEAY SCENARIO 1 (10-shifts)}

Assumptions :

1. $6 \mathrm{NB}$ sources operated with pure tritium; $6 \mathrm{NB}$ sources operated with $\mathrm{D}_{2}$.

2. $1.8 \mathrm{~g}$ of deliverabie tritium per U-Bed loading of $2.5 \mathrm{~g}$.

3. All gas exhaust to the PET (P1asma Exhaust Tank)

$D_{2}$ Cas Load $\quad T_{2}$ Gas Load

(törr-liters) (torr-1iters)

Shift 1: Plasma Condition Ing and Diamnost te Check-Out

$\mathrm{D}_{2}$

120

(He)

4-8 hr. He oH fiducials $e 4$ shot $/ \mathrm{hr}$.

Shift 2: Tritium Neutral Beam Operation

$0-2 \mathrm{hr} .48$, NB conditioning shots in $\mathrm{D}_{2}$

e 24 shot/hr.

80,640

0

2-9 hr. 8, T-NB shots into plasma

e 1 shot/hr. preceded by 5 accel

6,720

5,376 conditionting shots in $D_{2}$

e 1 shot $/ 2.5 \mathrm{~min}$.

58,800

0

Shift 3: Post-TNB Vessel Clean-Up

0-4 hr. He conditioning

120

0

4- $\delta$ hr. NB cryopanel regeneration

and transfer to PET (Start)

TOTAL

Shift 4-10: Gas Processing

Complete NB cryopanel regeneration

Transfer exhaust gas to PET

Unload PET

Transfer new $2.5 \mathrm{~g}$ load of tritium to U-bed. 
TABLE 2.3

No. $0 r^{\circ}$

D-T RUN PLẠN

Plasma

Neutron Fluence

Shots

n $(2.5 \mathrm{MeV}) \leq 10^{19}$

92

n $(2.5 \mathrm{MeV}) \leq 10^{19}$

Bakeout, GDC, PDC

Diagnostic checkout

First $50 \mathrm{kCi}$ shipment on site

Full power DD run

$50 \mathrm{kCl}$ Tritium System checkout

Start tracking gas exhaust

18 I/D diagnostic checkout

Week

n $(2.5 \mathrm{MeV}) \leq 10^{19}$

46

DD run w/o access

is $\mathrm{T}$ in $\mathrm{D}$ for checkout

Test run of 2 NB in T (not in tokamak)

8 TNB shots, Tokamak System maintenance

Repeat D (2-times)

E. $12-13$

Full parameter run with NB in Deuterium F $14-15$ 12. $\mathrm{T}$ in Deuterium

46

Ohmic discharges - 1 NB source in

Deuterium and $\uparrow$ NB source in Tritium

Vessel conditioning (CDC, YYe conditioning)

Analyze events weeks 1-19. Vacations.

$n(14 \mathrm{MeV}) \leq 10^{19}$

92

Low $Q$ experiments: TNB Scenario 2

$1 \mathrm{NB}$ source in $\mathrm{T}$; varying number of sources in Deuterium; 1 TNB Scenario 2 cycle per week; 23 shots per cycle

Repeat J 3-times

Vessel conditioning

n (14 MeV) $\leq 10^{21}$

High $Q$ experimerits: TNB Scenario 1

$2 \mathrm{NB}$ in $\mathrm{T} ; 2$ NB in $\mathrm{D} ; 2$ THB Scenario 1 cycles per week; $B$ shots per cycle

Bepeat 5 -times

$n(14 \mathrm{MEV}) \leq 10^{21}$

Vessel conditioning

$\mathrm{n}(14 \mathrm{MeV}) \leq 1 \times 10^{20}$

Medium Q experiments: TNB Scenario 1 2 NB in $T ; 2$ NB in D; 2 TNB Scenario 1 cycles per week; 8 shots per cycle

$n(14 \mathrm{MeV}) \leq 5 \times 10^{20}$

Repeat P 5-times 


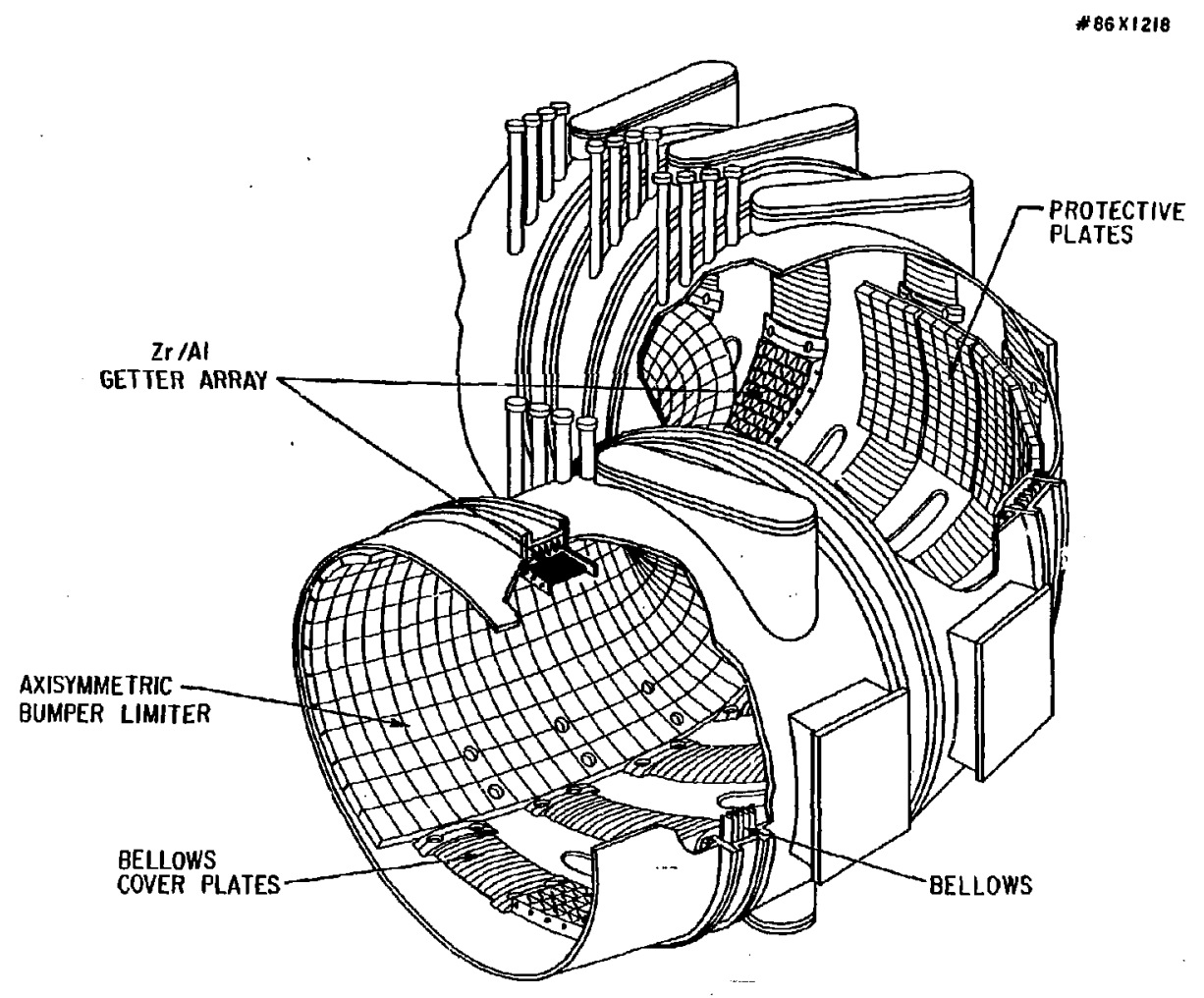

Fig. 2.1. Diagram of the TFTR vacuum vessel and first-wall components [1]. 


\subsection{LABORATOHY MEASUREMENTS OF D-T RETENTION}

Contributors: Laboracory Simulation Working Group

R. A. Causey, Chairman

3.1 Tritium Retention and Bemoval from Graphite and Codeposited Layers of Carbon and Tritium

\subsubsection{Tritium Retention in Graphite}

Hydrogen is found in rather large quantities in graphite. This hydrogen may be partially in the form of water vapor at lower temperatures and may also be an integral part of the graphite crystallites thenselves. However, tritium introduced during TFTR operation will not necessarily be retained to the same extent.

When tritium becomes used as a fuel in TFTR, there will be three mechanisms by which tritium will be retained in toe graphite and carbon-carbon composites used as plasma facing materials [1-3]. The temperatures where the different mechanisms control the retention are shown in Eig. 3.1. One mechanism is the saturation of the implant region. This mechanism has been studied extensively $[4-6]$, and the model used to deseribe it is called the Local Mixing Model [7]. At temperatures below about $800 \mathrm{~K}$ tritium is immobile in graphite crystaliltes. Tritium injected into graphite at lower temperatures diffuses throughout the region near the range of the energetic particles until saturation is reached. At that time, the tritium migrates back into the heavily damaged region near the surface. Eventually the entire region from the external surface to the end of the energetic particle range becomes saturated, and any additional atoms or lons entering the graphite result in an equal number being released from the external surface or to the internal pore surfaces. At room temperature and below, the saturated region has a tritium to carbon ratio of approximately 0.4 . Because the thickness of the saturated layer is limited to that of the range of the energetic particles, this mechanism results in tritium retentions less than about $2 \times 10^{17} \mathrm{~T}_{\mathrm{cm}} \mathrm{cm}^{2}$ for triton energies in the keV range. As the temperature of the graphite is increased, the stability of the saturated layer is decreased, resulting in lower retention.

Graphites and carbon-carbon composites are normally porous materials. POCO AXF-50, the graphite used in TFTR, has a density of only $1.84 \mathrm{~g} / \mathrm{cm}^{3}$ and a BET surface area of almost $1 \mathrm{~m}^{2} / \mathrm{B}$ [1]. As the near-surface region of the graphite becomes saturated when exposed to a tritium plasma, some of the tritium finds its way to the surface of the pores and can diffuse deep into the graphite. The depth of penetration depends on the temperature of the graphite and the duration of the exposure. In theory, it should be possible 
to saturate the entire internal surface of the graphite with a monolayer of tritium. For a surface area of $1 \mathrm{~m}^{2} / \mathrm{g}$, this would result in volunetric concentrations of about $5 \times 10^{18} \mathrm{~T} / \mathrm{cm}^{3}$. In reality, concentrations of this magnitude are not observed. Because of the limsted mobility of the tritium on the graphite surface, temperatures in the range of $700 \mathrm{k}$ or above are required to allow deep penetration of the tritium. At these higher temperatures, the graphite is not able to maintain a monolayer of tritium on the surfaces, and release in the form of molecular tritium occurs. In tests performed in the Tritium Plasma Experiment (TPX) using virgin samples of FOCO AXF-50 graphite, penetration depths of only a few hundred microns were measured for samples exposed to a ritium plasma at $573 \mathrm{~K}$ and $773 \mathrm{~K}$ for 1.5 hours. In contrast to these results, similar experiments performed with graphite tiles removed from TFTR showed enhanced penetration to several millimeters [8]. Meta! deposits in the near-surface region may have been responsible for the enhanced migration rate, but they also resulted in lower surface coverage of ti:e pore surfaces. The net result was a low concentration tail extending deep into the sample with the cumulative amount of tritium being the same as for the virgin graphite. Also, conditioning prior to plasma exposure was not seen to have a significant effect on the amount of tritium retained in the graphite after removal from the plasma. No enhancement in retention was noted for a sample exposed to steam immediately prior to plasma exposure or for a sample intentionally oxidized by rapid heating to $1273 \mathrm{~K}$ before water vapor had a chance to escape. These results are shown in Fig. 3.2.

The FISCES Group at UCLA investigated the surface modification of. graphite by helium plasme bombardment and its effect on hydrogen isotope retention [9]. They found that a 100 eV helium ion fluence of $5 \times 10^{21}$. ions/cm ${ }^{2}$ sitnificantly increased surface pore opening. From the gettering capacity of residual gasses after the exposure, they calculated a surface rouginess factor of 345. From H-alpha measurements they found the dynamic hydrogen retention of the hellum pre-activated surface to be as large as $2 \times$ $10^{18} \mathrm{H} / \mathrm{cm}^{2}$ at temperatures below $373^{\circ} \mathrm{K}$. For a pre-activated sample that had recently been saturated with hydrogen, the dynamic retention was still almost $1 \times 10^{18} \mathrm{H} / \mathrm{cm}^{2}$. The experimental results are shown in Fig. 3.3. Both of these values are higher than that achieved in similar experiments with nonactivated samples. An explanation suggested by the experimenters is enhanced dynamic retention associated with the increase in porosity that actuaJ.1y connects with free surface after the carbon grit that blocks the pores has been removed in the plasma cleaning process. This increase in pornsity open to the free surface would allow greater tritium coverage of the internal porosity.

The third mechanism of tritium retention in graphite is the true diffusion of tritium into the graphite crystallites. This occurs only at 
temperatures above about $1000 \mathrm{~K}$. As the tritium migrates into the crystallites, it is caught in $4.3 \mathrm{eV}$ traps with a density of 5 to 20 appm [1], depending on the type of graphite. It is the trapped tritium that dominates the retention because of the apparent low solubility of tritium in graphite. For POCO AXF-5Q graphite, saturation of the traps results in a uniform loading of $1.7 \times 10^{18} \mathrm{~T} / \mathrm{cm}^{3}$. Concentrations this high have been obtained for poco AXF-50 graphite exposed to the plasma and $0.66 \mathrm{~Pa}$ gas pressure in TPX at $1300^{\circ}$ $B$ for only several hours. It has been shown through the comparison of results for gas-only exposures and exposures to both plasma and gas that the gas pressure and not the plasma is principally responsible for this loading. The gas easily enters the graphite porosity and acts as a source of tritium for the $10 \mathrm{um}$ grains inside the samples. It is stiil not known at this time if it is possible to uniformly load thick graphite tiles in this manner if the gas pressure is not present. The gas pressure in TFTR near the graphite tiles is not nearly as high as the $0.66 \mathrm{~Pa}$ in $\mathrm{TPX}$.

The RF antenna limiter for TFTR is composed of B. F. Goadrich Staple Knit ${ }^{T M}$. Carbon-Carbon Composite. Measurements performed in TPX showed this composite and several others to retain less tritlum than POCO AXF-5Q graphite at all temperatures between room temperature and $1500 \mathrm{~K}$ [10].

Although tritium retention measurements performed in TPX have shown tritium concentrations in graphites to be limited to a few parts per million, laboratory measurements by B. Doyle, R. Bastasz, and A. Haasz et al. have shown graphite to contain protium in substantially larger quantities. Doyle [11] reported hydrogen concentrations in POCO AXF-5Q graphite of $1.0 \%$ to $1.3 \%$ atomic with the readings peaking at $5 \%$ on the surface. The measurements were made with fluorine-19 resonant nuclear reaction analysis. He found that only an insignificant amount of the hydrogen could be outgassed with vacuum baking at $873^{\circ} \mathrm{K}$. Bastasz [11] used SIMS to profile the hydrogen soncentration in POCO graphite. His results indicated that at a depth of 5 to to um from the surface, untreated POCO graphite has a residual hydrogen level of approximately $0.45 \mathrm{H} / \mathrm{C}$. Vacuum annealing at $1173^{\circ} \mathrm{K}$ reduced this leivel by over an order of magnitude. Examination of the deuterium to protium ratio in the depth profile did not show any significant deviation from natural abundance. Beutler et al. [13] measured protium conceitrations in pyroljtic graphite using laser-induced thermal desorption spectrometry. For a sample baked at $500 \times$ for 24 to 48 hours, the residual protium concentration was about $0.1 \%$ to $1 \% \mathrm{H} / \mathrm{C}$. This level was reduced progressively by about four orders of magritude following vacuum annealigg at temperatures ranging up to approximately $2400 \mathrm{~K}$. 


\subsubsection{Tritium Retention in Layers of Codeposited Carbon and Hydrogen}

During plasma interaction with graphite tiles, carbon is constantly eroded and redeposited. Hydrogen chemically reacts with the eroded carbon and is codeposited to form a hydrogen-rich carbon layer. Thick carbon deposits with high levels of hydrogen have been observed on graphite tiles exposed to TETR discharges. The main concern about codeposition is its capacity for enhancing the in-vessel tritium inventory. Although our present studies of codeposited layers are based on protium and deuterium, we do not expect tritium to behave any differently.

The major mechanisms responsible for the erosion of graphite under plasma exposure include: physical sputtering, chemlcal erosion, radiation-enhanced sublimation (RES), and thermal sublimation. These mechanisms dominate over the following temperature ranges: (a) physical sputtering, $T<600 \mathrm{~K}$; (b) chemical erosion, $600 \mathrm{~K}<\mathrm{T}<1000 \mathrm{~K}$; (c) RES, $\mathrm{T}>1200 \mathrm{~K}$; (d) thermal sublimation, $T>2500 \mathrm{~K}$. The data base for physical sputtering is reasonably well established. This process occurs in the temperature range for first-wall actively cooled protective tiles. At the high end of the temperature scale ( $T$ > $2500 \mathrm{~K}$ ) thermal sublimation dominates, and such a condition normally occurs only during disruptions and runaway current events. Normal operation for wall tiles, without active cooling, is expected to be in the chemicalerosion-dominated regime $(600 \mathrm{~K}<\mathrm{T}<1000 \mathrm{~K})$. Normal operation for limiters is expected to be in the RES-dominated range $(T>1200 \mathrm{~K})$. In the case of chemical erosion, the dominant hydrocarbon formed due to energetic hydrogen ion impact is methane. For combined energetic ions and thermal atoms, as in the case of fusion reactors, the nigher order hydrocarbons also become a significant part of the carbon erosion [14]. At $T>1200 \mathrm{~K}$, a significant increase in the erosion of carbon occurs due to the impact of srengetic ions. The released carbon is monatomic (not $c_{2}$ and $c_{3}$ as for thermal sublimation) with a thermal energy distribution corresponding to the substrate temperature: A model based on the formation of carbon interstitials during ion impact has been proposed to explain the enhanced sublimination $[13,14]$. New results of the flux dependence of RES due to hydrogen ion impact [15] and argon ion impact [14] show a quasilinear dependence of RES with incident ion flux, in disagreement with the proposed model.

The codeposition process has been investigated in plasma simulators by both Hsu et al. [3] and Clausing et al. [18]. In the work of Hsu, a deuterium Penning discharge was struck with POCO AXF-5Q graphite cathodes. After a period of discharge operation, a codeposited layer with a $D$ to $C$ ratio of about 0.5 was formed on a catcher foil adjacent to the graphite cathodes. The trapping of deuterium by codeposition resulted in a removal of the deuterium feed gas. Based on the deuterium concentrations measured in the film, 
approximately one-half of the removed deuterium gas can be accounted for in the layer. The amount of deuterium trapped in the graphite cathodes was relatively insignificant, which is consistent with earlier studies on hydrogen isotope retention in bulk graphite. The rate at which deuterium gas was removed was constant and no abatement of the rate was observed even over long periods of operation. The codeposition process, therefore, can go on indefinitely without any apparent self-limiting mechanism.

A nonsaturable hydrogen pumping phenomenon has been observed on TFTR [19]. (See Sec. 4.2.2). After a typical low density, ohmic discharge with a non-conditioned graphite wall, only 5 torr-liters of hydrogen are outgassed out of a total of 20 torr-liters of feed gas [20]. Although there is no direct proof that the differential of 15 torr-liters is trapped in carbon films, the non-saturable removal is a strong indication that this phenomenon is due to codeposition. In the work of Clausing, a graphite-lined hollow cathode discharge was used. A similar nonsaturable removal of hydrogen gas was observed when a hydrogen plasma was struck with the graphite electrodes. The rate of removal $(0.5 \%)$, however, was much smaller than that observed by Hsu (17\%) for the same ion flux to the graphite. This difference was presumed to be due to differences in the discharge geometry. In the case of Hsu, the eroded carbon has a high probability of escaping the discharge and depositing on a non-plasma contacting wall. The set-up of Clausing was much more closed, with the eroded carbon having less probability of escape.

In the work of Langley [21], a nonsaturable removal process was also observed. Although interpreted at the time to be diffusion of the hydrogen into the graphite, the lack of supporting data suggests that this also was caused by the codeposition process.

\subsubsection{Release of Tritium from Graphite and Codeposited Layer}

The mechanisms of tritium release are as important to the operation of TFTR as the mechanisms of retention. If glow discharge cleaning can be used to renove tritium from the codeposited layer, then that retention mechanism loses its importance for the long-range inventory problem. By the same token, the release of tritium from graphite during air exposure would elevate safety concerns about the possible breach of the vacuum vessel. Several experiments have been performed to examine some of these release mechanisms.

In TFTR it has been found that conditioning the limiter with low density helium/carbon plasmas significantly improves the confinement for subseguent neutral-beam-heated plasmas [19]. The improved confinement is thought to result from the removal of hydrogen from the graphite limiter by the conditioning plasmas. Wampler et al. [22] used ion implantation and nuclear

reaction analysis to investigate ion-induced release of deuterium from 
graphite during low-energy carbon and helium bombardment as a possible mechanism for the conditioning. Graphite samples were initially saturated with deuterium at $300 \mathrm{eV}$. The areal density of deuterium remaining in the samples was then monitored during bombardment with 3 kel carbon ions and with 1.2 and $0.6 \mathrm{keV}$ hellum ions. The energies of the carbon and helium lons were chosen to give ranges comparable to the depth of the initially implanted deuterium and were simflar to energies expected at the 1 imiter in TFTR. Release yields at low fluences were on the order of 6 deuterium atoms per incident ion for the carbon and $1.2 \mathrm{keV}$ helium ions. Release yields for the $0.6 \mathrm{keV}$ helium ions were about $2 \times 10^{16} \mathrm{D} / \mathrm{cm}^{2}$ for fluences of $1 \times 10^{17}$ ions $/ \mathrm{cm}^{2}$. The deuterium release was consistent with a model based on ioninduced detrapping with retrapping [23].

Hsu used a DC-glow discharge in the Laser Assisted Material-Plasma Experiment (LAMPE) to study the removal of hydrogen f'rom a codeposited layer of hydrogen and carbon. In these experiments, a known amount of hydrogen was first codeposited with carbon on the vacuum vessel walls by measuring the pressure change in the isolated chamber during a Penning discharge. The carbon originated from the graphite electrodes. A 41 mtorr differential pressure decrease was recorded for the 60-liter chamber during the Penning discharge. In the subsequent glow discharge removal process with helium, only 15 mtorr of the differential pressure loss were recovered with a voltage of $400 \mathrm{~V}$. When the helium was replaced with hydrogen and the discharge repeated, an additional 9 mtorr of pressure rise were recorded.

An experiment was performed in TPK to examine the efficiency of glow discharge cleaning with deuterium to remove tritium deposited into the saturated layer and porosity of POCO AXF-5Q graphite. The graphite sample was exposed to a fluence of $3 \times 10^{20} \mathrm{~T} / \mathrm{cm}^{2}$ at an energy of $100 \mathrm{eV}$ over a 1.5 hour time span at $323 \mathrm{~K}$. It was removed from the experimental apparatus where it was mechanically sectioned, dissolved, and the tritium content determined using liquid scintillation counting. A second sample was treated to the exact same conditions except that it was exposed to a deuterium plasma after the tritium plasma. Like the tritium plasma, the deuterium exposure was for 1.5 hours at $323 \mathrm{~K}$ with a fluence of $100 \mathrm{eV}$ deuterons of $3 \times 10^{20} \mathrm{D} / \mathrm{cm}^{2}$. The tritium distribution for the two samples are shown in Fig. 3.4. It can be seen that the deuterium exposure reduced the tritium retention by about one order of magnitude.

The PISCES group investigated the effect of helium plasma exposure on the amount of hydrogen remaining in saturated layers of POCO graphite using helium ion energies of 15 to $300 \mathrm{eV} \mathrm{[9].} \mathrm{The} \mathrm{cross} \mathrm{section} \mathrm{for} \mathrm{removal} \mathrm{was} \mathrm{of}$ the order of $10^{-19} \mathrm{~cm}^{2}$ for all energies. This helium depletion technique was seen to decrease the hydrocarbon formation rate during subsequent hydrogen plasma exposures. 
Langley also studied the helium-ion-induced release of hydrogen from the saturated surface layers of POCO AXF-5Q graphite [24]. He found the release cross sections to be essentially the same as the detrapping cross section, indicating little retrapping for the $350 \mathrm{eV}$ energy used for the helium ions. His results plotted with previous results of Wampler and Myers [23] and Roth et al. [25] are shown in Fig. 3.5.

The LAMPE facility was also used by Hsu to examine the effect of air exposure on codeposited layers of hydrogen isotopes and carbon. A deuterium plasma was used with a graphite electrode to deposit a layer containing about $2 \times 10^{18} \mathrm{D} / \mathrm{cm}^{2}$ on a stainless steel catcher foll. The deuterium concentration in the film was measured at 24 days, 73 days, and 88 days after the deposition. The sample was exposed to air during the entire walting time. The results showed (Fig. 3.6) the deuterium concentration to be dropping exponentially with air exposure time with an exponential folding time of 87 days.

Thermal desorption is another mechanism by which hydrogen isotopes can be removed from graphite. A compllation of the data in the literature [26-28] for the thermal release of hydrogen implanted into graphite is shown in Fig. 3.7. It can be seen that the releases measured by the three experimenters agreed very well even though different energies and types of graphite were used. The factor common to the three experiments was that all were continued to saturation. It was noted that release from nonsaturated samples is very similar, but has a $200^{\circ} \mathrm{C}$ to $300^{\circ} \mathrm{C}$ shift to higher temperatures for the release curves. In experiments performed by Causey using a tile removed from TFTR, samples were cut from an area containing $1 \times 10^{13} \mathrm{~T}^{2 \mathrm{~m}^{2}}$. One-hour anneals in vacuum at $473 \mathrm{~K}, 773 \mathrm{~K}$, and $1073 \mathrm{~K}$ reduced the amount of remaining tritium by $0 \%, 40 \%$, and $95 \%$, respectively. These data points fall almost exactly on the curve shown in FiB. 3.7.

\subsection{Tritium Retention in TETR Neutral Beam Lines and Copper Beam Dumps}

\section{-3.2.1 Tritium Retention in TFTR Neutral Bean Line Component Materials}

Experiments have been performed both at Sandia, Livermore and at Los Alamos to examine the uptake of tritiun by neutral beam line somponent materials. For both sets of experiments, samples were exposed to 1 torr of pure tritium gas for 1 hour, followed by 30 minutes in vacuum prior to removal for tritium analysis. In the Sandia study, the samples were inmersed in dilute sulfuric acid for 15 minutes to remove the absorbed tritium. The acid solution was distilled, and a neutralized sample was collected for scintillation counting. In the Los Alamos tests, the samples were placed in Jars filled with dilute hydrochloric acid and left there for several days. Scintillation samples were prepared by diluting $1 \mathrm{ml}$ of tritiated acid 
solution with $200 \mathrm{ml}$ of water. The results for these experiments are shown in Table 3.1 There were two samples in common between the two sets of experiments. These were the painted nickel and painted copper samples. When the results in Table 3.1 are adjusted to have common dimensional units, the numbers reported agree very well.

In a subsequent set of experiments performed at SNLL, painted cryopanel samples were exposed to tritium at different pressures and times. The results for these measurements are shown in FiB. 3.8 where tritium retention is plotted versus the product of tritium partial pressure times time. The highest point corresponds to a pressure of one atmosphere and a time of 30 hours. The middle and lowest (open) points data were exposed for a time of one hour and a total pressure of $q$ torr, but the open data point corresponds to an exposure with $99 \%$ deuterium and $1 \%$ tritium. The lower closed data point corresponds to an exposure of df 0.01 torr tritium for one hour. These two lower data points are the most interesting. The lower (open) data point is an order of magnitude less than that recorded for the pure tritium exposure. This result suggests that the decay of the tritium is affecting the amount of absorbed hydrogen isotopes. This affect could either be due to radiation damage of the paint resulting in trapping, or it could be due to the formation of reactive ions or atoms in the gas by the beta decay. All of the exposures were performed at room temperature, and the actual retention that will occur in the neutral beams where the painted surfaces $w i 11$ be at $77 k$ may be significantly different from these measured values.

\subsubsection{Tritium Retention in Copper Beam Dumps and Calorimeters}

Accelerator and plasma experiments were performed at Sandia, Livermore to examine the behavior of tritium in copper [29]. TPX was used to measure the plasma-driven permeation of deuterium through a copper membrane. The results of these measurements were used to extract the molecular recombination rate coefficient. The measurements indicated that the coefficient was $6.7 \times 10^{18}$ $\mathrm{cm}^{4} / \mathrm{s}$ over the temperature range of $575 \mathrm{~K}$ to $825 \mathrm{~K}$, in agreement with theory. Thermal desorption spectroscopy measurements of deuterium implanted into copper at an energy of $10 \mathrm{keV}$ showed two distinct trapping energies, one at $0.55 \mathrm{eV}$ and one at $0.93 \mathrm{eV}$. The first is thought to be the binding energy of deuterium in copper vacancies, and the second is associated with release from precipitated bubbles. The results from these two experiments were combined to predict the tritium inventory in the copper beam dumps and calorimeters. A comparison of the predicted deuterium retention and release from a copper calorimeter was compared to measurements performed for one of the calorimeters in TFTR. There was good agreement between measured and 
predicted values. These same parameters were used to predict the tritium inventory for the twelve calorimeters and bean dumps once tritium is used in TFTR. These calculations predict 0.15 grams total tritium retention (see Sec. 7.0$)$. 


\section{REFERENCES}

[1] R. A. Causey et al., J. Vac. Sci. Technol. A4 (1986) 1189.

[2] R. A. Causey et al., J. Nucl. Mater. 138 (1986) 57.

[3] W. L. Hsu et al., J. Vac. Sci. Technol. A5 (1987) 2768.

[4] S. K. Erents et al., Nucl. Instrum. \& Meth. 170 (1980) 449.

[5] R. A. Langley et al., J. Nucl. Mater. $76 / 77$ (1978) 313.

[6] W. R. Wampler et al., J. Nucl. Mater. 102 (1981) 304.

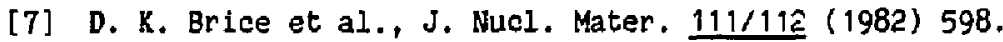

[B] A. E. Pontau et al., J. Nucl. Mater. 145-147 (1987) 775.

[9] Y. Hirooka et al., J. Vac. Sci. Technol., in press.

[10] R. A. Causey et al,, in Proc. 12th Symposium on Fusion Engineering, Nonterey, Ca., 1987, in press.

[11] B. L. Doyle, in Proc. 4ch DT Materlals Physics Group Meeting, Princeton, April 1987 (unpublished).

[12] R. Bastasz, J. Vac. Soi. Technol. A6 (1988) in press.

[13] R. Beutler et al., J. Nucl. Mater. 145-147 (1987) 280.

[14] J. Davis et al., J. Nucl. Miter. (in press).

[15] J. Roth et al., Nucl. Instrum. Meth. B7/8 (1985) 788.

[16] V. Phllipps et al.; J. Nucl. Mater. (in press).

[17] A. Haasz et al., J. Nucl. Mater. 151 (1987) 77.

[18] R. E. Clausing et al., J. Vac. Sci. Technol. A6 (1988) in press.

[19] H. F. Dylla et al., Nucl. Fusion 27 (1987) 1221.

[20] M. Ulrickson et al,, J. Vac. Sci. Technol. A6 (1988) in press.

[21] R. A. Langley, J. Vac. Sct. Technol. A5 (1987) 2205.

[22] H. R. Wampler et al., in Proc. 8th Intern. Conf. on Plasma Surface Interactions in Controlled Fusion Devices, Julich, 1988, J. Nucl. Mater., submitted.

[23] W. Wampler et al., J. Nucl. Mater. 111/112 (1982).

[24] R. A. Langley, J. Vac. Sci. Technol. A6 (1988) in press.

[25] J. Roth et al., J. Nucl. Mater. 93/94 (1980) 601.

[26] R. A. Langley et al., J. Nucl. Mater. 76/77 (1978) 313.

[27] B. L. Doyle et al., J. Nucl. Mater. 103/104 (1981) 513.

[28] Braun et al., J. Nucl. Mater. 128/129 (1984) 657 .

[29] K. L. Wilson et al., J. Vac. Sci. Technol, A5(4) (1987), 
TABLE 3.1: Tritium Retention on TFTR Neutral Beam Component Materials

Material

Allegheny Ludlum 4750

OEHC

CORR 99

1010 Rod - Anodized

1018 Rod - Anodized

CORR 99 - Ni Plated

1010 Rod - Ni Plated

1018 Rood - Ni Plated

Kapton Wire

Eiberglass Wire

Thermocouple Hire

Ceramic Beads

Fiberglass Insulation

Kevlar Cord

Viton O-Ring

Viton 0-ring (Greased)

Mylar sheet

Epoxy black

$\underset{n}{\operatorname{mainted} \text { Metal - }}$

Painted Metal - Cu
Test Location

S:ILL

SNLL

SNLL

SNLLL

SNLL

SNLL

SNLL

SNLL

LASL

LASL

LASL

LASL

LASL

LASL

LASL

LASL

LASL

LASL

LASL

SNLL

LASL

SNLL
Tritium Retention

$3.0 \times 10^{13} \mathrm{~T} / \mathrm{cm}^{2}$

$1.7 \times 10^{14} \mathrm{~T} / \mathrm{cm}^{2}$

$9.4 \times 10^{13} \mathrm{~T} / \mathrm{cm}^{2}$

$5.0 \times 10^{13} \mathrm{~T} / \mathrm{cm}^{2}$

$6.4 \times 10^{13} \mathrm{~T} / \mathrm{cm}^{2}$

. $1.9 \times 10^{14} \mathrm{~T} / \mathrm{cm}^{2}$

$2.0 \times 10^{14} \mathrm{~T} / \mathrm{cm}^{2}$

$1.1 \times 10^{14} \mathrm{~T} / \mathrm{cm}^{2}$

$4.2 \times 10^{15} \mathrm{~T} / \mathrm{cm}^{2}$

$1.4 \times 10^{15} \mathrm{~T} / \mathrm{cm}$

$1.1 \times 10^{15} \mathrm{~T} / \mathrm{cm}$

$2.4 \times 10^{12} \mathrm{~T} / \mathrm{cm}$

$2.6 \times 10^{15} \mathrm{~T} / \mathrm{cm}$

$2.6 \times 10^{16} \mathrm{~T} / \mathrm{cm}$

$8.0 \times 10^{16} \mathrm{~T} / 0-$ ring $1110 . \mathrm{D}$

$3.6 \times 10^{16}$ T/O-ring 110.0

$3.4 \times 10^{15} \mathrm{~T} / \mathrm{cm}^{2}$

$6.6 \times 10^{15} \mathrm{~T} / \mathrm{cm}^{2}$

$1.8 \times 10^{15} \mathrm{~T} / \mathrm{cm}^{2}$

$9.5 \times 10^{14} \mathrm{~T} / \mathrm{cm}^{2}$

$2.4 \times 10^{15} \mathrm{~T} / \mathrm{cm}^{2}$

$1.3 \times 10^{15} \mathrm{~T} / \mathrm{cm}^{2}$ 


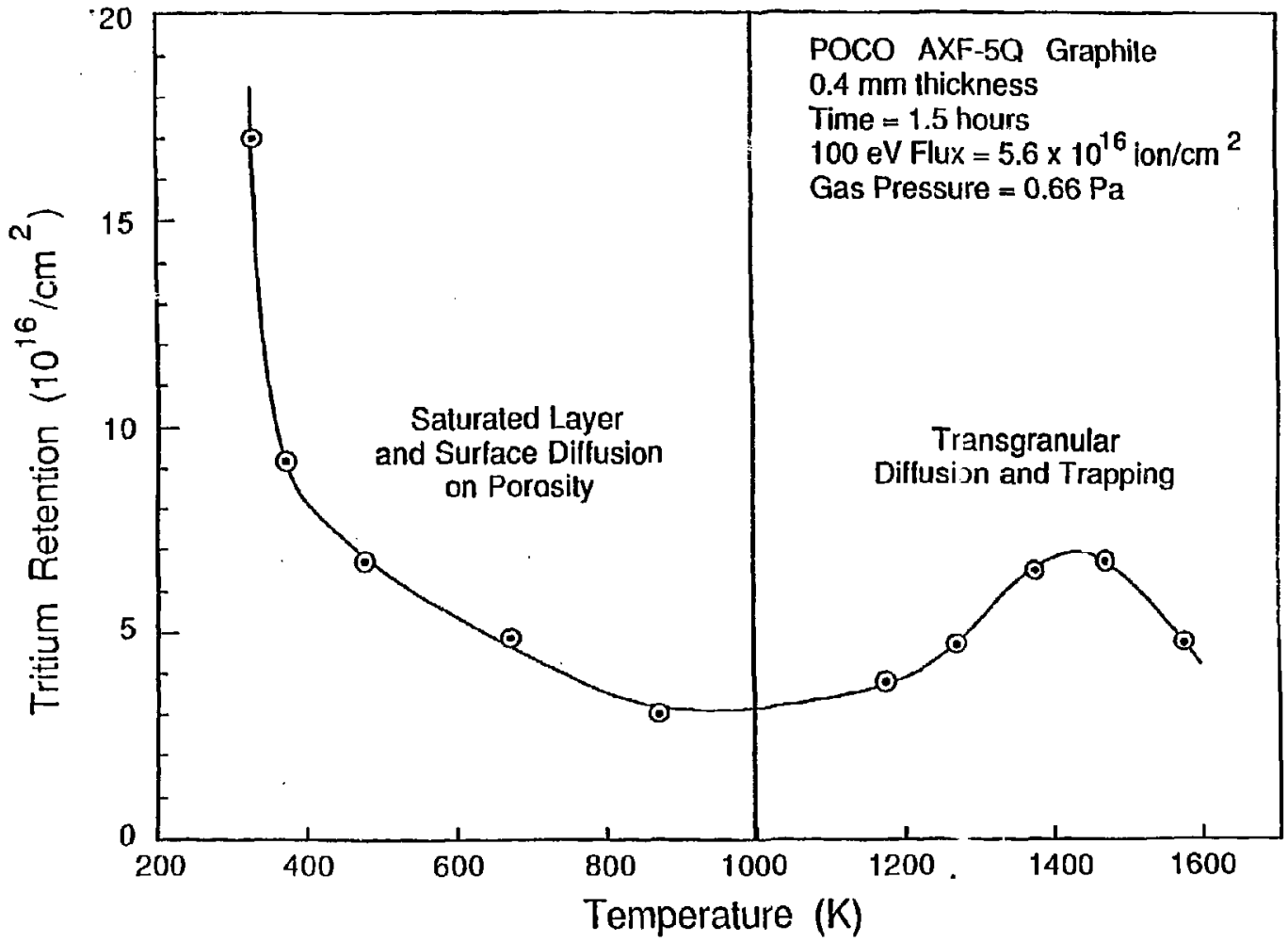

Fig. 3.1. TPX results for tritium retention in POCO AXf-50 Graphite. 




Effect of Conditioning on Tritium Uptake in POCO AXF-5Q Graphite

Fig. 3.2. Effect of conditioning on tritium uptake in POCO AXF-50 $\pi$ mphite. 
$88 \times 3128$

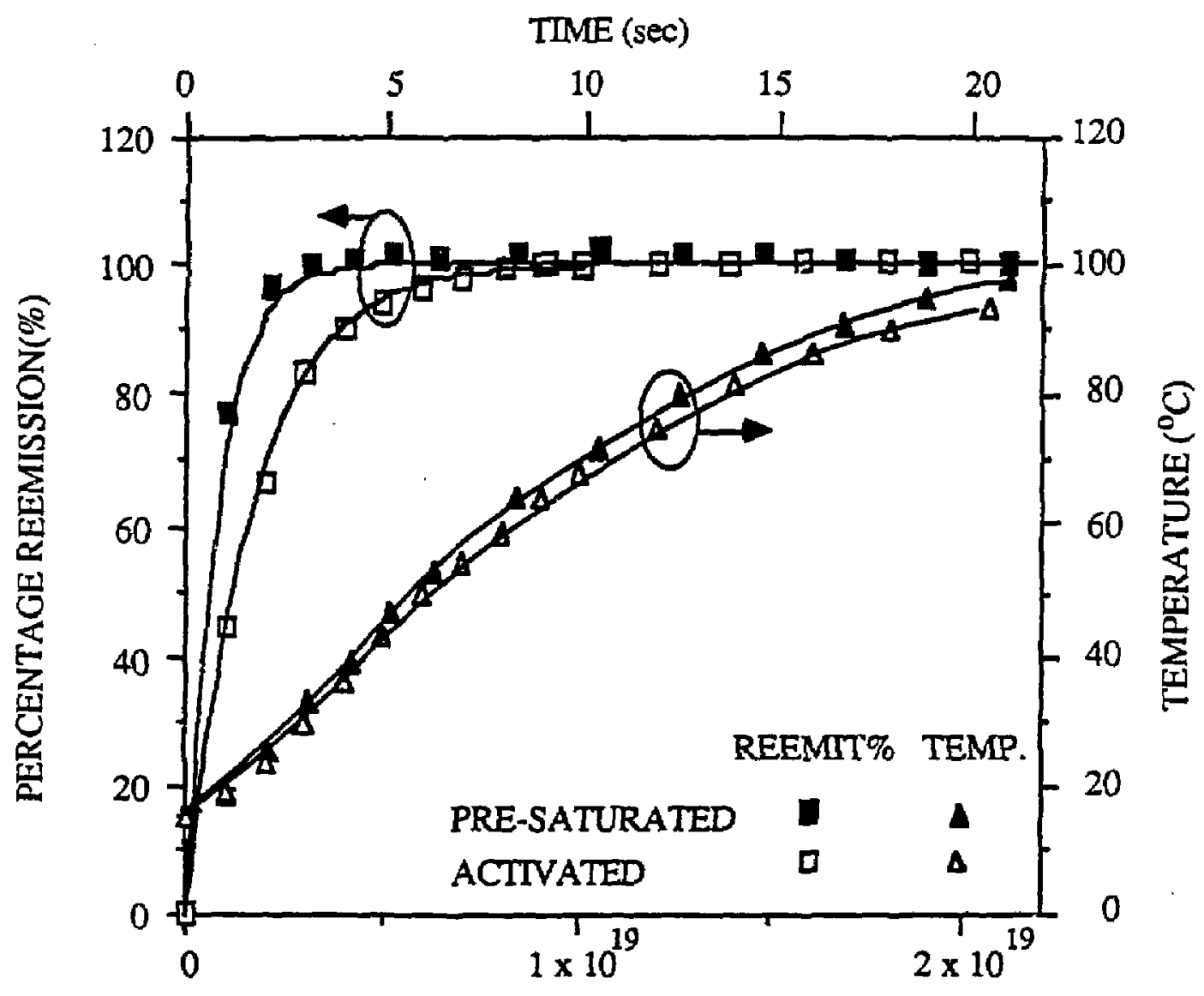

PLASMA BOMBARDMENT FLUENCE (ions/ $/ \mathrm{cm}^{2}$ )

Fig. 3.3. Hydrogen recyeling behavior from activated and pre-saturateg graphite surfaces under H-olasna borabardment at a flux of $1 \times 10^{18}$
ions $\mathrm{s}^{-1} \mathrm{~cm}^{-2}$ at an energy of $300 \mathrm{eV}$ and at temperatures below $100^{\circ} \mathrm{C}$. 


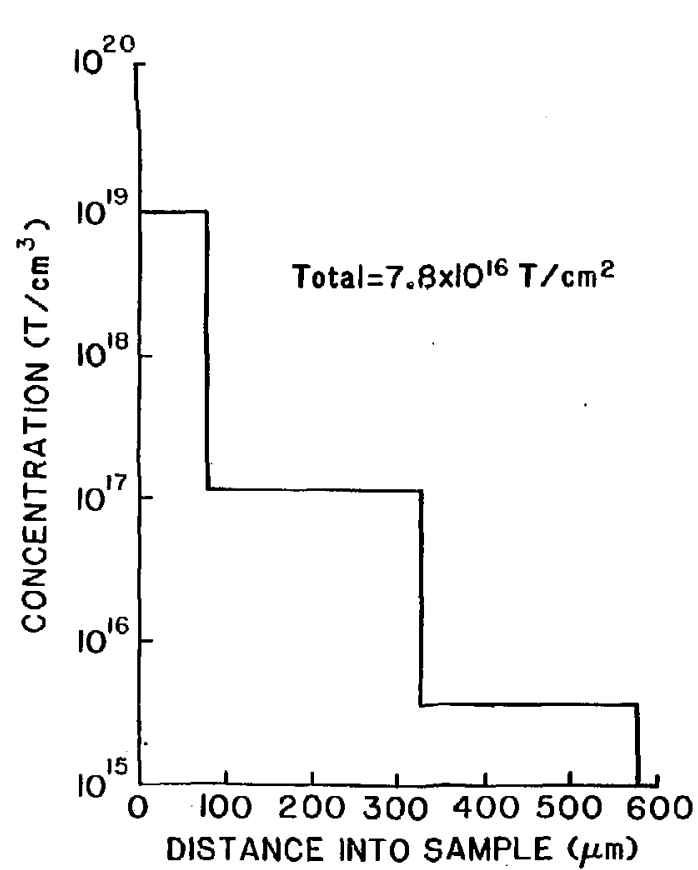

\#88x0370

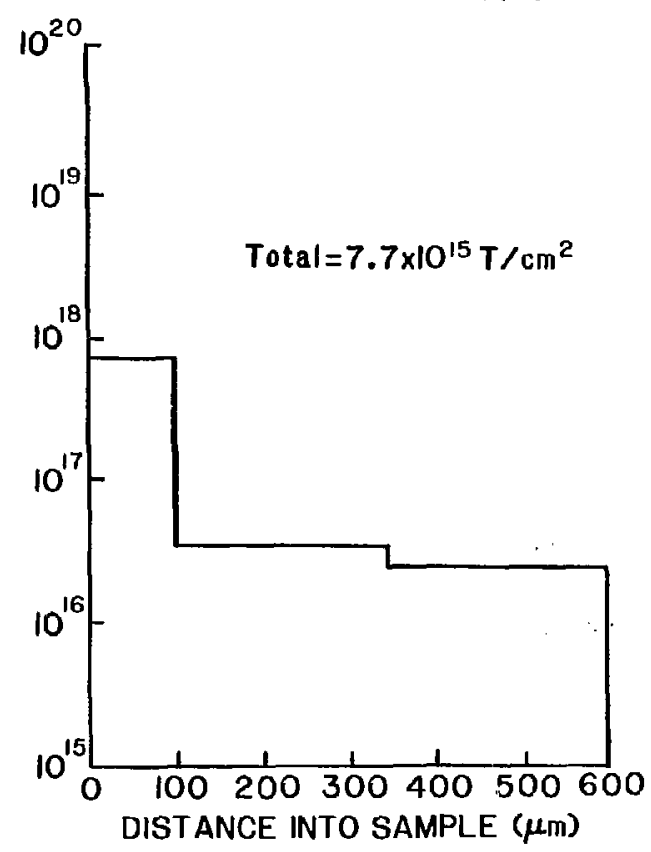

Fig. 3.4. Effect of a $1.5 \mathrm{hr}$ deuterium glow discharge exposure on a tritium saturated POCO AXF-5Q graphite sample. 




Fig. 3.5. Measurements of He-ion induced release cross-sections from H-saturated ed graph1te (see References for complete citations). 


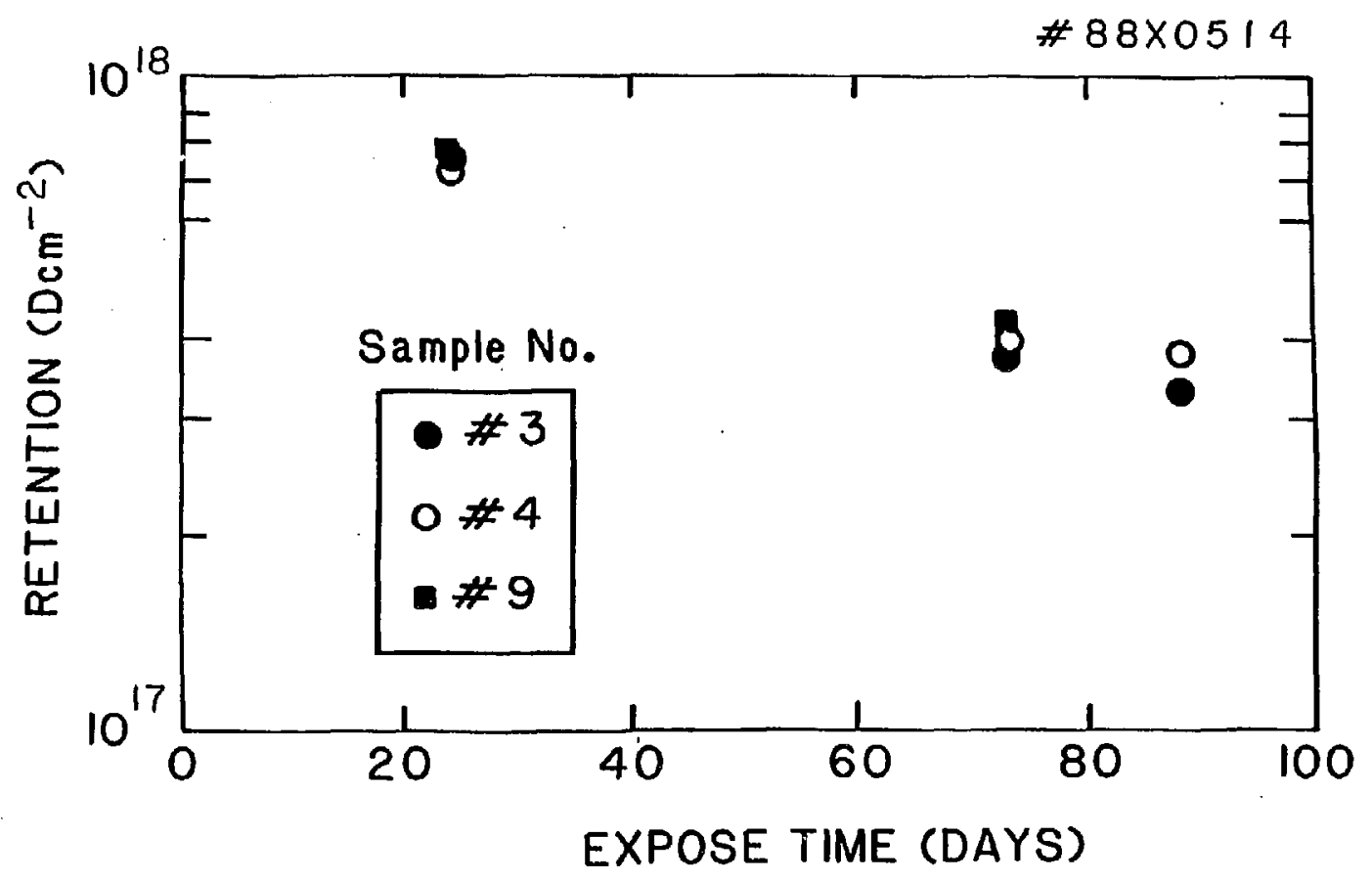

Fig. 3.6. Loss of deuterium from a codeposited carbon film as a function of alr exposure time. 


\section{IMPLANTED DEUTERIUM RETAINED IN THE SURFACE REGION vS ISOCHRONAL ANNEAL TEMPERATURE}

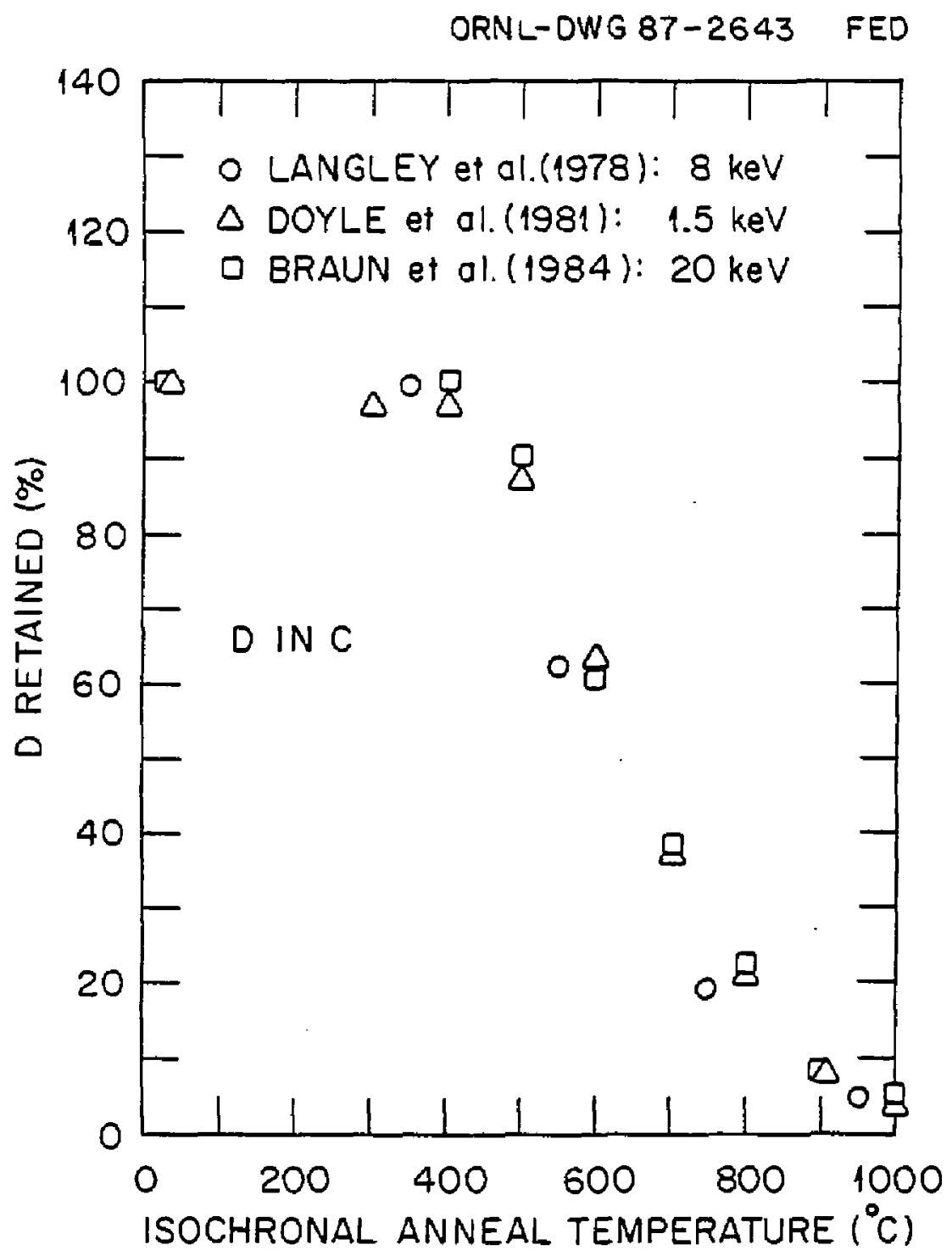

Fig. 3.7. Implanted deuterium retained in surface region of graphite versus isochronal anneal temperature. 


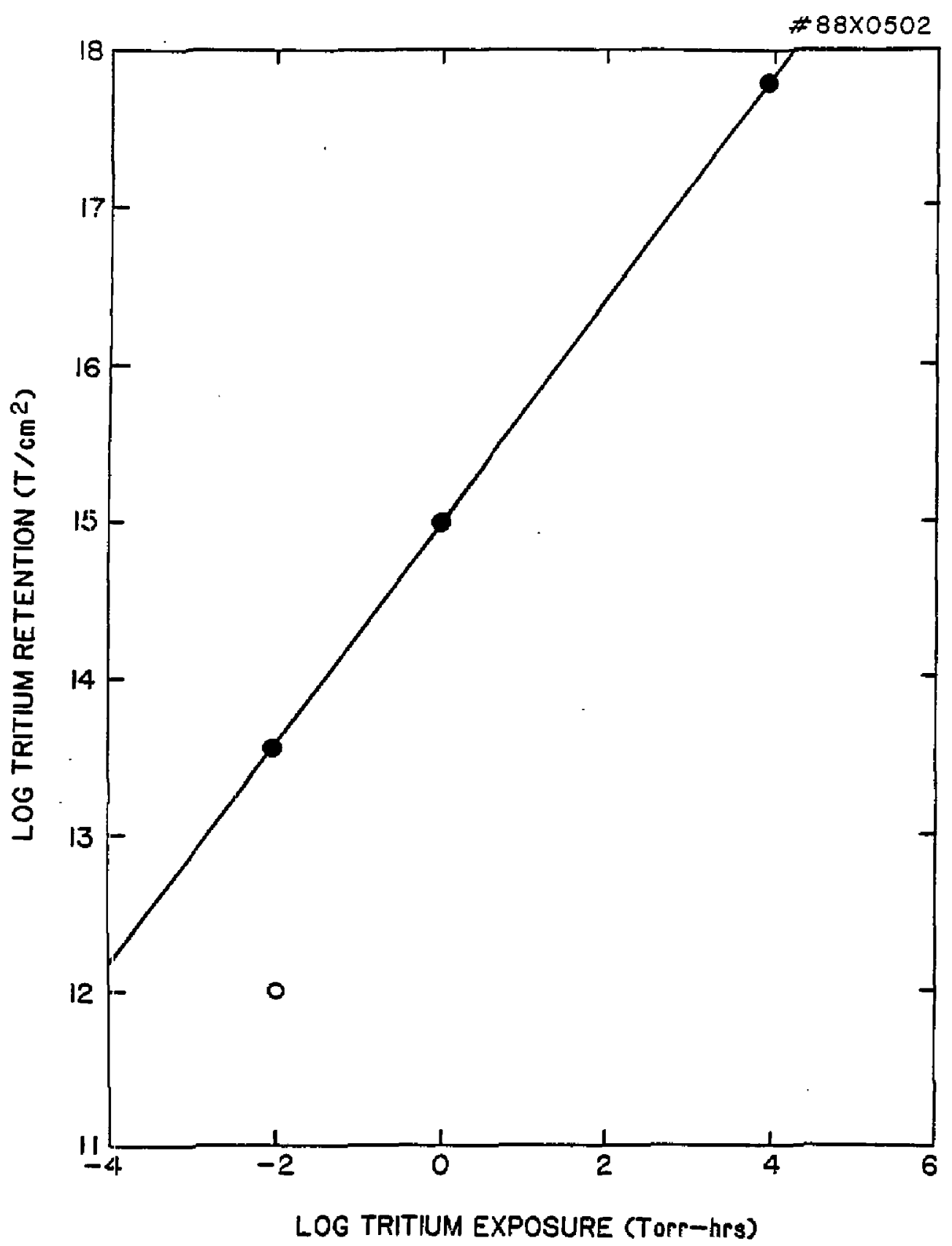

FiB. 3.3. Tritium adsorption as a function of exposure on samples of TFTA $\mathrm{LN}_{2}$ cryopanel material (black-painted copper). The open data point at an exposure of $10^{-2}$ torr-hrs corresponds to a 1 torr total exposure to $1 \% \mathrm{~T}_{2} / 99 \% \mathrm{D}_{2}$ for one hour. The exposure to $10^{-2}$ torr of pure tritium for one hour (closed data point) shows there is isotopic competition for the adsorption sites. 


\subsection{IN-SITU MEASUREMENTS OF D-T RETENTION IN TFTR}

Contributors: In-situ Measurement Working Group

M. U1rickson, Cha irman

\subsection{Introduction}

Plasma particle pumping effects with carbon limiters have been seen in TFTR [1], JET [2], and TEXTOR [3,4]. These pumping effects significantly affect the recycling of plasma particles in the edge region of the plasma. In addition, the pumping is evidence of a trapping mechanism for plasma particles in the torus. Such trapping effects will determine in part the amount of tritium that will be trapped in the torus. The cimount of this trapping is an essential ingredient in determining how much tritium is required to operate TETR in the D-T phase. In order to better understand the pumping effect, and the retention for hydrogen isotopes in the limiter, a series of in situ experiments was carried out in TFTR during the 1985-1987 run period. Some of these experiments involved the placement of wall coupons in the tokamak. The analysis of these coupons is described in Sec. 5 of this report. The other experiments included the measurement of gas loading of the first-wall, particle balance measurements, and several probe measurements of the plasma cdge. These measurements will be described in this section.

\subsection{Wall Loading and Particle Balance}

The wall loading . experiment consisted of a carefully controlled transition from a condition of relatively low recycling coefficient $(R=0.6)$ on the inner bumper 1 imiter to a condition of high recycling $(R=0.8)$. This revealed the capacity of the bumper limiter graphite tiles to absorb deuterium atoms. The particle balance experiments compared the amount of gas and particles input to the plasma to the amount of particles outgassed after a discharge. This was done for both ohmic and neutral-beam-heated plasmas.

\subsubsection{Wall Conditioning for Particle Control in TFTR}

The conditioning of the inner wall axisymmetric bumper limiter (BL) in TFTR [1] is done using ohmic discharges with plasma currents between 0.8 and 1.8 MA with minimal gas input ( $<3$ Torr 1 of He or $D_{2}$ are used). The optimal current for conditioning discharges is still unclear at present. It typically requires between 25 and 100 discharges to obtain a low recycling condition depending on the conditions of the limiter at the start of the discharge sequence; i.e., a totally unconditioned limiter requires more shots than a partially conditioned limiter. 
The particle recycling changes dramatically during a conditioning sequence. Figure 4.1 shows the low density limit and the $D_{B}$ brightness during a conditioning sequence. The minimum density is determined by particle recycling and is a good measure of the state of limiter conditioning. The minimum density achieved at $0.8 \mathrm{MA}$ was $5.5 \times 10^{18} \mathrm{~m}^{-3}$. The edge neltral density (see Fig. 4.2) and the $D_{\beta}$ brightness bath fall by approximately $a$ factor of ten during a conditioning sequence. Substantially less gas is required to reach a given density with an unconditioned bumper Iimiter as compared to a conditioned bumper limiter (see Fig. 4.2). We also observe the time constant for plasma density decay (see Fig. 4.2d for example) decreases during conditioning as shown in Fig. 4.3. We infer effective particle decay constants $\left(\tau_{p}^{*}\right)$ as short as $0.15 \mathrm{~s}$ fron these data. The recycling coefficlents inferred [1,5-6] from the decay time decrease from near unity to as low as 0.5 for a well-conditioned bumper limiter (see Fig. 4.3). The limiter pumping effect and the reduction in recycling are prerequisites for the enhanced confinement neutral-beam-heated discharges observed on TFTR [7] which is the prifuary discharge mode for the D-T phase.

\subsubsection{Wall Loading Experiment}

We investigated the gas loading of a previously conditioned limiter with deuterium gas [8]. A sequence of 11 identical $0.8 \mathrm{MA}$ deuterium discharges was made using a prescribed density that was maintained by feedback control. The sequence began with the recycling coefficient at a value of $\theta .6$.

The particle inventory in the limiter and wall during the gas loading sequence was obtained from calibrated measurements of the required gas input per discharge $\left(Q_{\text {In }}\right)$ and the integrated vessel outgassing ( $\left.Q_{\text {out }}\right)$ for an $80 \mathrm{~s}$ period after a discharge. Figure 4.4 shows the measured values of $Q_{i n}$, $Q_{\text {out }}$, and the computed wall inventory, $W=Q_{\text {in }}-Q_{\text {out, }}$ during the gas loading sequence. At the beginning of the sequence 40 torr-liters of $D$ were required to reach the fiducial plasma density $\left(1.25 \times 10^{19} \mathrm{~m}^{-3}\right)$. At the end of the sequence, the required gas input decreased to an asymptotic value of 20 torrliters, as the limiter became loaded and the recycling coefficient increased. For the entire sequence, the amount of $D$ outgassed from the vessel between discharges was a relatively constant value of $Q_{\text {out }}=5$ torr-liters. Thus, the wall loading also showed a decrease to an apparent asymptotic value of $W=15$ torr-liters/discharge during this shot sequence. The total wall loading minus the asymptotic value for the entire sequence was 70 torr-liters, which can be equated to the pumping capacity of the limiter induced by the initial He discharge conditioning. This pumping capacity is consistent with the wall pumping model described in Ref. 1, where the capacity for pumping ohmic plasma is estimated to be equal to the saturation capacity of the active limiter volume contained within the scrape-off area $\left(5 \mathrm{~m}^{2}\right)$ and the mean range of incident deuterium. 
The asymptotic value of $W=15$ torr-liters per discharge is apparently not related to plasma pumping by the active area of the limiter, because $W$ was relatively constant during the shot sequence, while the recycling coefficient changed from $R=0.6$ to $R=0.8$. The residual pumping of deuterium may have been due to pumping of deuterium by molecular components $\left(C_{n} D_{m}\right)$, and deuterium incorporation into sputtered carbon films on low flux areas of the limiter. Such codeposition phenomena have been invoked to explain carbon pumping effects in tokamaks [2,3] and glow discharge experiments [11-12]. For codeposition to have been responsible for the residual (15 torrliters/discharge) pumping seen in TFTR, the effect would have to domina' $a$ during the non-steady-state (i.e., formation and/or termination) phases of the discharge. It appears that the observed residual pumping is related to deuterium/carbon chemistry because similar particle balance measurements with He-gas-fueled discharges showed that $Q_{1 n}=Q_{\text {out }}[B]$.

\subsubsection{Particle Balance in TFTR}

The data analyzed for this study [8] were taken from the TFTR gas infection system [9] (GIS), a fast magnetically shielded ionization gauge (IG) mounted on the vacuum vessel [10], and a residual gas analyzer (RGA) mounted on one of the torus pumping ducts. These systems are described in detail in Refs. 9 and 10. The GIS includes both a high pressure supply manifold with a diaphragm pressure transducer, and a feed-back-controlled calibrated gas valve. The gas flow values derived from the two systems are compared to assure the accuracy of the amount of gas injected into the torus. For neutral beam shots the injected bear power was calibrated using water-cooled calorimeters. The IG was periodically calibrated using the GIS to determine the gauge factor for both deuterium and helium. The torus pumping speed was periodically measured using the GIS both with and without the neutral beam isolation valves open to the torus. The data from the IG and GIS were recorded for each shot. In addition, the IG data were recorded for 80 sec after each shot.

The IG data were integrated to determine the outgassing after a shot. The accuracy of this integral was compared to the integral of the long-term (about eight hours) RGA data following the last shot of the day. It was found that the IG integral evaluated at $80 \mathrm{sec}$ after a discharge gives at least $80 \%$ of the total outgassing before the next shot (typically 6 to 8 minutes elapse between shots). The time integral of the pressure is nultiplied by the measured pumping speed of the torus to determine the total outgassing.

A comparison of the outgassing to the gas input for a sequence of ohmic deuterium plasmas is shown in Fig. 4.5. These data are for discharges with plasma currents of 1.4 and $1.8 \mathrm{HA}$. The line-integral density varied between $1.2 \times 10^{19}$ and $3.6 \times 10^{19} \mathrm{~m}^{-3}$. The solid line in $\mathrm{Fig} .4 .5$ represents equality between the gas input and the outgassing after a shot. These data fall snto 
two general categories. At high gas input only about $10 \%$ of the input gas appears as outgassing. At low gas input much more gas is released after the shot than was put in during the shot. In fact, discharges following a high density plasma require almost no gas flow to achieve the same density as the preceding high density shot. If a sequence of plasmas is followed chronologically, one observes that the outgassing on succeeding low gas input shots gradually falls with shot number, and the density falls with the outgassing. Over a sequence of about 30 discharges approximately $80 \%$ of the excess gas injected during high density plasmas is recovered during succeeding low gas input plasmas.

In contrast to the deuterium ohmic plasmas, helium ohmic plasmas show nearly equal amounts of gas input and outgassing. This is shown in Fig. 4.6. These discharges were also 1.4 and $1.8 \mathrm{MA}$ plasmas. The line integral density ranged from $1.8 \times 10^{19}$ to $4.9 \times 10^{19} \mathrm{~m}^{-3}$. If the correction for the additional contribution to the outgassing beyond $80 \mathrm{sec}$ is applied to this data, there is slightly more outgassing than gas input for the helium plasmas. This is particularly evident at low gas input. These low density helium-initiated discharges are the type of discharges described in Sec. 4.2.1 that we have found useful for conditioning of the bumper liniter [1]. The integrated outgassing during a sequence of such low density helium-initiated plasmas is shown in Fig. 4.7. The starting conditions were characteristic of high recycling because the conditioning sequence followed operation with high density deuterium-fueled, ohmic plasmas. The gaps in the data occur when deuterium plasmas were initiated to check the recycling coefficlent. About 0.9 torr-liter of helium gas was input for each shot. The total amount of gas released by these discharges was 400 torr-liters (helium equivalent). Thus, the excess amount of gas released by these 140 shots is 300 torr-liters (helium equivalent). Since we see the $D_{B}$ line intensity fall in the same fashion (see Fig. 4.1) as the outgassing shown in Fig. 4.7, we conclude that the extra gas is deuterlum not helium. Correcting for the different ionization gauge factor for deuterium (one half of that for helium), the amount of deuterium released by these helium-initiated discharges is 150 torr-liters. This quantity is about 1.5 times the estimated gas-loading capacity of the bumper limiter determined from the wall loading experiment. The discrepancy may be because these measurements were made after much more extensive conditioning of the bumper limiter. Even at the end of the sequence 0.5 to 1.0 torr-liter of excess gas was being released per discharge.

In deuterium neutral-beam-heated discharges the outgassing after a shot is also very different from ohmic deuterium plasmas. The outgassing after neutral-beam-heated discharges is compared to the cold gas plus neutral beam particle fueling in F1g. 4.8. It can be seen from these data that on the average about $65 \%$ of the input particles are outgassed after a plasma. The percentage is $75 \%$ if the correction to the outgassing is applied. This is 
consistent with the observation that many more neutral-beam-heated discharges can be made at the same total particle fueling before reconditioning of the bumper limiter is required.

Our observations show that as much as 60 torr-liters of gas can be retained by the bumper limiter following a single high density ohmic plasma in deuterium. If several high density plasmas are made in succession, then the total retention can be several times this value. However, it was also observed that subsequent low density discharges can release up to $80 \%$ of this retained gas. The mechanism responsible for this limiter pumping is characterized as a filling of near-surface sites with deuterium and/or codeposition of carbon and deuterium on lower flux areas of the limiter or wall $[1,6]$. It is apparent from the particle balance data that low density operation can induce release of some of the retained gas in the limiter. It is unlikely that these plasmas have any influence on the wall-retained deuterium gas because examination of wall coupons (see Sec. 5) indicates that the wall deposition accumulates at a rate roughly proportional to the number of shots [13] (about $10^{i 4} \mathrm{D} / \mathrm{cm}^{2} /$ shot). Ion-induced desorption is suggested as the mechanism [1] for the release of gas from the active area on the limiter. The total amount of gas released by the helium conditioning plasmas ( $10^{22}$ deuterium atoms) is the order of 19 of the total amount of deuterium $\left(10^{24}\right.$ deuterium atoms) $[13,14]$ retained in the near-surface region of the tiles at the end of our last operating period (see Sec. 5).

The higher outgassing in neutral-beam-heated discharges may be due to the higher Iimiter temperatures during neutral beam operation. The limiter surface is estimated to be about $300^{\circ} \mathrm{C}$ at the end of a neutral beam shot. For ohmic operation it is less than $50^{\circ} \mathrm{C}$. This suggests a thermal release mechanism for the retained gas. Operation at the full beam power $(-30$ MW with the 2-sec beam duration should raise the surface temperature to about $800^{\circ} \mathrm{C}$ to $1000^{\circ} \mathrm{C}$.

\subsection{Edge Probe Measurements}

Three types of edge probe measurements have been made on TFTR. Collector probes are placed in the plasma edge and sample the constituents of the edge plasma. The collectors are operated in both a time integral and a time differential mode. Moveable Langmuir probes are used to determine the profiles of plasma density and temperature in the scrape-off region outside the last closed flux surface. These measurements are made during both ohmic and neutral-beam-heated discharges. The flux and energy of charge exchange neutrals in the plasma edge have been measured using a resistance probe. 


\subsubsection{Collector Probe Measurements}

Measurements with a rotatable collector probe [15] were made to increase understanding of the boundary layer during special limiter conditioning sequences using low density deuterium or helium discharges. A set of silicon films positional behind slits facing the ion and electron drift directions was exposed to a series of similar $\mathrm{D}^{+}$discharges, and a series of similar $\mathrm{He}^{++}$ discharges. Another exposure was made by overlaying a serles of the same $\mathrm{He}^{++}$ discharges on a prior exposure from $D^{+}$plasmas. A time-resolved expusure was also made to compare the flat-top and ramp-down phases of a $D^{+}$discharge. The samples were positioned at the bottom of the TFTh vacuum vessel, with the innermost sample being $17-19 \mathrm{~cm}$ from the plasma boundary.

The amounts of deuterium and impurities trapied in the surface regions of the samples were measured by different analytical techniques. Nuclear reaction analysis (NRA) gave deuterium areal densities for all exposures, which ranged as high as $5 \times 10^{16} \mathrm{D} / \mathrm{cm}^{2}$ per discharge, and were generally a factor of about 2-4 higher on the electron drift side. Radial profiles of these measurements show e-folding lengths on the order of $4-8 \mathrm{~cm}$ on the electron drift side, and longer on the ion drift side. Rutherford backscattering spectrometry (RBS) was used to estimate the amounts of carbon and metals present. The carbon concentration was about $10^{17} \mathrm{c} / \mathrm{cm}^{2}$ per discharge, which is consistent with the codeposition of deuterium and carbon during these discharges. The concentration of metals was about $2 \times 10^{14} \mathrm{~cm}^{-2}$ per discharge. Analysis of the time-resolved exposure by NRA showed a steady decrease in the retained deuterium from the end of the plasma current flattop through the current ramp-down, with a large burst at the termination of the discharge.

\subsubsection{Moveable Langmuir Probe Measurements}

A reciprocating Langmuir probe positioned on the plasma midplane has measured single-discharge radial profiles of electron density and temperature for a variety of plasma scenarios $[16,17]$. The probe gathered data up to the last closed flux surface (LCFS) during ohmic discharges, and to within 4 cm of the plasma boundary during neutral beam heating.

The edge characteristics of $\mathrm{D}^{+}$and $\mathrm{He}^{++} 1.4 \mathrm{MA}$ conditioning discharges fordued on the inner and outer limiters have been examined. They share several features, particularly that of strong deviations from a purely exponential decay of the electron density, as shown in Fig. 4.9. The reason for this characteristic shape is not jet fully understood. In general, the density scrape-off length, $\lambda_{n}$, varies from 3 to $6 \mathrm{~cm}$ close to the plasma, to about 1 cm in the distant scape-off. The particle scrape-off length is slightly shorter, while the temperature profile is nearly flat. 
The variation of the density profile with plasma current, $I_{p}$, was investigated during inrer wall $D^{+}$discharges for $I_{p}=0.9$ to $1.4 \mathrm{MA}$. This is sumarized in Fig. 4.10, where radial profiles have been differentiated to give e-folding lengths throughout the scrape-off layer (SOL). The e-folding lengths tend to decrease as the distance (d) into the SOL increasos, and are smaller for larger plasma currents. In the distant SOL ( $d>10 \mathrm{~cm}$ ) $\lambda_{n}$ is about 2 to $5 \mathrm{~cm}$, while at the plasma boundary $\lambda_{n}$ is estimated in the range of $6-11 \mathrm{~cm}$. Extrapolated values on $n_{e}(0)$ at the LCFS are on the order of $10^{18} \mathrm{~m}^{-3}$, showing a linear increase with $I_{p}$ (and with the line-integral density in the plasma). In all cases $T_{e}(0)$, the edge electron temperature at the LCFS was extrapolated to about $55 \mathrm{eV}$. This information can be used to calculate the particle diffusion coefficient $\left(D_{1}\right)$ at the plasma boundary for these discharges. $D_{1}$ is found to be greater than $30 \mathrm{~m}^{2} / \mathrm{sec}$ for $I_{p}=0.9 \mathrm{MA}$, decreasing to about $15 \mathrm{~m}^{2} / \mathrm{sec}$ for $I_{p}=1.4 \mathrm{MA}$.

Radial profiles have also been collected [19] during neutral beam injection, and can be sumarized as follows. The edge density and temperature increase by factors of approximately 2-5 and less than two, respectively, during the beam heating phase. The radial oensity profile appears to remain curved, and all e-folding lengths stay roughly the same.

\subsubsection{Resistance Probe Measurements}

Recycling of hydrogen between the plasma and the wall in tokamaks critically affects plasma conditions at the center of the plasma. Low energy charge-exchange ( $\mathrm{CX}$ ) neutrals are an important component of this recycling. Conventional diagnostics for studying $\mathrm{CX}$ neutrals can only detect high energy (above $1 \mathrm{keV}$ ) particles, which give information on ion temperatures in the core of the plasma where they originate. However, most of the neutrals incident on the wall originate in the cooler outer edge of the plasma and have energies less the $1 \mathrm{keV}$. Measurements of the energy and flux of low energy neutrals incident on the wall are needed to assess their role in recycling and impurity generation.

The first study of low energy CX neutrals at the wall in the TFTR tokamak was recently made using the carbon-reslatance particle analyzer [20], which is sensitive to particles with energies down to about $30 \mathrm{ev}$. This device utilizes the increase in electrical resistance of a thin carbon $f i l m$ produced by the Impinging particles to determine the particle flux. Particle energies are determined from the stopping effect of thin layers of silicon on top of the carbon.

The measurements on TFTR were made for plasmas with various plasma currents $\left(I_{p}\right)$, with neutral beam heating, and with deuterium pellet injection. The probe resistance was recorded periodically during the discharge, giving 
measurements of the particle energy and flux versus time with a resolution of about 10 msec. Although resistance probes have been used previously on several other tokamaks, the measurements on TFTR are the first in which timeresolved data were obtained. This new feature allows transient phenomena to be studied, such as the effects of neutral beam heating, pellet injection, and start-up and ramp-down phases of the discharge (see Fig. 4.11).

Preliminary analysis of the data from TFTR leads to the following conclusions. For the low current plasmas $(\mathrm{I}=1 \mathrm{MA})$ the energy $(\mathrm{kT})$ and flux of $\mathrm{CX}$ neutrals were $350 \mathrm{eV}$ and $0.6 \times 10^{14} / \mathrm{cm}^{2} \mathrm{~s}$, respectively, and nearly constant throughout the ohmic portions of the discharge. Neutral beam heating (10 MW) increased both the energy and flux by about a factor of two. High current plasmas $\left(I_{p}=1.8 \mathrm{MA}\right.$ ) had Iarge transients in the cx neutral flux at the beginning and end of the discharge which were not present during the low current plasmas. A time constant for the flow of particles from the plasma to the wall as CK neutrals can be obtained from the number of particles in the plasma divided by the flux and the wall area. This time constant is about 4 sec for both the ohmic and neutral-beam-heated portions of the low current discharges, which is comparable to the duration of the discharge. The neutral flux to the wall is, therefore, large enough to affect the plasma density significantly, and changes in the recycling of these particles by wall conditioning would be important.

\subsection{Surface Coupons}

A poloidal and toroidal array of surface coupons is installed in TFTR in order to monitor long-term changes in surface conditions. Square pieces of graphite are attached to the wall of the torus in locations away from the bumper limiter (these are called wall coupons). The limiter coupons are actual graphite tiles removed from the limiter surface (these are replaced at each major opening). The analysis of these coupons is described in Sec. 5 of this report. This section will describe the location and nature of the coupons that were installed during the fall 1987 opening on TFTR.

Table 4.9 lists the locations where wall coupons have been placed in the torus. All of the wall coupons installed have a 0.5 -in diameter circle of tungsten deposited on the plasma-facing side to aid in determining the thickness of the layer which is typically deposited on these coupons.

The bumper limiter tiles that were removed and replaced during the last opening are shown in Fig. 4.12. The new tiles have either a set of boron spots or a set of boron carbide spots (the spot types are indicated in F1g. 4.12). The purpose of the spots is to assist in determining whether a given tile experiences net erosion or net deposition due to plasma exposure. The data shown in See. 5 suggest that some tiles erode while others have net deposition. 


\subsection{Planr:2d Experiments}

In addition to continuing the type of experiments described above, two new experiments are planned for the next TFTR run. We are adding a quartz crystal thickness monitor on a mid-plane port. This device will allow us to determine what fraction of the carbon deposition observed on the wall is due to nomal aperation and what fraction is due to disruptions. These data will help us to extrapolate the present results on wall retention to D-T operation.

We will also determine the particle balance in a neutral beam line. We do not know what fraction of the hydrogenic particles that are put into a beam line are recovered during regeneration of the LHe cryogenic pumping panels, although we have made estimates of the retention on ambient temperature surfaces from the adsorption measurements described in Sec. 3.2.1. The Large surface areas in the neutral beam injectors are potential sinks for tritium that must be carefully evaluated for the inventory estimates (see Sec. 7.0). The neutral beam particle balance $w \neq l l$ be performed by calibrated gas input/output measurements and deuterium pumping speed measurements when the LHe panels have been warmed to $\mathrm{LN}_{2}$ temperature. 
REFERENCES

[1] H. F. Dylla et al., Nucl. Fusion 27 (1987) 1221.

[2] S. A. Cohen et al., Plasma Phys. Contr. Fusion 29 (1987) 1205.

[3] J. Hinter, J. Vac. Sci. Technol. A5 (1987) 2286.

[4] J. Winter, in Proc. 14th European Conf. on Controlled Fusion and Plasma Physics, Madrid, 1987, Vol. IID., pp.

[5] D. B. Heifetz et al., Presented at the 34th National Symposium of the American Vacuum Society, Anaheim, CA (October, 1987); J. Vac. Sci. Technol. A6 (1988) in press.

[6] H. F. Dylla et al., in Proc. 14th European Conf, on Controlled Fusion and Plasma Physics, Madrid, 1987, Vol. IID, pp. 698.

[7] J. D. Strachan et al., Phys. Rev. Lett. 58 (1987) 1004.

[8] M. Ulrickson et al., Presented at the 34th National Symposium of the American Vacuum Society, Anaheim, CA (October, 1987); J. Vac. Sci. Technol. A6 (1988) in press.

[9] P. H. LaMarche et al., Rev. Sci. Instrum. 56 (1985) 981.

[10] W. R. Blanchard et al., J. Vac. Sci. Technol. A4 (1985) 1715.

[11] W. L. Hsu et al., J. Vac. Sci. Technol. A5 (1987) 2768.

[12] R. A. Langley, J. Vac. Sci. Technol. A5 (1987) 2205.

[13] W.R. Wampler et al., Presented at the 34th National Symposium of the American Vacuum Society, Anaheim, CA (October 1987); J. Vac. Sci. Technol. A6 (1988) in press.

[14] H. F. Dylla et al,, in Proc. 3rd Inter. Conf. on Fusion Reactor Materials, Karlsruhe, 1987; J. Nucl. Mater., in press.

[15] S. J. Kilpatrick et al., in Proc. 8th Intern. Conf. on Plasma Surface Interactions in Controlled Fusion Device, Julich, 1988; J. Nucl. Mater., submitted.

[16] S. J. Kilpatrick et al., Bull. An. Phys. Soc. 32 (1987) 1806.

[17] S. J. Kilpatrick et al., J. Vac. SeL. Technol. A4 (1986) 1817.

[18] D. Manos et al., in Proc. 8th Intern. Conf. on Plasma Surface Interactions in Controlled Fusion Device, Julich, 1988; J. Nucl. Mater., submitted.

[19] R. V. Budny, et al., J. Nucl. Mater. 145-147 (1987) 245.

[20] H. R. Wampler, Appl. Phys. Lett. 41 (1982) 335. 
Table 4.1

Location of Wall Coupons in TETR

\begin{tabular}{|c|c|c|c|}
\hline Bay & Location & Position & Serial Number \\
\hline $\mathrm{D}$ & Top & Right & $870609-048$ \\
\hline$D$ & Top & Left & $870609-046$ \\
\hline$D$ & Bottom & Right & $870009-026$ \\
\hline $\mathrm{D}$ & Bottom & Left & $870609-004$ \\
\hline $\mathbf{J}$ & Midplane & Right & 870609-059 \\
\hline$J$ & Midplane & Left & $870609-015$ \\
\hline $\mathrm{H}$ & Midplane & Right & $870609-084$ \\
\hline H & Midplane & Left & 870609-095 \\
\hline L & Top & Right & $870609-001$ \\
\hline L & Top & Left & $870609-121$ \\
\hline $\mathbf{N}$ & Midplase & Right & 870609-025 \\
\hline $\mathbf{N}$ & Midplane & Lent & $870609-075$ \\
\hline $\mathbf{N}$ & Bottom & Right & $870609-091$ \\
\hline $\mathbf{N}$ & Bottom & Left & $870609-067$ \\
\hline P & Midplane & Right & $870609-078$ \\
\hline$P$ & Midplane & Left & $870609-093$ \\
\hline $\mathbf{R}$ & Midplane & Right & $870609-051$ \\
\hline $\mathbf{R}$ & Midplane & Left & $870609-098$ \\
\hline
\end{tabular}

NOTE: Theee are the locations and serial numbers at the end of the fall 1987 opening of TFTR. 


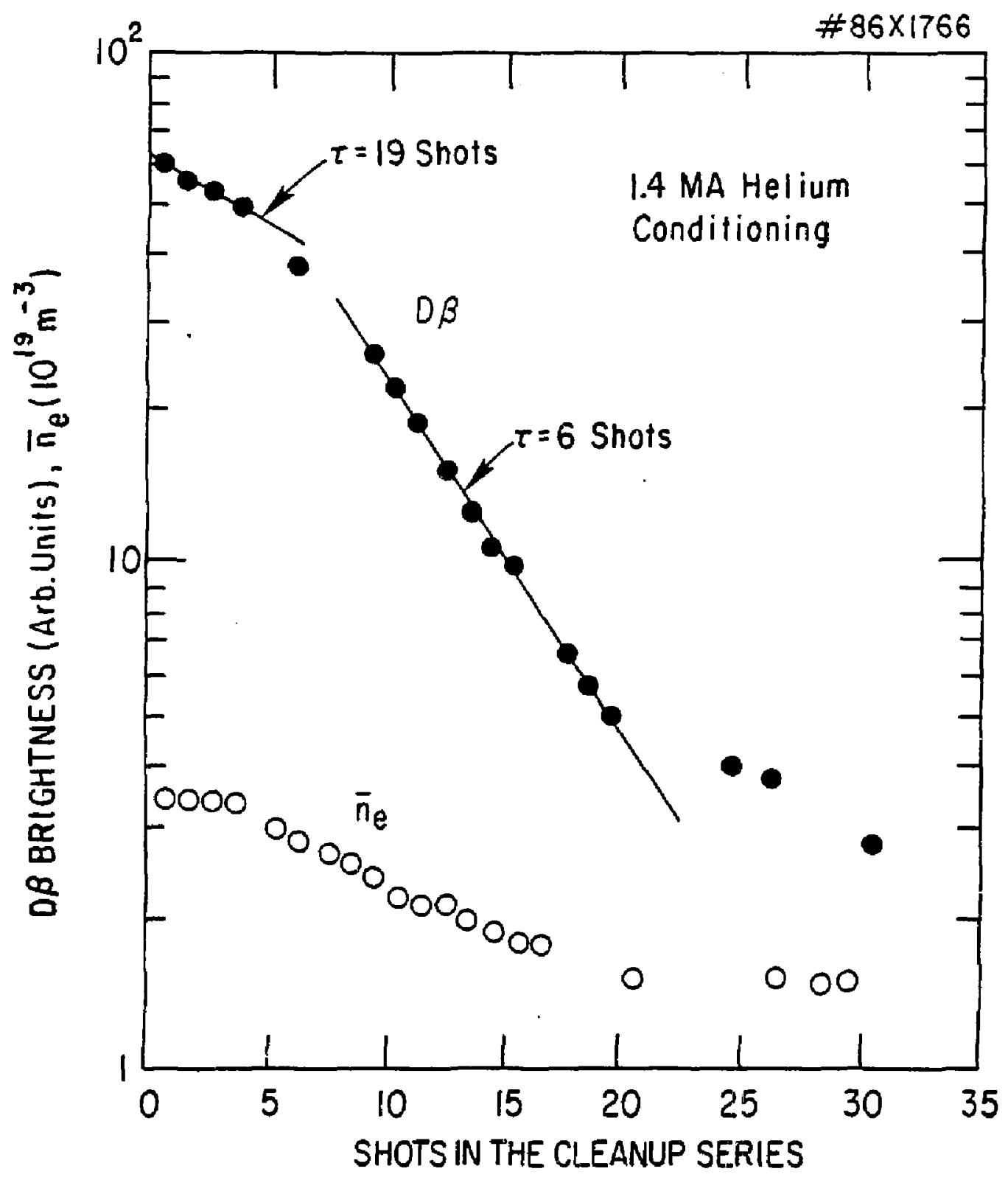

F1g. 4.1. The decrease of the prefill only density and the $D_{B}$ brightness during a typlcal conditioning sequence. 

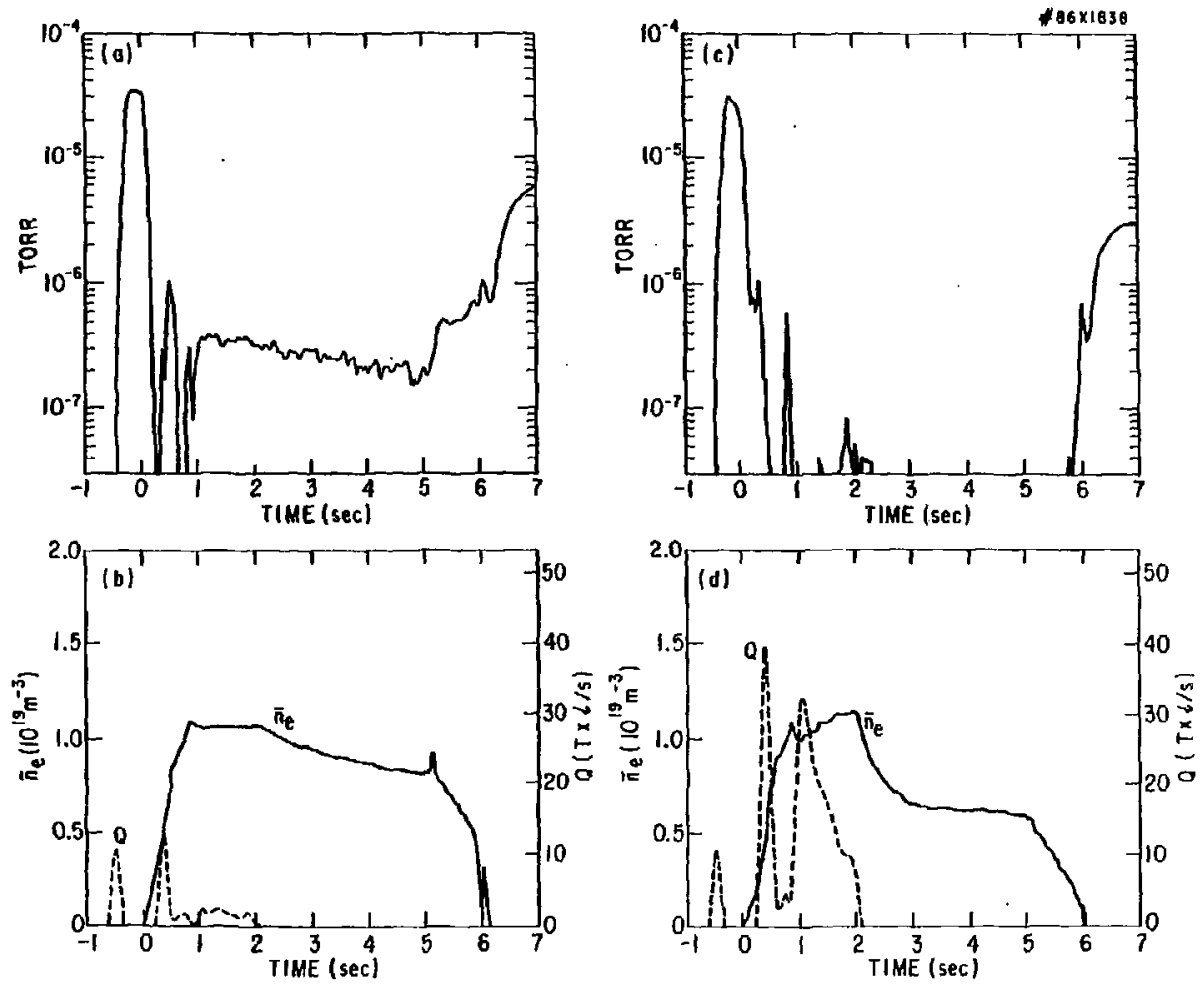

Fig. 4.2. Time dependence of the edge neutral pressure $(a, c)$, plasma density $(b, d)$, and the required gas input $(b, d)$ for fiducial discharges at the beginning $(a, b)$ and end $(c, d)$ of a conditioning sequence. 


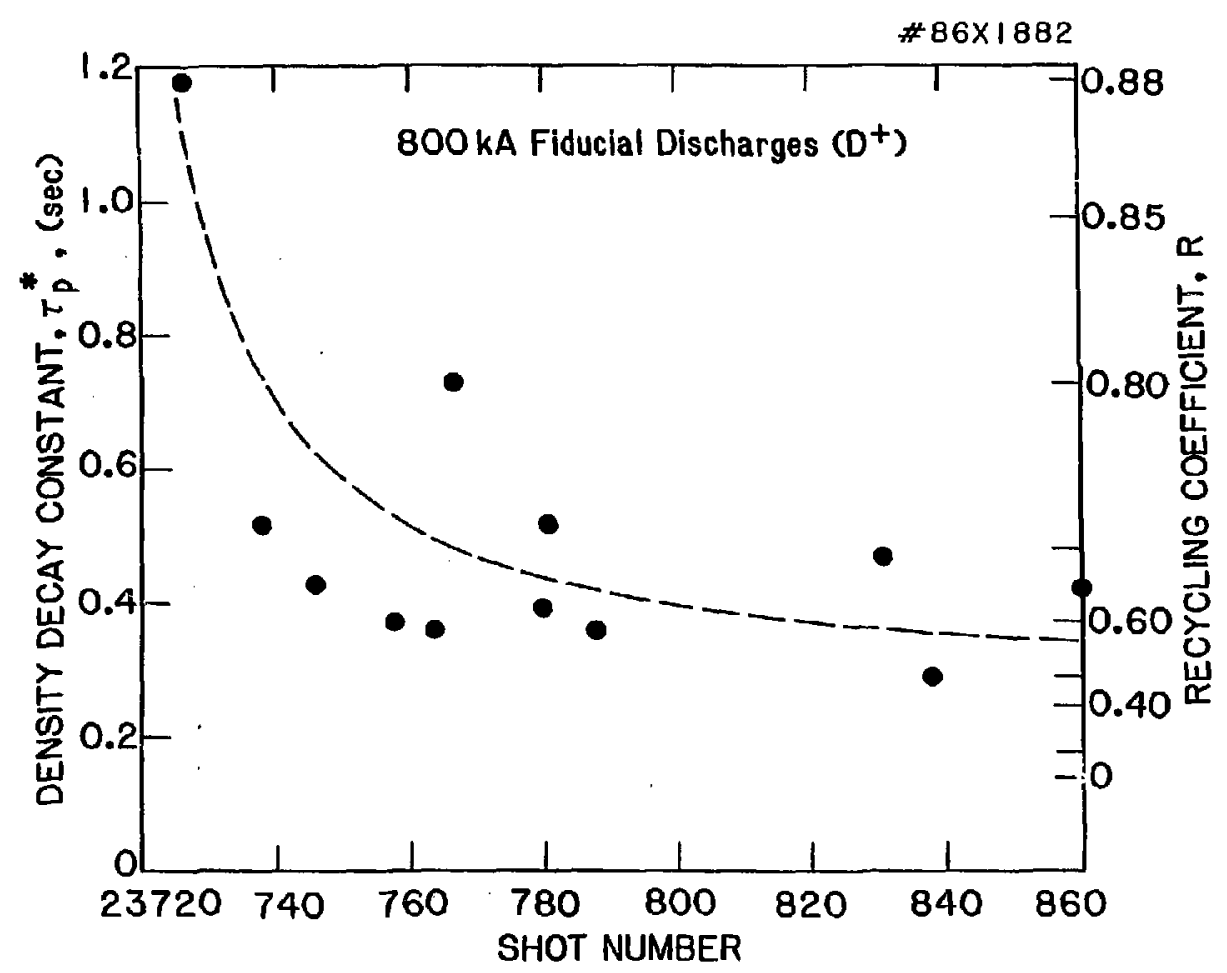

Fig. 4.3. The change of the density decay time constant and the particle recycling coefficient during a typical condtioning sequence. 


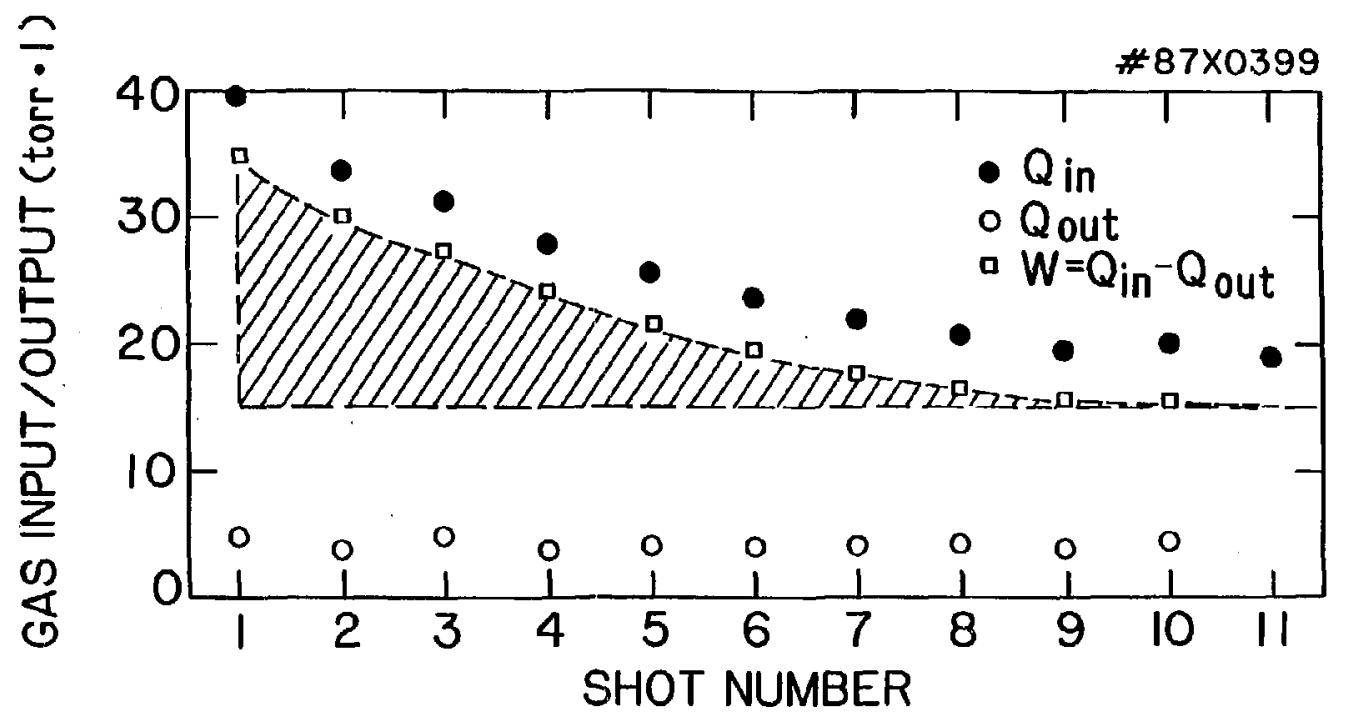

Fig. 4.4. The variation of the gas input $\left(Q_{j n}\right)$, outgassing after the shot $\left(Q_{\text {out }}\right)$, and the amount of gas retained in the wall (W) during the ilmiter loading experiment. 


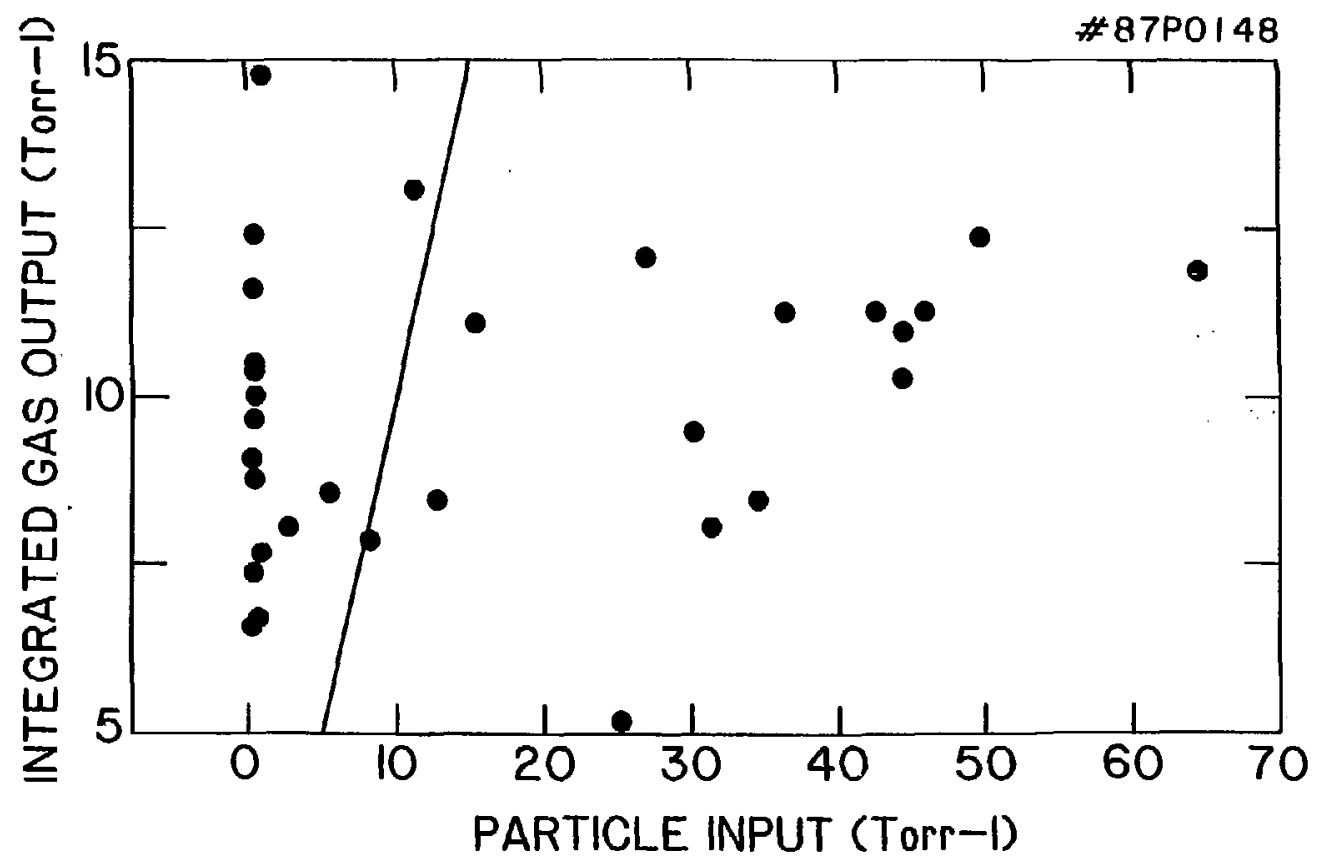

$\hat{\mathrm{u}}$

FlB. 4.5. A comparison of the gas Input to ohmic deuterium plasmas with the integrated outgassing following the discharge. 


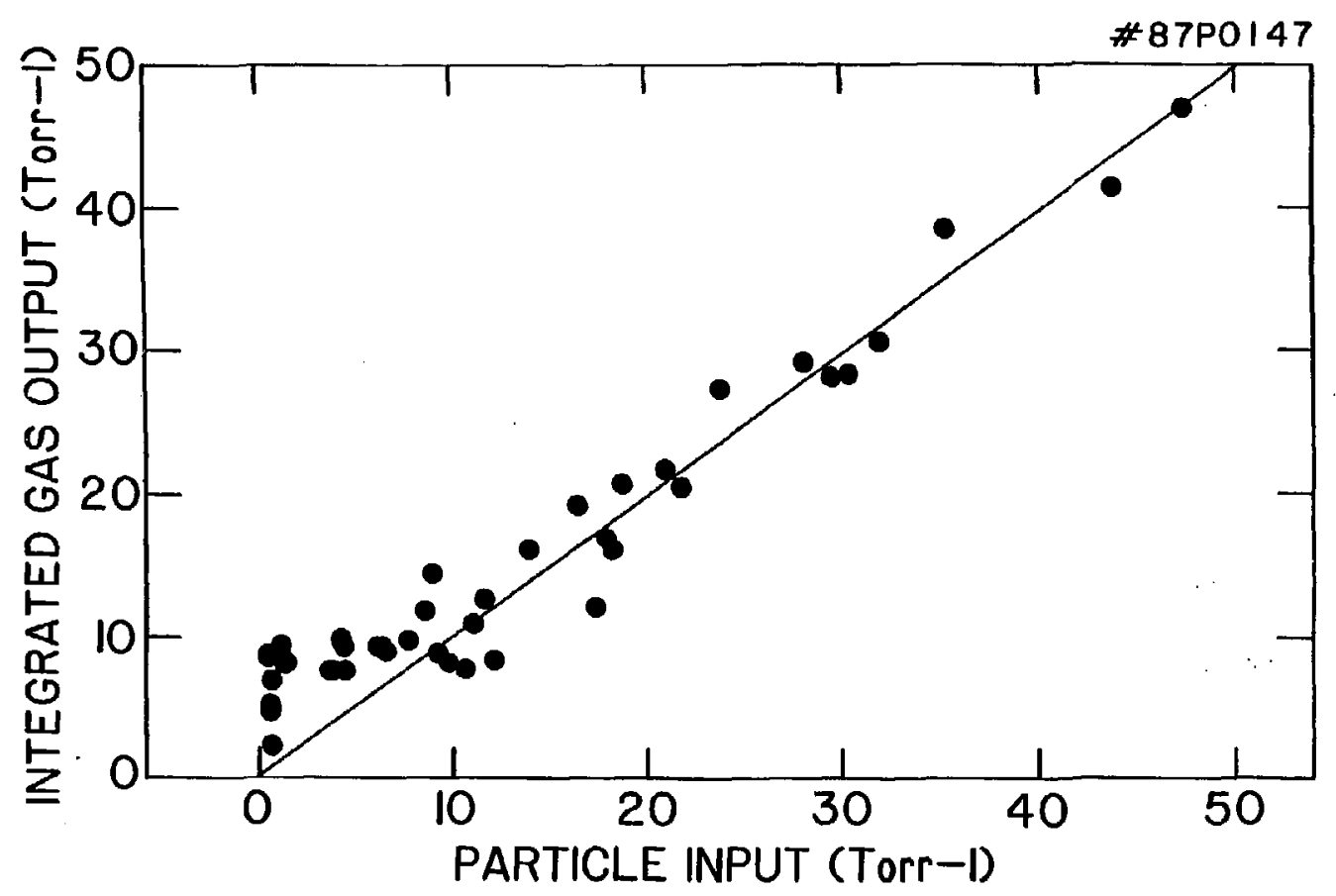

Fig. 4.6. A comparison of the gas input to ohmic helium plasmas with the integrated outgassing following the discharge. 




Fig. 4.7. The change in outgassing after the plasma for a sequence of low density helium-initlated conditioning pulses. 


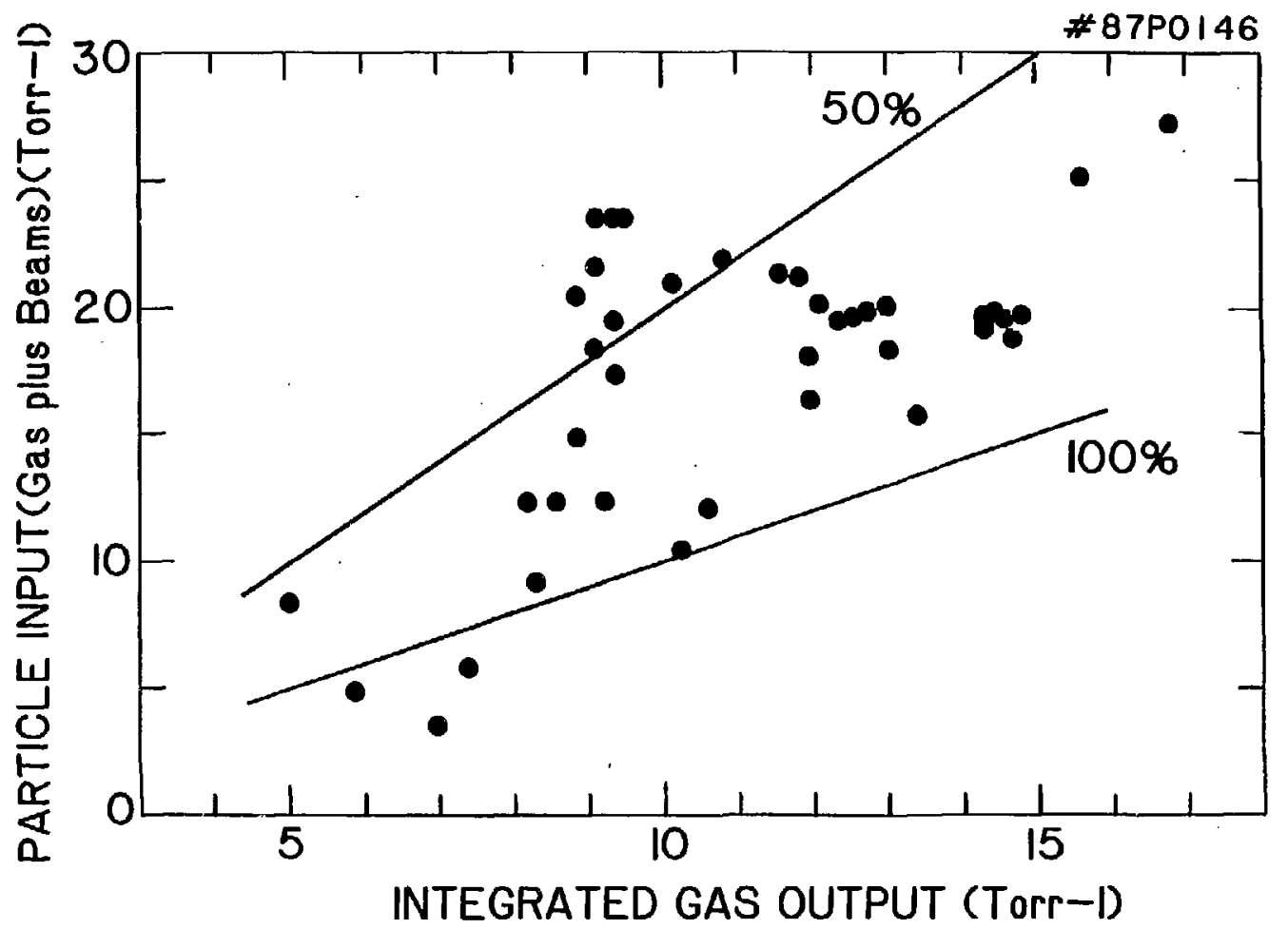

Fig. 4.8. A comparison of the sum of the beam fueling and the gas input to neutral-beam-heated plasmas with the integrated outgassing following the discharge. 


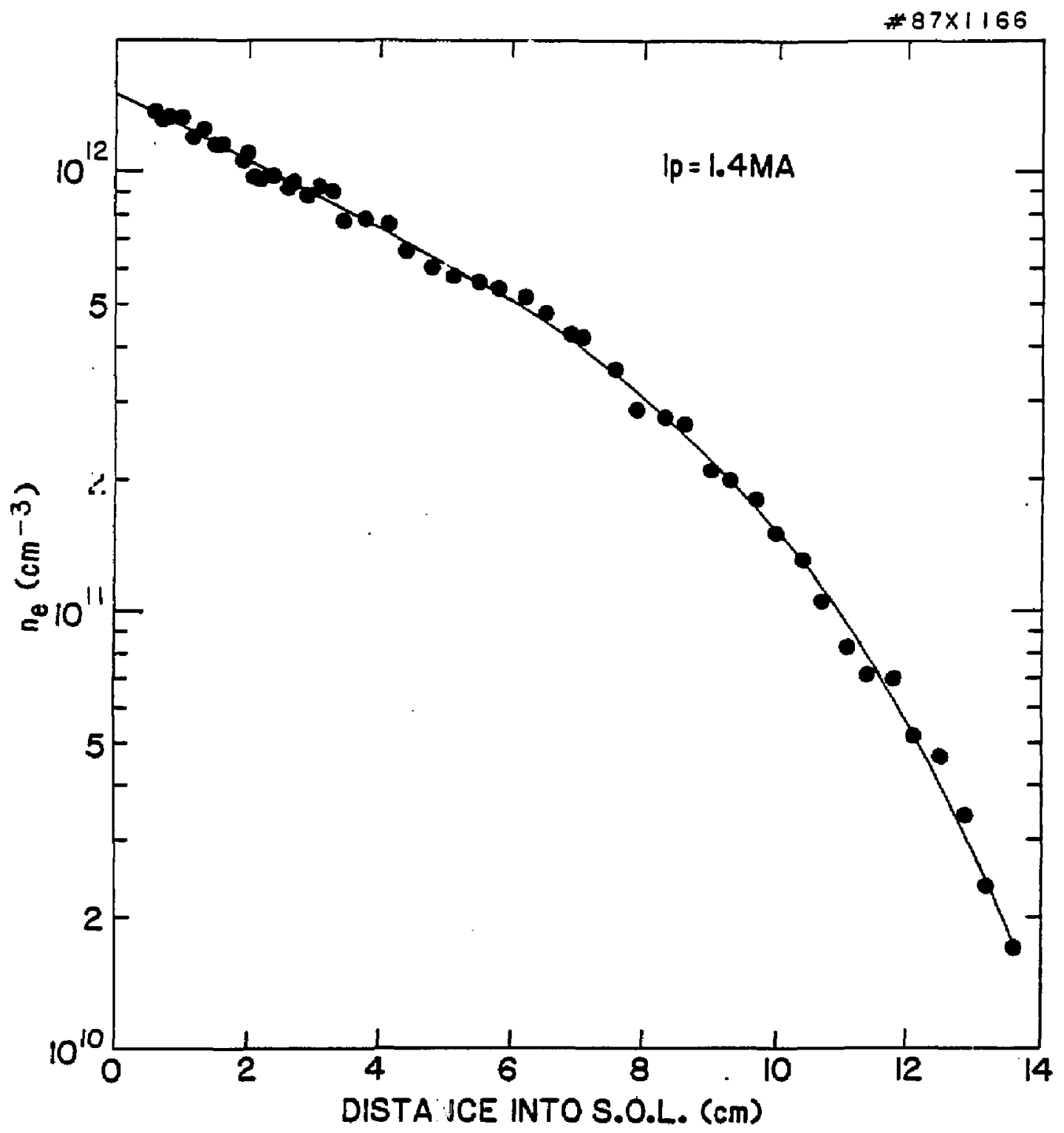

Eig. 4.9. Curved density profile of a 1.4-MA $\mathrm{D}^{+}$ohmle discharge as recorded by a reciprocating Lapgmujr Probe. The plasma density, $n_{e}$, is estimated as $1.4 \times 10^{18} \mathrm{~m}^{-3}$ at the last closed flux surface. 


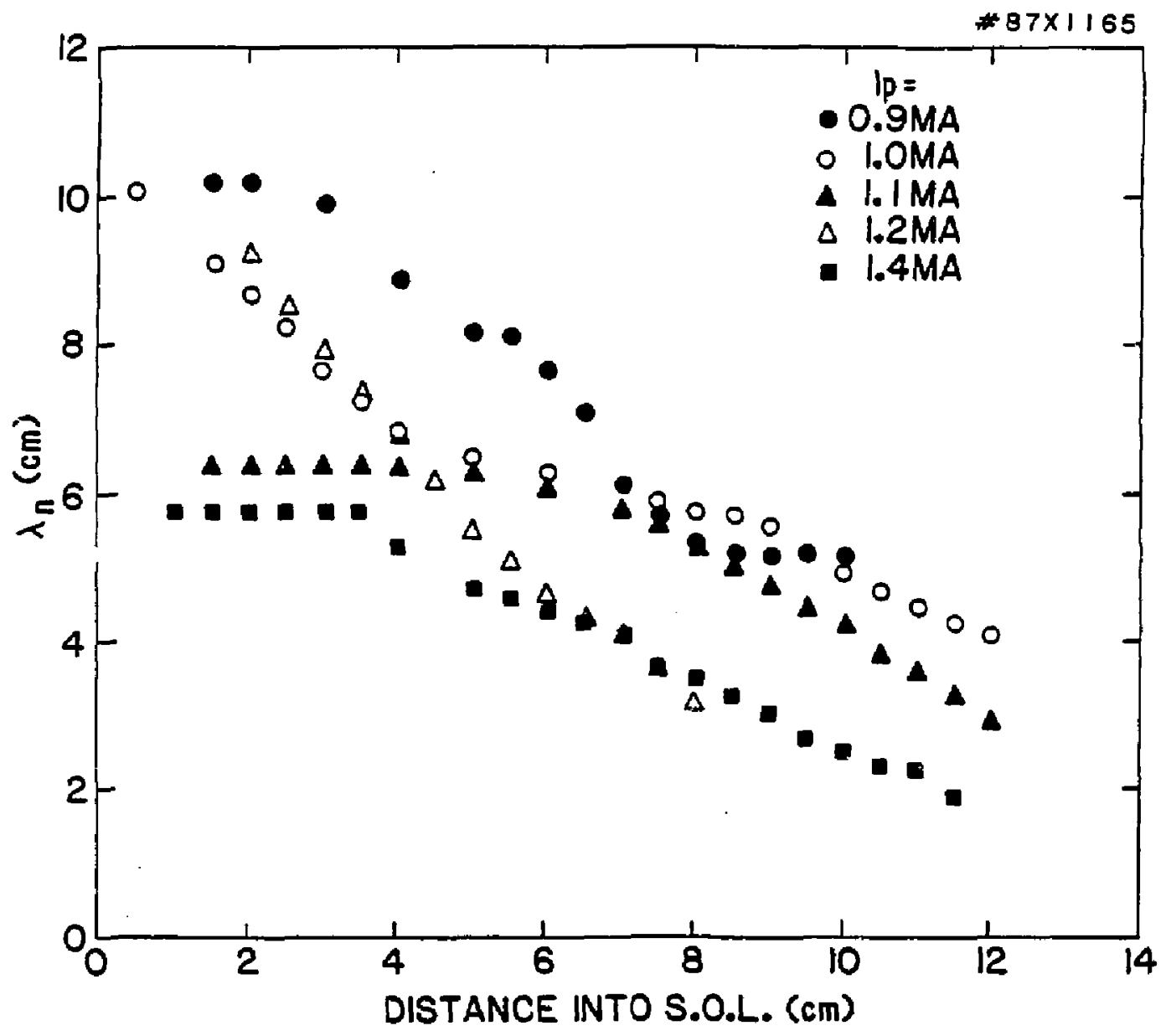

Eig. 4.10. Variation of the density e-folding length in the scrape-off layer during ohmic heating for a range of plasma surrents. 


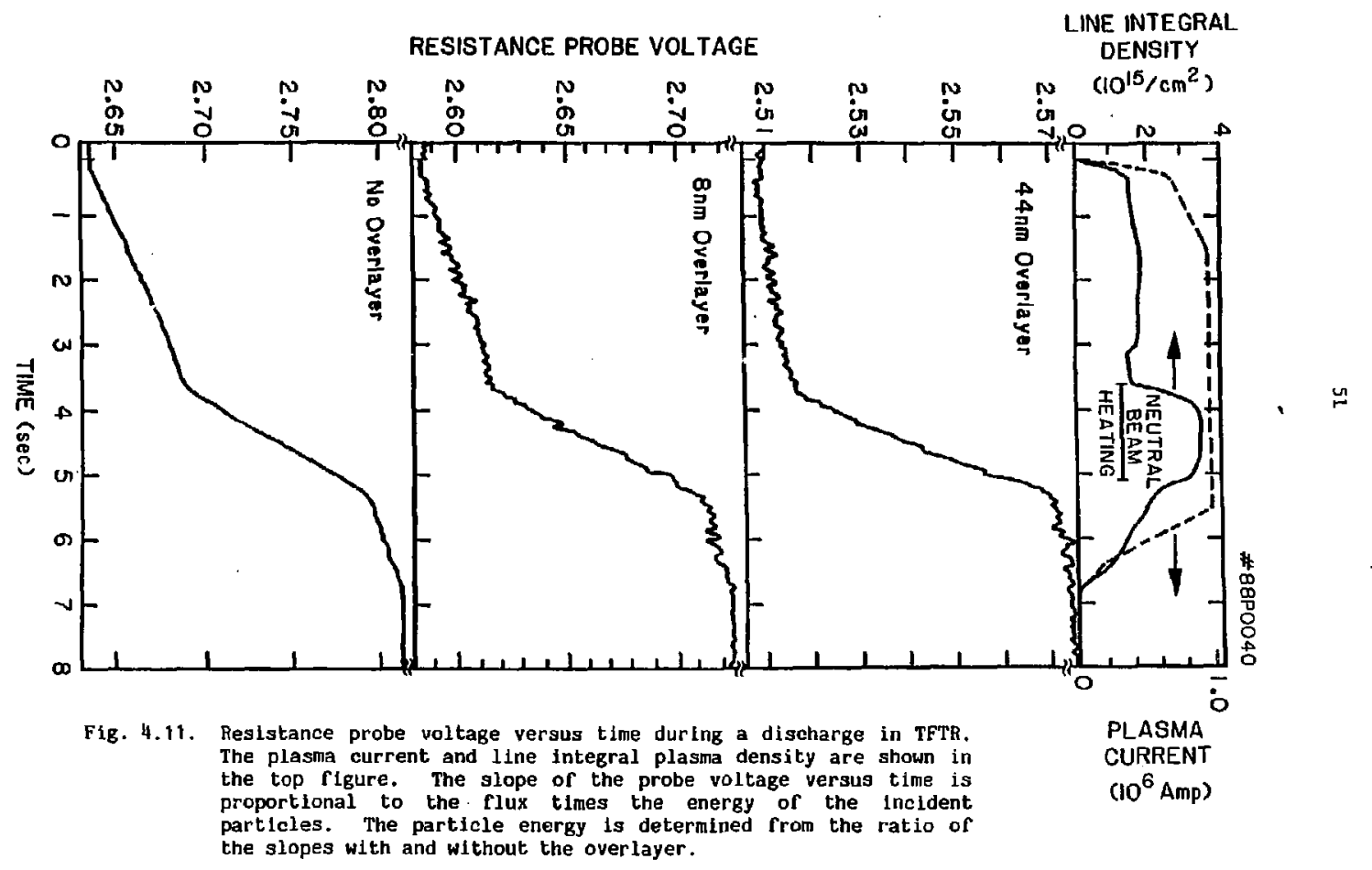




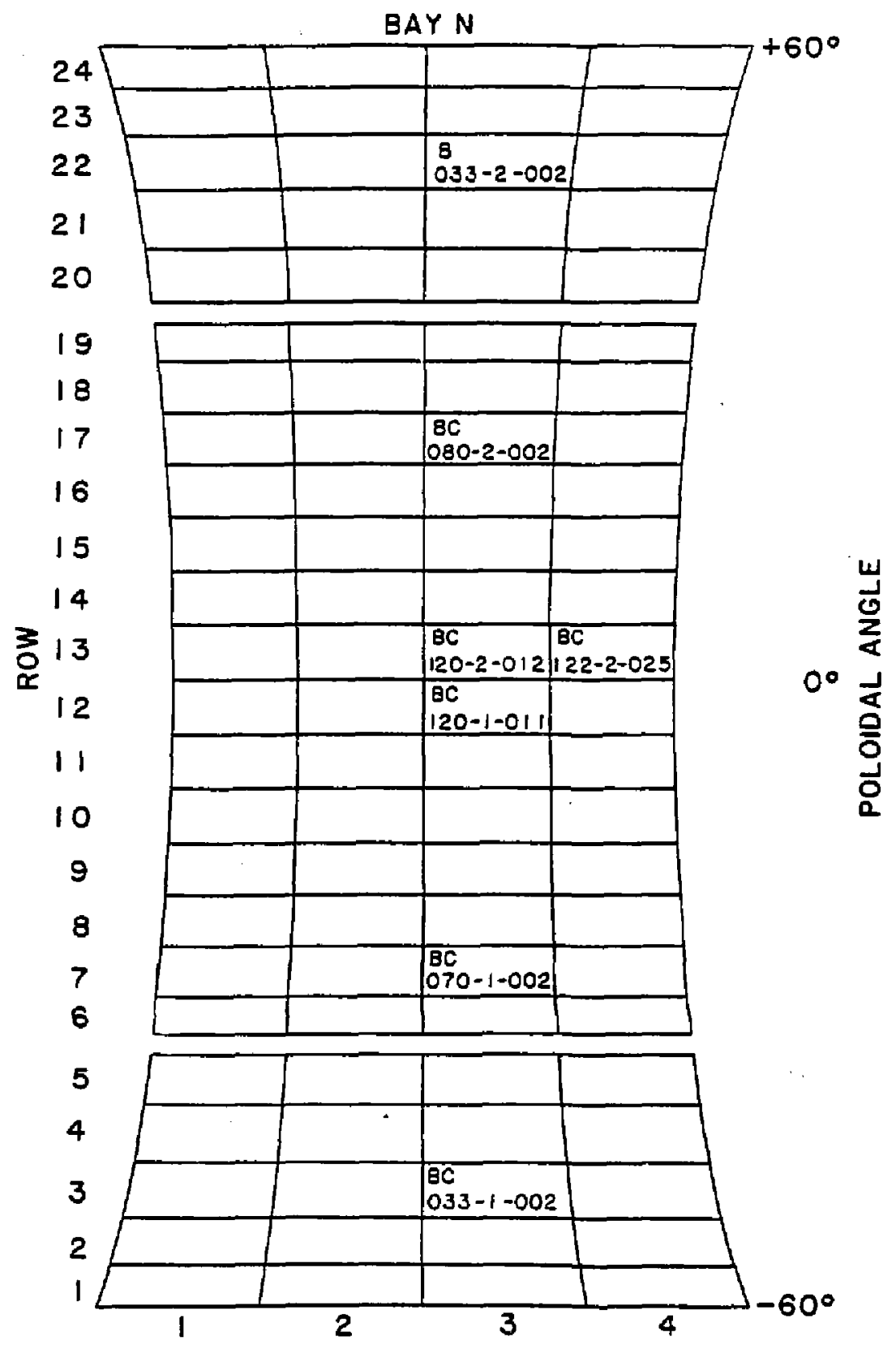

Fig. 4.12. A schematic diagram of a bumper limiter segment in Bay $N$ showing the location of the specially marked limiter tiles that are used for analysis. B stands for boron markers, and BC stands for boron carbide markers. 


\subsection{SUREACE AND BULK ANALYSIS OF FIRST-WALL SAMPLES REMOVED FROM TFTH}

Contributors: Surface Analysis Working Group

B. L. Doyle, Chairman

\subsection{Introduction}

Following the November 1985 to July 1987 operational period for TETR, a multifaceted experimental program was initiated to provide basic data for tritium recycling/retention studies by mapping deuterium and metal deposition in the interior of TFTR $[1,2]$. This program involved both in-situ measurements performed inside the tokamak and external analyses on components which were removed from TFTR. The metal deposited on the bumper limiter tiles on three entire bays and five complete toroidal scans at different poioidal levels in TFTh was measured in-situ using beta-backscattering. Measurements were also made on wall coupons and on a number of wall areas such as the bellows cover plates, the neutral beam ports, and various flanges and shutters in the outer wall. Several interior components were removed for analysis of deuterium retention in the laboratory. These components included 33 graphite tiles from the inner bumper Iimiter and 17 wall coupons. In addition, 288 stainless steel clips, which were used to attach getter panels to the TFTR wall, were obtained from a number of bays spanning a poloidal angle of $+30^{\circ}$ to $+90^{\circ}$ and $-30^{\circ}$ to $-90^{\circ}$, thereby representing most of the TFTR wall. Betabackscattering, a number of ion beam analysis techniques, and various surface mioroscopies were applied to the examination of these samples. The resulting quantitative determinations of near-surface and bulk deuterium deposition, near-surface carbon, oxygen, and metal deposition provided by ion beam analysis, and qualitative information supplied by the other technlques are being used in both the planning of future TFTR operations and the interpretation of past performance.

\subsection{Experimental}

\subsubsection{Ion Beam Analys is}

The ion beam analysis techniques applied in these studies include $3 \mathrm{He}(d, p)$ nuclear reaction analysis (NRA) for detection of $D$; autherford backscattering analysis (RBS) for the determination of $\mathrm{C}, 0$, and metals in the near-surface region; and proton-induced $x$-ray emission (PIXE) for measurement of metals in both the near and sub-surrace region. Some of the NRA and all of the PIXE analyses were performed using a novel in-air method which allowed a complete areal mapping of some limiter tiles and greatly expedited the analysis of the large number of samples. The ex-vacuo nuclear reaction analyses (X-NRA) eX-vacuo proton-induced $\mathrm{X}$-ray emission (X-PIXE) analyses, and in-vacuo experiments are described in some detail below. 


\subsubsection{In-Vacuo Analyses}

Two types of in-vacuo NRA were carried out. The first involved a fixed energy, $700 \mathrm{keV}$ He analysis beam spatially scanned across the sample surface. This analysis gave the areal density of $D$ within the first micron of the sample surface. The second type of analysis required measurement of the ${ }^{3} \mathrm{He}(d, p)$ proton yield as a function of incident beam energy, but was performed only at a few selected positions. D depth distributions were calculated by deconvaluting the proton yields versus beam energy using the procedure described by Myers et al. [3]. Varying the incident He beam energy from 300$2800 \mathrm{keV}$ gave the $\mathrm{D}$ concentration versus depth to 10 microns. The RBS analysis was done with the samples 1n-vacuo. Normally incident, 2 MeV 4 He was used with an annular surface-barrier detector. Areal densities and near-surface concentrations of $c$, 0 , and metals were determined within the first few microns of the surface at several locations.

\subsubsection{Ex-Vacuo Analyses}

The experimental apparatus for our in-air ion beam analyses [4] is shown in Fig. 5.1. The ex-vacuo end-station is installed on the nuclear microprobe beamline of the Sandia EN Tandem Van de Graaff. External beams for both X-NRA and X-PIXE were obtained by using the microprobe lens to focus the beam onto a $1 \mathrm{~mm}$ diameter, $0.5 \mu \mathrm{m} \mathrm{Au/3.0} \mu \mathrm{m}$ Al exit window. $X-N R A$ was used for near surface areal mapping of $D$ using the same ${ }^{3} \mathrm{He}(d, p)$ nuclear reaction applied in the In-vacuo NRA. Typically, $2.2 \mathrm{MeV}$ or $3.1 \mathrm{MeV}$ He beams were incident on the exit window. Window-to-target air gaps of $2 \mathrm{~mm}$ or $1 \mathrm{~cm}$ yielded on-target beam energies of approximately $780 \mathrm{keV}$. An array of one to three ruggedized surface barrier detectors mounted in air (see Fig. 5.1) approximately 1 to $2 \mathrm{~cm}$ from the target detected $14 \mathrm{MeV}$ protons produced from $3 \mathrm{He}(d, p)$ nuclear reactions in the target. The solid angle subtended by the detectors was on the order of one steradian. Using a $1 \mathrm{nA}, 2.2 \mathrm{HeV}{ }^{3} \mathrm{He}$ beam, deuterium could be detected with a sensitivity limit of $10^{14}$ atoms/cm ${ }^{2}$ using analysis times of 1000 seconds. The in-vacuo annular detector shown in Fig. 5.1 was used to monitor the Au backscattering yield from the beam exit window during a given D analysis run. The Au yield was used to determine the He fluence incident on target. Sample data, taken from the analysis of a ScD standard used to calibrate our deuterium measurements, are shown in Fig. 5.2. The rather unusual proton spectrum resulted from changes in the effective detector depletion depth due to variation of the proton's angle of incidence and variation in the nominal $100 \mu \mathrm{m}$ depletion thickness of the various detectors in the array. X-PIXE was carried out using a $4.5 \mathrm{MeV}$ proton beam. The in-air Si-Li detector shown in Fig. 5.1 was used to measure proton-induced $x$-ray emission from the target. Since the metal doposits which we analyzed were only a few microns thick, the measurement could be easily calibrated by direct 
comparison with thin metal standards. Standards containing $10-20 \mathrm{~nm}$ of $\mathrm{Cr}$, $\mathrm{Fe}, \mathrm{Ni}$, and/or Mo were prepared and then characterized using ABS. X-PIXE has previously applied to an analysis of the ALT-i Pump Limiter [5]. Reference 4 presents additional details and examples of the application of X-PIKE.

\subsubsection{Beta-Backscattering}

The beta-backscattering technique was used to analyze areas on the bumper limiter, the wall coupons, the SPS (getter) clips, and other in-vessel components. This method is used to measure the thickness of a layer of one material on top of another by taking advantage of the fact that atoms of high atomic number have a larger electron backscattering cross-section than atoms of low atomic number. In this way the effective thickness of layers of both metals on carbon and carbon on metals can be determined. Different energy beta particles can be used for different choices of materials and thicknesses. In our case the source was the isotope Ct 109, which is a low energy beta emitter. The backscattered electrons were detected in a GeigerMueller tube placed behind and shadowed from the isotope source. For all of the measurements reported here, the relation between counts and thickness is linear. Standards were used to calibrate the thickness vs. counts relationship. The calibration standards for the metals was $N i$ on POCO graphite. The measurements of carbon thickness were calibrated using the backscattering yield of $1 \mathrm{MeV}$ protons to determine the absolute areal density of carbon on a few of the samples. Standards were counted for 100 sec while in-vessel measurements were counted for 10 sec.

\subsubsection{Other Analyses}

Additional analyses of components removed from TFTR employed several techniques. $X$-ray fluorescence measurements of several tiles were made to analyze the alloy composition of metallic deposits. Optical microscopy was used to observe the thickness variation and morphology of tile deposits. Polarized light microscopy highlighted the difference between crystalline and amorphous materials in the deposited layers. Scanning electron microscopy was applied to determine roughness on the surfaces of interest, and electron backscattering images indicated the effective $Z$ of layered structures in deposits on limiter tiles with very high spatial resolution. Electron stimulated $x$-ray emission was used to distinguish the various components that make up the electron backscattering signal, albeit with somewhat lower resolution. Secondary ion mass spectroscopy was used to detect deuterium, metals, and oxygen in the deposit on the POCO graphite. Use of a cesium ion beam enthanced the yield of the hydrogen isotopes. 


\subsection{Results}

\subsubsection{Bumper Limiter}

The bumper limiter covers an area of about $22 \mathrm{~m}^{2}$ or $20 \%$ of the wall in TFT'R [6]. The limiter consists of 20 similar toroidal sectors labeied A through T. Each sector has 96 tiles in an array of 4 columns by 24 rows. Throughout this report the tiles are referced to by a letter indicating the sector followed by two numbers indicating the column and row, as indicated in Fig. 4.12. Numbering starts at the bottom left of the sector as viewed from inside the vessel.

The bumper limiter was installed in the summer of 1985 . During the plasma operations period from November 1985 to July 1987 the limiter was exposed to 9,922 high power plasmas of which 2,756 included neutral beam heating. Most of the plasmas were deuterium-fueled as were the neutral beams. The last several plasmas were ohmically heated, pellet-fueled deuterium plasmas. This period of operation included disruptive discharge cleaning [7] to remove water from the limiter, and low-censity belium plasma conditioning to remove hydrogen isotopes from the limiter [8]. Six wall coupons were removed for analysis in March 1986 after 1770 discharges. These six were replaced with fresh coupons. In July 1987 seventeen wall coupons were removed for analysis including five from the same positions sampled by the first set.

\subsubsection{Beta-Backscattering}

At the end of the run period the areal density of metal impurities deposited on the bumper limiter was mapped in-situ by beta-backscattering. Figure 5.3 gives an example of a two-dimensional map of one bay and Fig. 5.4 gives the results of toroidal measurements at four different poloical angles. These measurements provided a global picture of regions of high and low deposition over the entire 1imiter. In Fig. 5.3 the areal density of metal on the surface of the poco graphite tiles of Bay $N$ of the inner lumper limiter of TFTR is displayed. The measurements were made with a $5 \mathrm{am}$ mesh in the poloidal direction and a $2.5 \mathrm{~cm}$ mesh in the toroidal direction. The other 19 bays show a pattern of metal deposition similar to that shown in Fig. 5.3 for Bay N. Figure 5.4 shows the metal deposition around the bumper limiter at rows $2,7,10$, and 13 . The uniformity at the midplane (Row 13) is evident and the periodicity of the clean areas in the lower half of the liniter follows the bay periodicity.

Following the in-situ beta-backscattering analysis, thirty-three of the tiles were removed for detailed external anaiysis. These tiles were chosen to give one vertical (i.e., poloidal) scan from the top to the bottom of the 
limiter on sector $N$, column 3. Two tiles near the center from each of seven additional sectors were also included to examine variations with toroidal position near the midplane.

\subsubsection{Impurity Analysis by PIXE and RBS}

All tiles removed for external analysis were examined by external-beam PIXE to determine areal densities of deposited metals. The depth probed is greater than the thickness of the deposited layer. The poloidal scan along column N3 showed Low metal deposition $\left(<5 \times 10^{16} / \mathrm{cm}^{2}\right)$ on the lower half of the limiter below tile 12, and high metal deposition (up to $10^{18} / \mathrm{cm}^{2}$ ) on the upper half of the limiter as shown in Eig. 5.5. Metal areal densities near the midplane at various toroidal positions ranged between 0.6 and $1.0 x$ $10^{18} / \mathrm{cm}^{2}$ as shown in Fig. 5.6. The combined areal densities and distribution of metals measured by PIXE are consistent with the beta backscattering measurements. From the PIXE measurements the relative fractions of the major metal impurities $\mathrm{Cr}, \mathrm{Fe}$, and $\mathrm{Ni}$ in the areas of heavy deposition on the limiter were determined to be $19 \pm 1,38 \pm 5$ and $43 \pm 5$, atomic $\%$, respectively, as shown in $\mathrm{Fig} .5 .7$. The high nickel content points to Inconel as a major source of impurities on the limiter. RBS analysis was done on three tiles from column N3. All tiles had impurities extending beyond the depth probed by RBS, which is about $\uparrow \mu \mathrm{m}$. The main observable impurities were oxygen, $\mathrm{Cr}$, Fe, and $\mathrm{Ni}$. Tiles 12 and 15 from regions of high deposition had near-surface concentrations of 6 at $\$$ for oxygen and 1 at $\$$ for the sum of $\mathrm{Cr}$, Fe, and Ni. Tile 7 from a region of low deposition had near-surface concentrations of $<1$ at $\%$ oxygen and 0.1 at $\%$ metals. The metal areal density measured by PIXE and the metal concentration measured by RBS can be combined to give an estimate of the thickness of the deposited layer, using the approximation of uniform netal concentration. This gives a thickness of about $10 \mathrm{\mu m}$ in the regions of high deposition, assuming that the deposition is primarily carbon with a density of $1.8 \mathrm{~g} / \mathrm{cm}^{3}$.

\subsubsection{Deuterium Analysis}

The areal density of deuterium within about one micron of the surface was measured by NRA using a $700 \mathrm{keV}$ He analysis bear. At selected locations the deuterium concentration was measured versus depth to nearly 10 um from the surface by observing the nuclear reaction yield as a function of analysing beam energy [3]. The depth profiles were measured with the samples in vacuum. The near-surface deuterium areal density measurements were done in both vacuum and air.

Figure 5.5 shows the areal density of near-surface deuterium scanned along the pololdal direction on column N3 of the limiter. The values were 
measured at the center of the plasma-facing surface of each tile. The main feature is that there is much more deuterium on the upper half of column N3 than on the lower half, as was seen for the metals. The areal density of near-surface deuterium was mapped in detail over the plasma-facing surface of tiles $3,7,10,11,12,15$, and 18 of colum N3. Figures 5.8 and 5.9 show horizontal line scans of the near-surface areal density of deuterium on tiles N3-3 and N3-14 from regions of low and high deposition, respectively. The vertical scan across tile N3-11 shown in Eig. 5.10 shows that the transition from low to high deposition is rather abrupt, occurring in about $2 \mathrm{~cm}$. Figure 5.6 shows the areal density of near-surface deuterium near the midplane (tiles 3-12) for 8 toraldal positions. The values are fairly uniform except for the lower value at sector J. Visual examination of tile J3-12 revealed a burned and ablated region near the analyzed spot surrounded by an area of heavy carbon deposition. It is possible that runaway electrons caused local heating or sudden depasition of a relatively thick carbon film resulting in a localized reduction in the concentration of near-surface deuterium at this location. The poloidal and toroidal variations of deuterium areal densities follow the trends seen in the metal areal densities and again reveal regions of high and low deposition.

The distribution of deuterium on the sides of the tiles was also examined. Eigure 5.11 shows the areal density of near-surface deuterium on the sides of four tiles. For tiles with high front-surface deuterium areal density, the density on the sides reaches values comparable to the front surfaces. Tiles from regions of low deuterium retention on the front surface had much higher deuterium retention on the sides than on the front. On all the sides examined the deuterium areal density decreased approximately exponentially with distance from the front surface with a characteristic length of $0.6 \mathrm{~cm}$. Since NaA with a $700 \mathrm{keV}$ analysis beam does not detect deuterlum deeper than about 1 $\mu \mathrm{m}$ from the surface, the deuterium depth profile was measured in several spots to determine the thickness of the deuteriumcontaising layer and the total deuterium areal density. Flgure 5.12 shows the deuterium concentration versus depth on three front surfaces and on three sides. The total integrated deuterium areal density for each spot is also indicated on Fig. 12. On the front surface of tiles N3-12 and N3-15 the deuterium containing layer is several microns thick and the total areal density of deuterium is about $6 \times 10^{18} \mathrm{D} / \mathrm{cm}^{2}$. On tile N3-7 the deuterium is almost all within 0.5 micron of the surface. The deuteriun containing layer on the sides of the tiles is also several microns thick in some cases. The profiles for sides N3-12R, N3-12U, and N3-7U were made $0.2,0.3$, and $0.4 \mathrm{~cm}$ from the front-surface edge, respectively. Comparison between the lateral scans on the sides of the tiles in Fig. 5.11, and the corresponding depth profiles in Fig. 5.12, show that the flattening of the curves near the front 
surface for tiles N3-7U and N3-12U in Fig. 5.11 occurs where the deuteriumcontaining layer becomes thicker than the depth probed by the $700 \mathrm{keV}$ analysis beam used for the lateral scans. It should be noted that the tiles (N3-7 and N3-8) with the most deuterium on the sides had small amounts of deuterium on the front. This suggests that these are regions wher: net erosion prevents deuterium build-up on the front surface and where associated deposition of eroded material in the gaps between the tiles results in high deuterium buildup on the sides.

Uptake of hydrogen lsotopes into the bulk of the graphite has been a concern for estimating future tritium inventory. Concentrations at the level of a few atomic ppm can be a significant fraction of the tritium inventory because of the large amount of graphite in TFTR (2000 kg). The concentration of $D$ in the bulk of the TFTR bumper limiter was determined by measuring the NRA yield on a freshly fractured surface on one of the tiles. Tile N3-12 was seiected because it was from the midplane where there is close contact with the plasma and because it had a large amount of deuterium on the front surface (see Fig. 5.3). A slot was cut from the back of the tile to within $1.5 \mathrm{~cm}$ of the front surface. After careful removal of dust from cutting, the tile was split to expose a fresh surface perpendicular to the plasma-facing surface. The tile was placed in the analysj.s chamber which was pumped out within one minute of splitting the tile. The areal density of near-surface deuterium was measured by NRA using a $700 \mathrm{keV}$ analysis beam within 15 minutes of splitting the tile. The areal density of near-surface deuterium on the fresh surface was $(4 \pm 2) \times 10^{12} \mathrm{D} / \mathrm{cm}^{2}$, corresponding to a bulk concentration of $(0.4 \pm 0.2)$ atomic ppm. This measurement was made at a spot 2 mim beneath the surface exposed to the plasma.

\subsubsection{Tritium Analysis}

Approximately $6 \times 10^{18}$ tritium atoms have been produced by $D(d, p) T$ nuclear reactions in TFTA plasmas since the bumper limiter was installed [1]. Some of this tritium has been retained on the limiter along with the deuterium. The areal density of tritium on the limiter was determined by dissolving pieces of the tiles and measuring the activity of the solution by liquid scintillator counting. The areal density of tritium was measured on tiles N3 - 13, N3 -7 , and N3 -15 and a wall coupon to be $2.7 \times 10^{12}, 1.9 \times$ $10^{12}, 1.0 \times 10^{13}$ and $1.4 \times 10^{12} \mathrm{~T} / \mathrm{cm}^{2}$, respectively. Assuming these values are representative of regions of low deposition, high deposition, and the wall we can estimate the amount of tritium retained in TFTR to be about $1.3 \times 10^{18}$ tritium atoms on the limiter and $1.4 \times 10^{18}$ tritium atoms on the wall. Thus, about one-half of the amount of $T$ produced has remained in TFTR. 


\subsubsection{Microscopy}

SEM microscopy of the surfaces of tiles in the areas with a moderate amount of metallic deposition show a morphology illustrated in Fig. 5.13. The peak-to-valley height of the features in the high deposition region is < 30 $\mathrm{um}$; in the clean areas the features are an order of magnitude smaller. The furrowed features make an angle of -45 degrees with respect to the poloidal direction in TFTR. SEM backscattering images of this area show it to be entirely uniform in composition. A cross section of this area shown in Fig. 5.14 indicates the total thickness and the local relief. This sample was taken from the surface of a tile in the moderate deposition region near the midplane of the bumper limiter. It shows a rough layer of deposited material from 20 to $40 \mathrm{um}$ thick. This structure is uniform aver the plasma-facing surface of the tile. Beta backscattering measurements show that this area has a metal areal density of $-6.5 \times 10^{17}$ atoms $/ \mathrm{cm}^{2}$. Despite the variation of the thickness of the deposit on the scale of $10 \mu \mathrm{m}$, the average thickness $(-20$ microns) remains uniform for several $\mathrm{cm}$. The average thickness of 20 um is somewhat in disagreement with the ion beam analysis results, which indicated that the deuterium containing layers were 5-10 microns thick as shown in the deuterium profiles in the bottom panel of Fi.8. 5.12. This difference may be caused if the deposited layer is porous; the discrepancy, however, is under further investigation. Also shown in Fig. 5.13 is a surface micrograph of an area that has been eraded by the plasma. The sides and edges of the tiles are subject to thicker and Iess directional deposition.

The edge of a tile in a moderate deposition region is shown in the SEM backscattered image displayed in Fig. 5.15 along with the backscattered trace along the indicated Iine. Relative changes in the backscattered amplitude along the trace reflect variations in the amount of high 2 materials incorporated into the deposition layer at the point of analysis. Figure 5.15 shows striking changes in the average $z$ of the different sublayers or bands in the deposit. These strata represent the residue of two years of operation with the different compositions resulting from different operating conditions. Figure 5.16 shows an electron microprobe trace across a similar area. Only the major components are shown. The top graph indicates the iron, nickel, and chromium concentrations across the deposit. The features follow the SEM backscattered trace, although with much less resolution. The nickel concentration increases relative to the iron at the surface of the deposit, as does the chromium to a lesser degree. Similar changes were observed in the long term trends of metallic impurities observed in the plaswa during 1985-87 operations period. The lower graph in Fig. 5.16 compares the total metal to oxygen content of the deposit. The correlation in this case is not striking and may reflect differences in in-situ cleaning procedures. Secondary Ion Mass Spectrometry (SIMS) analysis of a similar area also failed to show any relationship between oxygen and metal deposition. 
SIMS was used to examine depth versus variation in the concentrations of carbon, metal, oxygen, and deuterium. When SIMS was used on the layered deposits, the layers could be seen; however, the lack of correlation between metals and oxygen was observed as when examined by the electron microprobe. However, there was a significant matrix effect, which makes interpretation of the data more difficult. The results on the front surface are also relevant to an estimate of tritium inventory. In this region the compositional variation was much less and, hence, the matrix effects were minimized. Figure 5.17 shows the change in the SIMS count rate as a function of depth on the front surface of a typical moderately covered tile (as in Fig. 5.13). Recalling that this surface is rough and that the depth resolution is poor, it can be seen that the trend of the metal signals is similar to the crosssectional microprobe data shown in Fig. 5.16. In particular, the metal concentration is highest near the interface between the deposited layer and the graphite substrate. The thickness of the deposited layer in Fig. 5.17 is approximately $14 \mathrm{~mm}$. The oxygen signal follows the metals, as does the deuterium signal. The concentrations of deuterix?, oxygen, and metals detected increased noticeably with depth. Deuterium depth profiles from several other areas of the bumper limiter tiles are shown in Fig. 5.18.

\subsubsection{Hall Coupons}

Graphite coupons were mounted on the wall of TFTR to monitor long-term deposition of $D$ and impurities. These were exposed facing the plasma between November 1985 and July 1987. The wall coupons have been analyzed by NRA, RBS, and PIXE. Deposited materlal was found to consist mainly of carbon but also included D, oxygen, and metal impurities. The results are summarized in Table 5.1. Sample set 1 consisted of the six samples exposed only to the first 1770 discharges. Sample set $1 \mathrm{~A}$ consisted of the five replacement samples to set 1 and were exposed only to the next 8,152 discharges. Samples from set 2 were exposed to all 9,922 discharges for the 1985-87 operations period. Table 5.1 gives the mean values and the standard deviation due to variations in deposition at different locations. The areal density of impurities on set 1 is twice as high as on the replacement set 1R. This indicates that most of the impurity deposition on the wall occurred early in the operational period, 1.e., before the March 1986 opening. This may be related to the initial conditioning of the bumper limiter which involved a large number of plasma disruptions. In contrast, the areal density of deuterium is 5 times higher on set 1R than on set 1. This suggests that the deuterium retention on the wall scales approximately linearly with the number of discharges at a rate of about $5 \times 10^{13} \mathrm{D} / \mathrm{cm}^{2}$ per discharge. The relative fractions of $\mathrm{Cr}, \mathrm{Fe}$, and $\mathrm{Ni}$ determined by PIXE analysis are also given in Table 5.1. The high Fe fraction shows that stainless steel components rather than Inconel were the dominant 
source of impurities reaching the wall. The toroidal variation observed for deuterium and metal deposition on the wall coupons is shown in Fig. 5.19.

\subsubsection{SPS CIips}

Stainless steel clips used to mount the surface pumping system (SPS) getter panels were examined to determine the amounts of carbon and deuterium deposited on the wall. These clips were located at poloidal angles from $30^{\circ}$ to $90^{\circ}$ above and below the ridplane in several bays. Beta-backscattering was used to determine relative areal densities of carbon on the clips. These measurements were calibrated by measuring the absolute carbon areal density on a few clips by RBS using a $1.2 \mathrm{MeV}$ helium analysis beam. The areal density of deuterium was measured by external-beam NRA. Figure 5.20 shows the areal density of deuterium plotted versus areal density of carbon on the SPS clips. The amounts of deuterium and carbon varied by about an order of magnitude. In general there were several times more deuterium and carbon at. the top and bottom of the machine than near the midplane. Since the limiter is a major source of carbon and neutral deuterium, the fluxes of deuterium and carbon to the wall are expected to be higher nearer the limiter. The average areal density of deuterium on the SPS clips was $5.2 \times 10^{17} \mathrm{D} / \mathrm{cm}^{2}$ which is in good agreement with the average deposition $\left(5.7 \times 10^{17} \mathrm{D} / \mathrm{cm}^{2}\right)$ observed on the wall coupons. The average areal density of carbon on the SPS clips was $1.6 \times 10^{18} \mathrm{c} / \mathrm{cm}^{2}$. The ratio of average deuterium to average carbon was 0.33 which is close to the saturation value of 0.4 . This may indicate that the rate at which deuterium builds up on the wall. is determined by the carbon deposition rate rather than by the flux of deuterium to the wall.

\subsection{Discussion}

The surveys of deuterium distribution on the limiter by NRA and of impurity distribution by beta-backscattering give a consistent picture of areas of high and low net deposition. Each sector has reglons of lowest deposition above and left of center and below and right of center, and areas of highest deposition above and right of center and below and left of center. The midplane also had fairly high deposition. The deposition of deuterlum and impurities on the various toroidal sectors were found to be similar. This pattern is due to self-shadowing by high spots at the center of each sector. The measured deuterium areal densities can be used to estimate the total amount of deuterium in TFTR. Eirst we estimate the amount of deuterium on the plasma-facing surfaces of the bumper limiter. On the bumper limiter the regions of high and low deposition have about $6 \times 10^{18} \mathrm{D} / \mathrm{cm}^{2}$ and $3 \times 10^{17} \mathrm{D} / \mathrm{cm}^{2}$ respectively (Fig. 5.5). From the beta-backscattering we estimate that about two thirds of the limiter has high deposition and one third has low deposition. This gives about $9 \times 10^{23}$ deuterium atoms on the 
plasma-facing surface of the bumper limiter. Measurements of the amount of deuteriur on the sides of several tiles, shown in Figs. 5.11 and 5.12 together with microscopy observations of the deposit thickness were used to estimate that the amount of deuterium on the sides of the tiles is about $6 \times 10^{23}$ deuteriun atoms. The amount of deuterium in the bulk of the bumper limiter is estimated to be Iess than $0.4 \times 10^{23}$ atoms, which is much less than the amount in near-surface deposits. Finally, the amount $f$ deuterlum in deposited material on the rest of the vacuum vessel wall can $i$. estimated from the mean areal density measured on the wall coupons and SPS jetter clips $\left(-6 \times 10^{17}\right.$ $\left.\mathrm{D} / \mathrm{cm}^{2}\right)$ times the area of the wall $\left(10^{6} \mathrm{~cm}^{2}\right)$ to be $6 \times 10^{23}$ deuterium atoms. Thus, the total amount of deuterium retained on the limiter and wall in TFTR since the bumper limiter was installed is estimated to be $2.1 \times 10^{24}$ atoms with an uncertainty on the order of $\pm 50 \%$. This is about 3000 times more than the amount of deuterium in a plasma and about $30 \%$ of the total throughput of deuterium used to fuel the plasmas. Small fractional changes in the amount of deuterium in the limiter and wall therefore, can cause large relative changes in the plasma density. The amount of delterium on the burper limiter is much greater than the amount estimated to be on the moveable limiter in a previous study $[9,10]$. This is partly due to the higher areal densities of deuterium on the bumper limiter and partly due to the 10 times larger area of the bumper limiter. The estimates of total deuterium retention in TFTR can be used to predict the amount of tritium which will be retained when operation with D-T plasmas begins. This is a serious issue for TFTR because of the requirement to minimize the total on-site tritium inventory. If half of the deuterium now in TFTR were tritium, then there would be 3.8 grams of tritium on the limiter, and 1.5 grams on the wall. However, this overestimates the tritium retention likely to occur because the number of D-T plasmas will be much smaller than the number of deuterium plasmas which produced the deuterfum retention we have measured. In addition, no attempt was made to remove deuterium by discharge cleaning or helium plasma conditioning as might be used to reduce the tritium inventory. The number of full power D-T plasmas is restricted to about 200 to 300 by the limit $\left(3 \times 10^{21}\right)$ on $D-T$ neutrons produced (see Sec. 2.0), whereas the deuterium retention we report here is the result of 9,922 deuterium-fueled plasmas. It is likely that the deuterium retention on the wall and on regions of thick deposition on the limiter has continued to build-up over the two-year exposure period. The amount of D-T retalned after 300 D-T plasmas should, therefore, be much less than the amount of deuterium retained after 9,922 deuterium plasmas (see Sec. 7.0). 


\subsection{Conelusions}

Measurements of areal densities of metals and deuterium show areas of net deposition of material at the lower left and upper right and at the midplane in each of the 20 sectors of the bumper limiter. Relatively clean areas, corresponding to regions of high plasma flux and presumed net erosion, were found at the lower right and upper left of each sector. The deposited material was mainly carbon with 20 at $\$$ deuterium, 6 at $\$$ oxygen, and 1 at $\%$ metal atoms with a deposition depth up to many microns. Using the measured areal densities of deuterium on the limiter and wall coupons the total amount of deuterium retained since the installation of the bumper limiter was estimated to be $1.5 \times 10^{24}$ atoms on the 1 imiter, and $6 \times 10^{23}$ atoms on the wall. The main mechanism for deuterium retention on the limiter and wall is codeposition rather than implantation. The amount of deuterium retained in the bulk graphite of the limiter was found to be a small fraction of the amount in the near-surface region. 
REFERENCES

[1] H. F. Dylla et al., in Proc. Third Inter. Conf. on Eusion Reactor Materials, Karlsruhe, 1987; J. Nucl. Mater., in press.

[2] H. R. Hampler et al., Presented at the 34 th National Symposium of the American Vacuum Society, Anaheim, CA, 1987; J. Vac. Sci. Technol. A6 (1988) in press.

[3] S. M. Meyers et al., Met. Trans. 14A (1983) 2261.

[4] B. L. Doyle, J. Vac. Sci. Technol. A3 (1985) 1374.

[5] R. T. McGrath et al., J. Nucl. Mater. 145/147 (1987) 660.

[6] L. Sevier et al, in Proc. 10th Symposium on Fusion Engineering, Philadelphia, 1983 (IEEE, New York, 1984), pp. 1072.

[7] H. F. Dylla et al., J. Nucl. Mater. 145/147 (1987) 48.

[8] H. F. Dylla et al, Nucl. Fusion 27 (1987) 1221.

[9] H. R. Wampler et al., J. Nucl. Mater. 145/147 (1987) 353.

[10] A. E. Pontau et al., J. Vac. Sci. Technol. A4 (1986) 1193. 
TABLE 5.1

Results from Wall Coupon Analysig

\begin{tabular}{|c|c|c|c|c|c|c|c|c|c|}
\hline Sample & Number of & & Areal & Density $\left(10^{17}\right.$ & atoms $/ \mathrm{cm}^{2}$ ) & Relative Fract & on $(x)$ & & \\
\hline Set & Disoharges & D & $\mathcal{C}$ & 0 & $\mathrm{Cr}+\mathrm{Fe}+\mathrm{Ni}$ & $\mathrm{Zr}+\mathrm{Mo}$ & $\mathrm{Cr}$ & $\mathrm{Fe}$ & $\mathbf{N}_{1}$ \\
\hline 1 & 1,770 & $1.2 \pm 0.3$ & $30 \pm 20$ & $3 \pm 2$ & $0.9 \pm 0.4$ & $0.040 \pm 0.01$ & $23 \pm 2$ & $50 \pm 2$ & $27 \pm 3$ \\
\hline in & 8,152 & $6.1 \pm 0.6$ & $12 \pm 6$ & $1.6 \pm 0.8$ & $0.45 \pm 0.14$ & $0.023 \pm 0.006$ & $15 \pm 1$ & $49 \pm 5$ & $35 \pm 4$ \\
\hline 2 & 9,922 & $5.7 \pm 2.4$ & $33 \pm 24$ & - & $1.50 \pm 0.70$ & $0.047 \pm 0.014$ & $17 \pm 1$ & $47 \pm 3$ & $36 \pm 3$ \\
\hline
\end{tabular}


X-NRA AND X-PIXE USING THE SANDIA NUCLEAR MICROPROBE

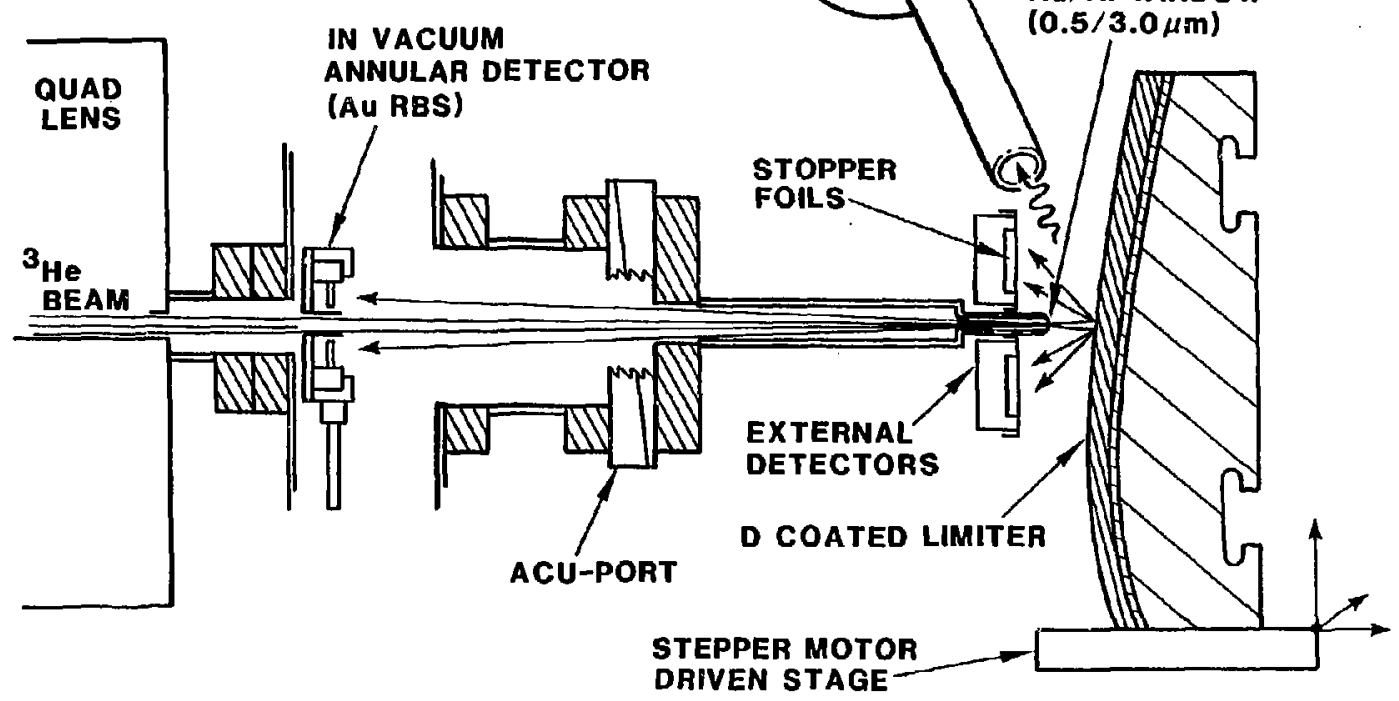

Fig. 5.1. Experimental apparatus for the measurement of deuterium and metals usIng $X-M R A$ and $X-P I K E$. 



Eig. 5.2. K-NRA sample data for 3 He(d,p)4He nuclear reaction amalysis of deuterium in a SCD standard. 


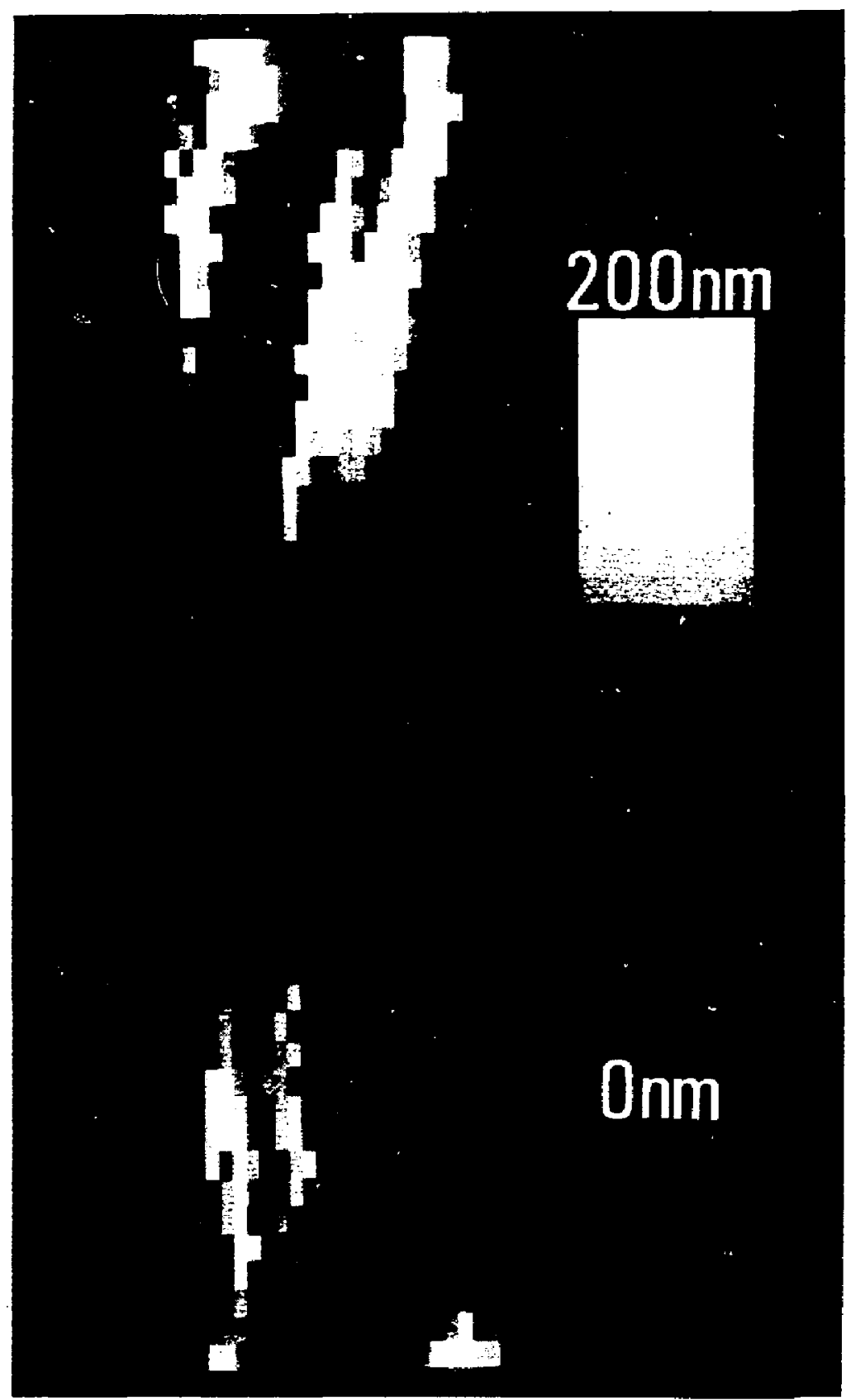

FIG 5.3. The areal density of metal on the surface of the poco graphite tiles of Bay $\mathbf{N}$ of the inner bumper limiter of TETR is displayed as apparent nickel thickness (grey-scale shown at $r$ ight) as measured by $C d 109$ beta backscattering. 


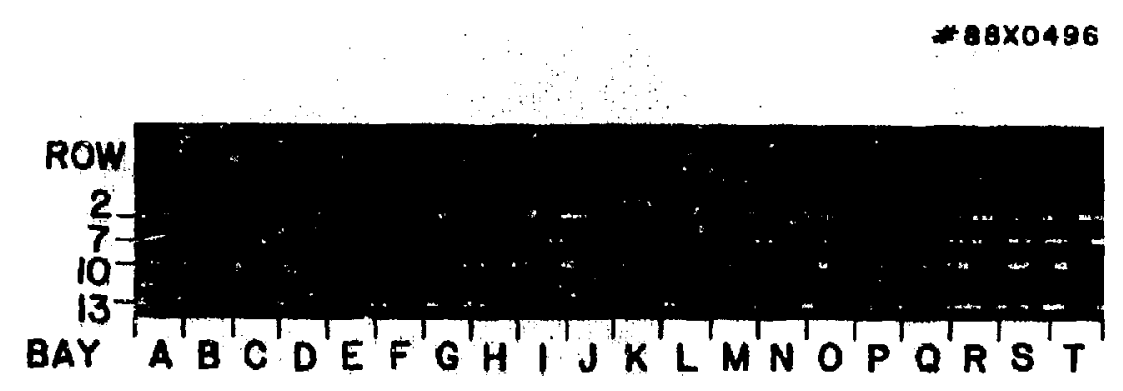

Fig. 5.4. Toroidal and poloidal metal deposition measurements on the Inner bumper limiter of TFTR. The measurements are displayed in a grey scale similar to that shown in Fig. 5.3. The uniformity at the midplane (Row 13) is evident and the periodicity of the lower clean areas follows the bay periodlcity. 


\section{POLOIDAL SCAN OF TFTR LIMITER}

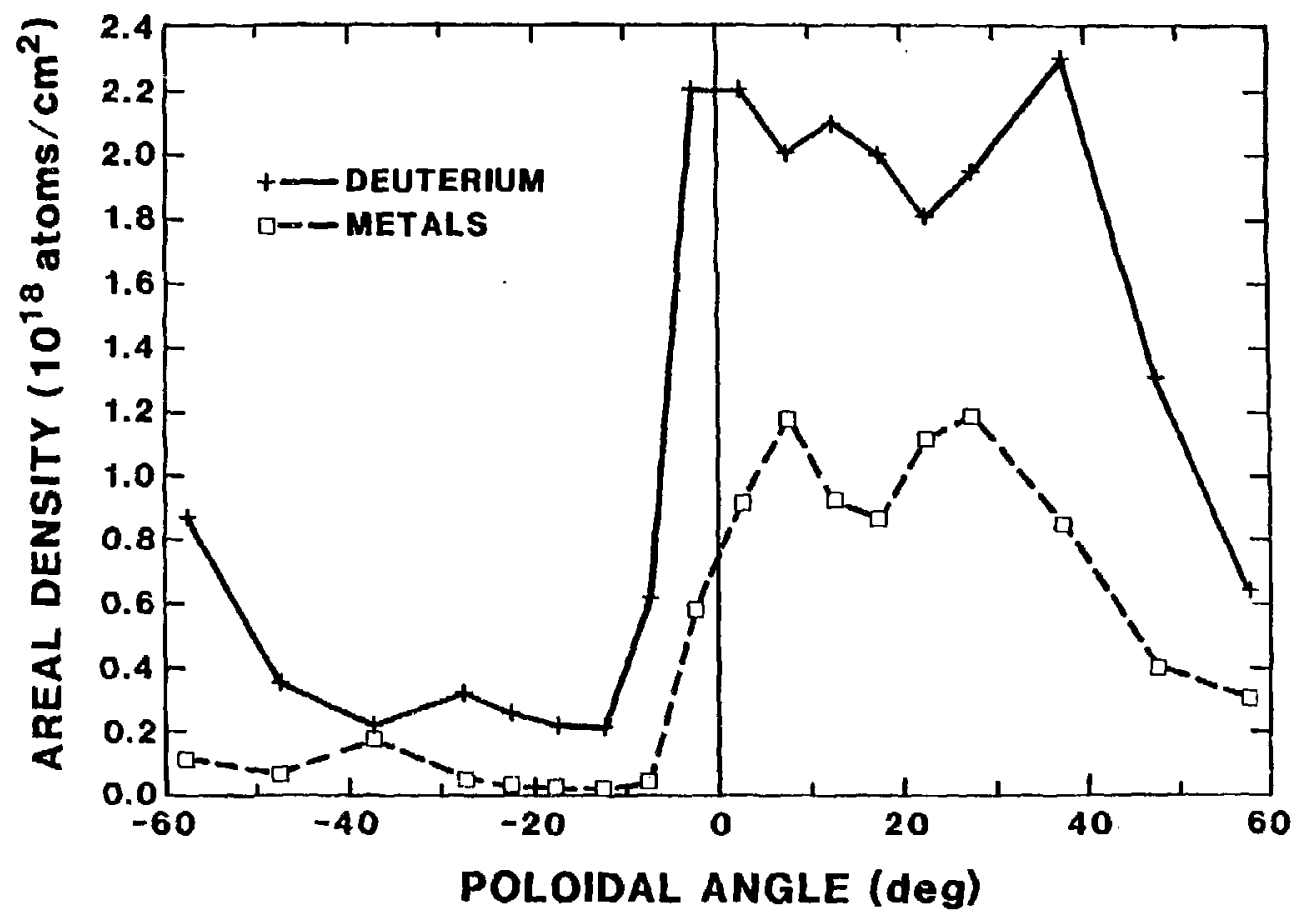

Fig. 5.5. Areal density of near-surface deuterium $(\kappa, \mu \mathrm{m})$ from NRA and of metals from PIXE versus poloidal angle on sector $N$ column 3 of the bumper Iimiter. 


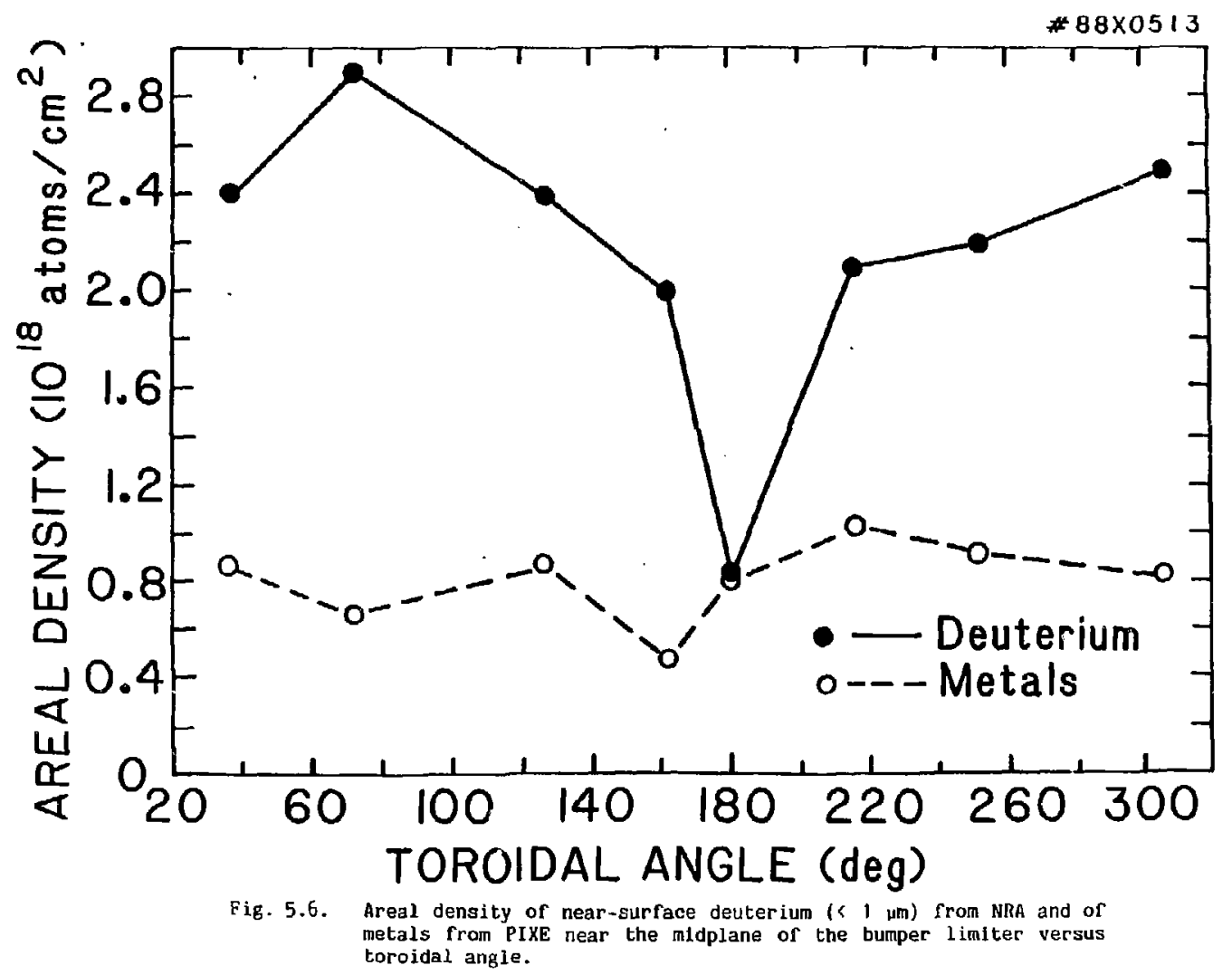


POLOIDAL SCAN OF TFTR LIMITER

COMPOSITION $X-P I X E$

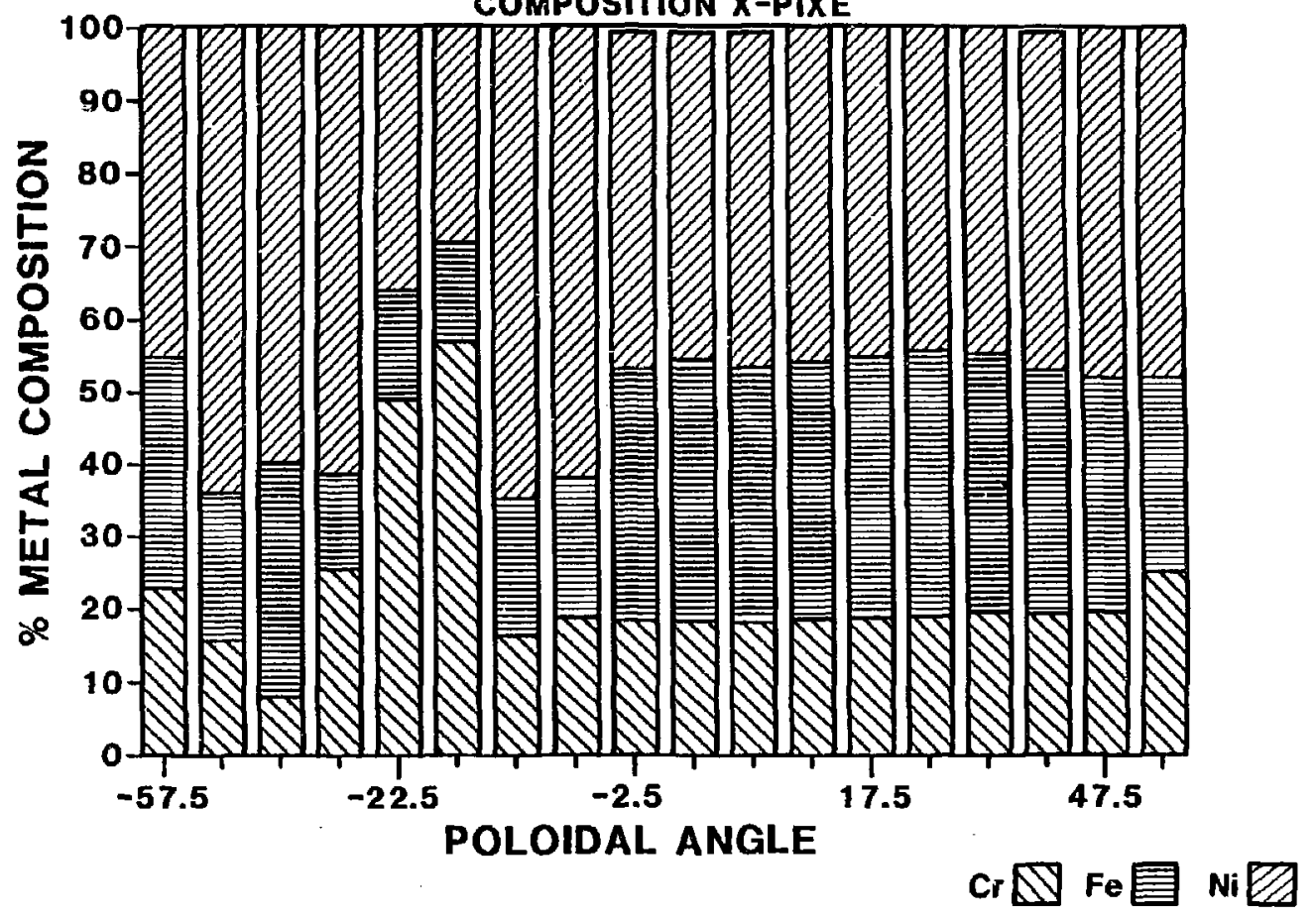

Fig. 5.7. Fractional composition of major metals versus poloidal angle on sector $N$ column 3 of the bumper limiter. 


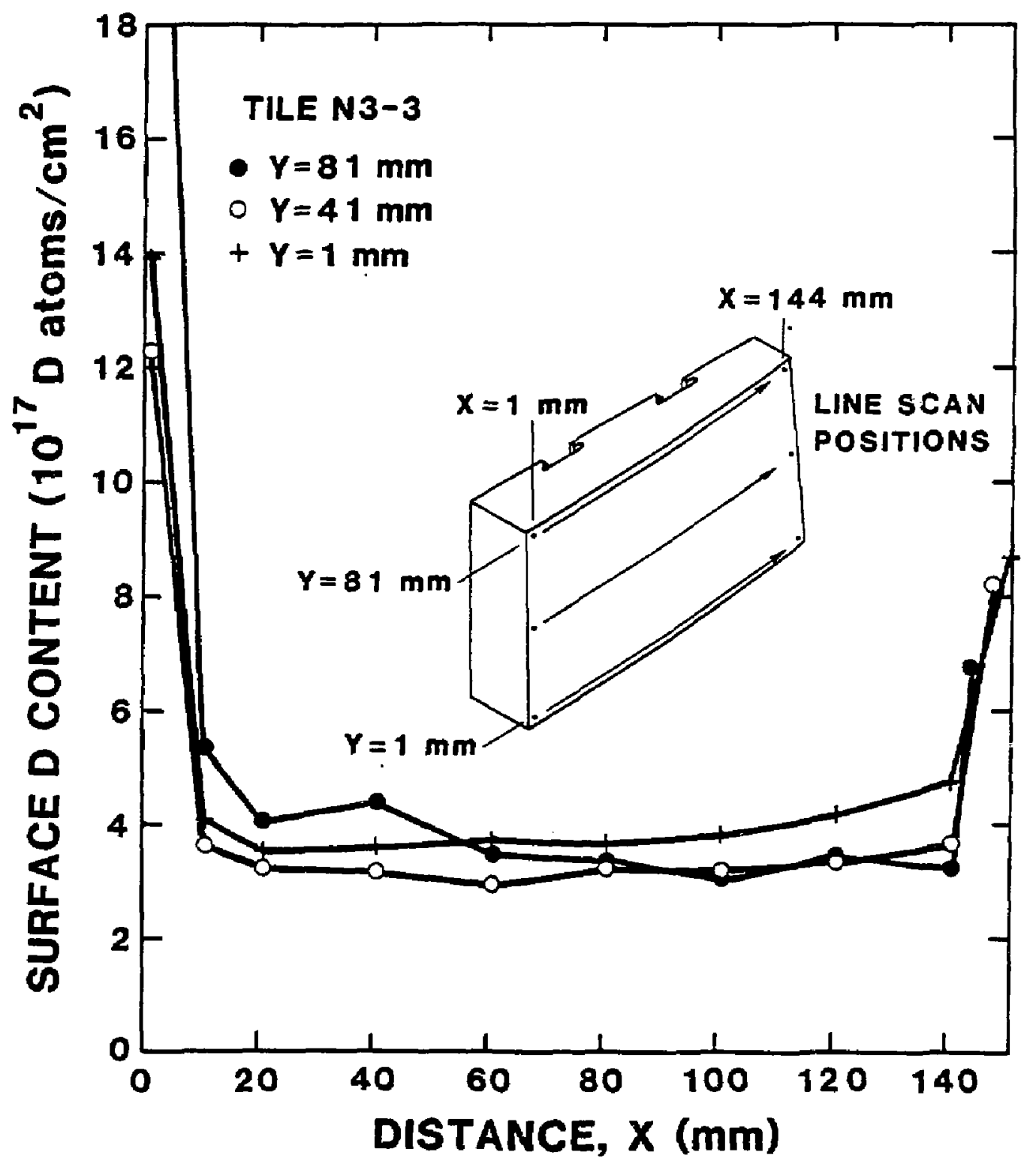

Fig. 5.8. Line scan of near-surface areal density of deuterium on tile N3-3 from a region of low deposition. 


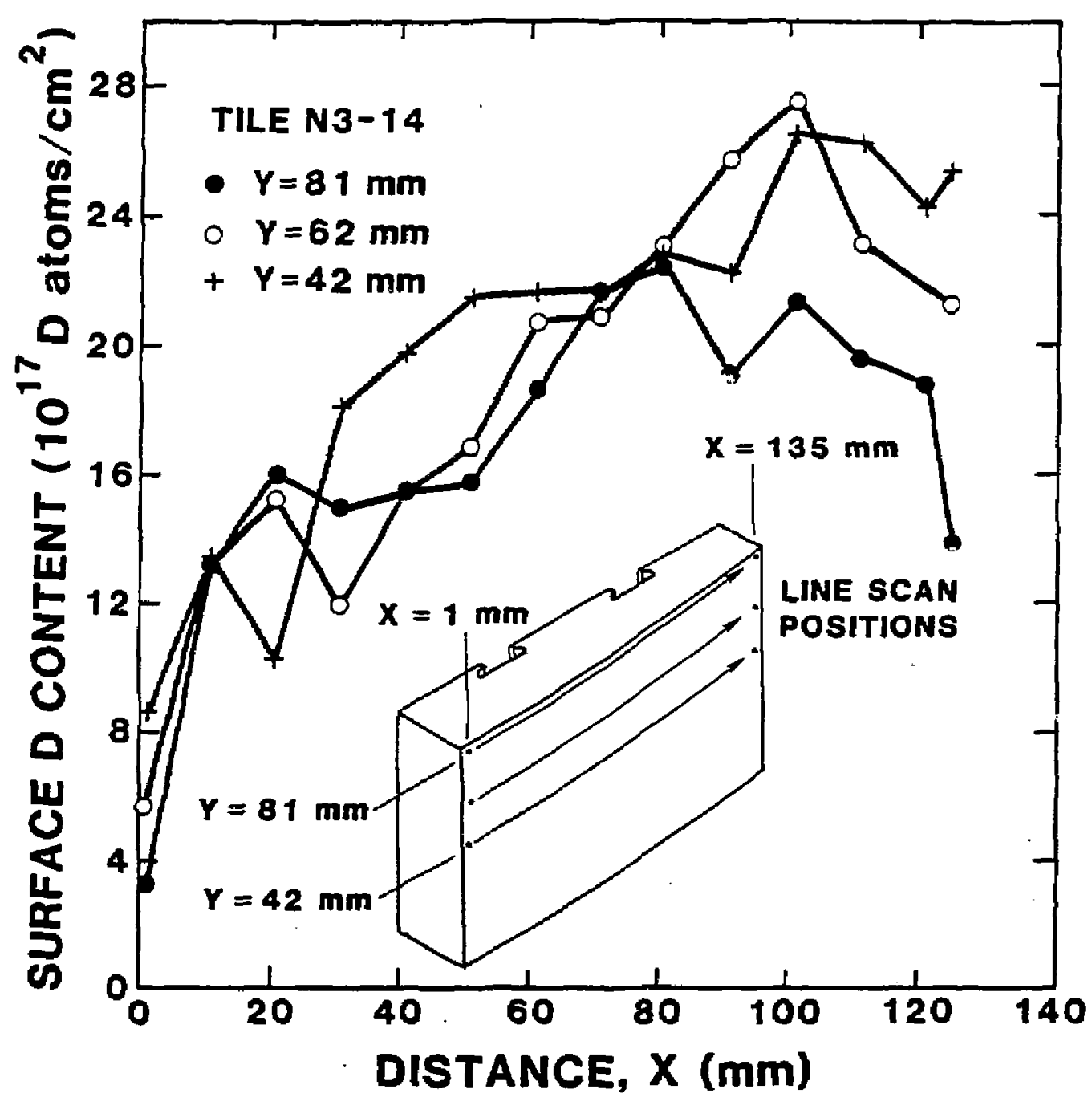

Fig. 5.9. Line scan of near-surface areal density of deuterium on tile N3-14 from a region of hlgh deposition. 


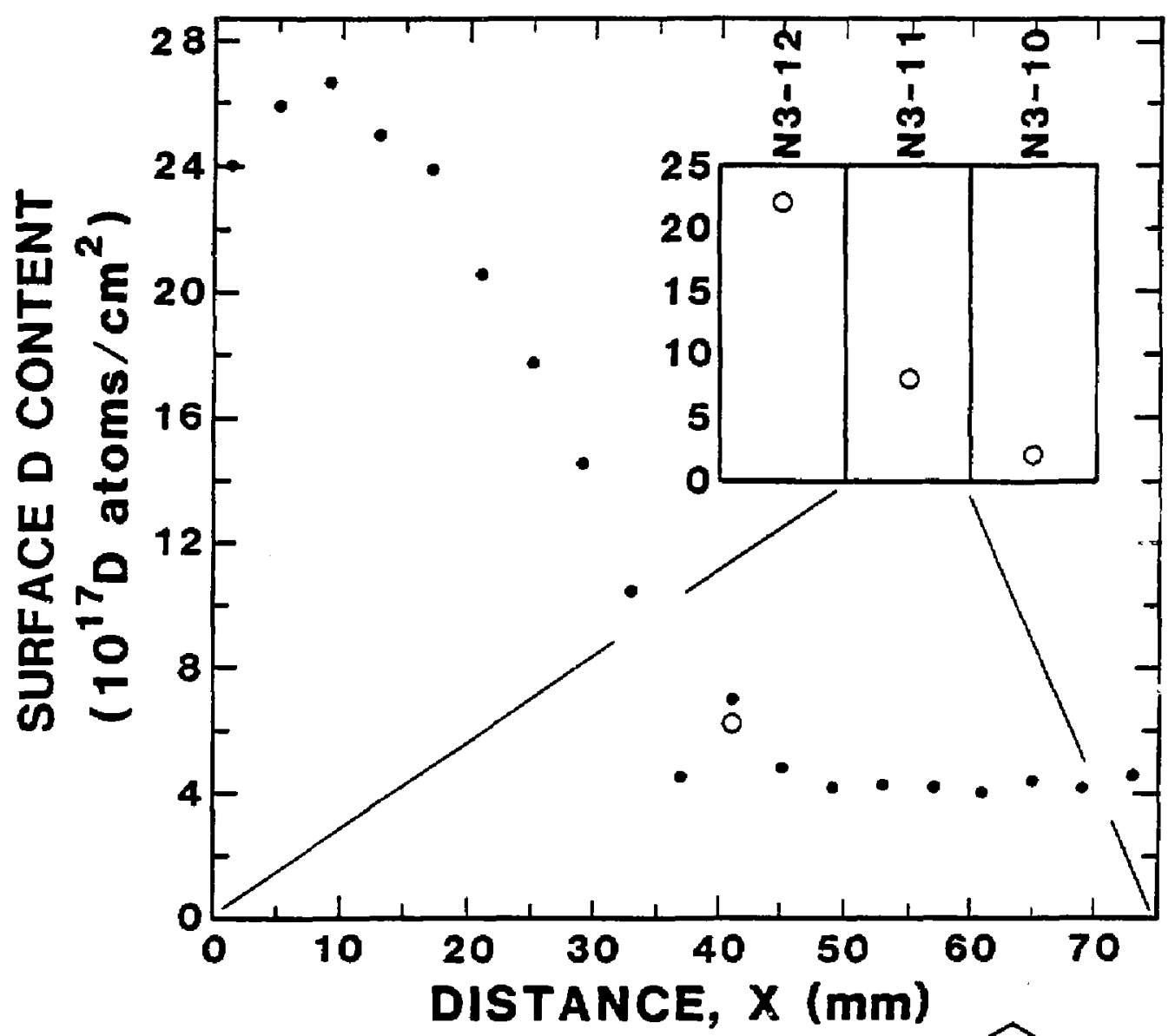

\section{XNRA LINE SCAN OF TFTR TILE N3-11}

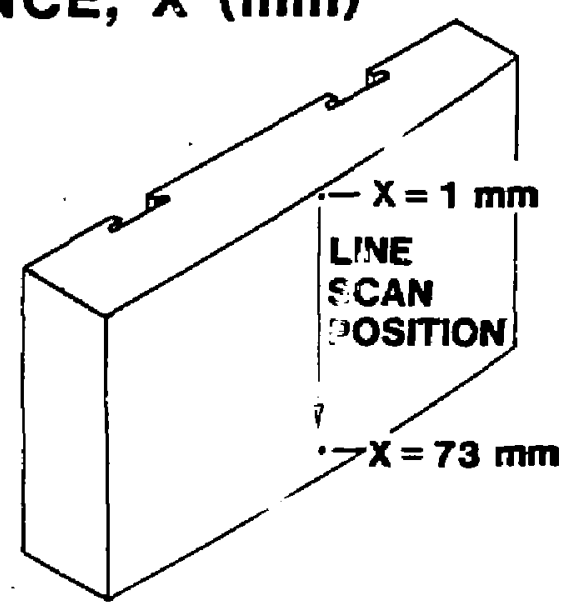

Eig. 5.10. Vertical line scan of near-surface areal density of deuterium across tile N3-11 showing sharpness of transition from low to high deposition. 


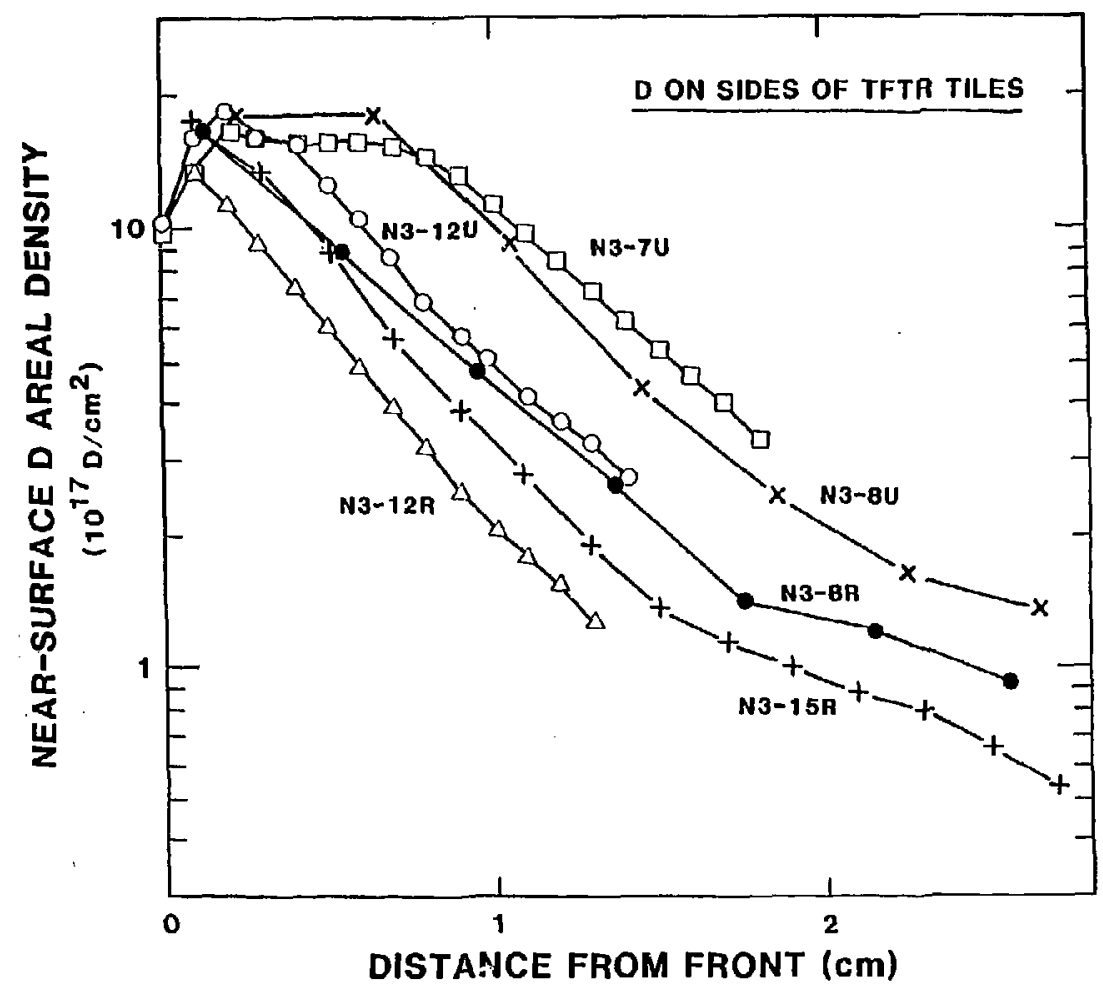

Fig. 5.11. Areal density of near-surface deuterlum $(<1 \mu \mathrm{m})$ on the sides of bumper limiter tiles versus distance from the piasma-facing surface. The labels $U$ and $R$ denote the upward and right-facing sides of the tiles, respectively. 




Fig. 5.12. Deuterium concentration versus depth for the plasma-facing or front surface and the sides of several tiles. Integrated areal densities are also indicated. 

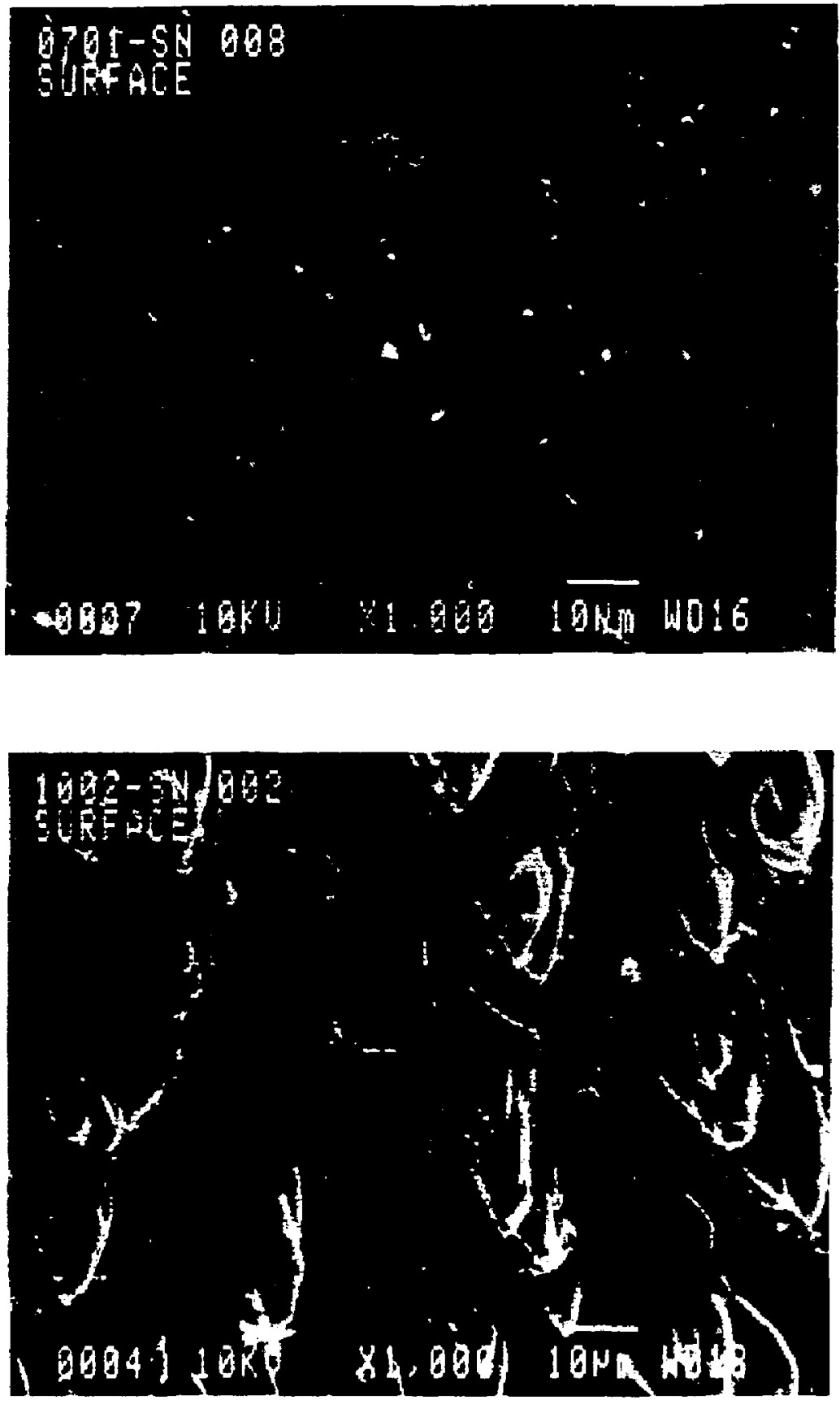

FIG 5.13. Electron micrographs of the surfaces of two tiles form the scored and the moderate deposition regions in $\mathrm{Fig} .5 .3$. 

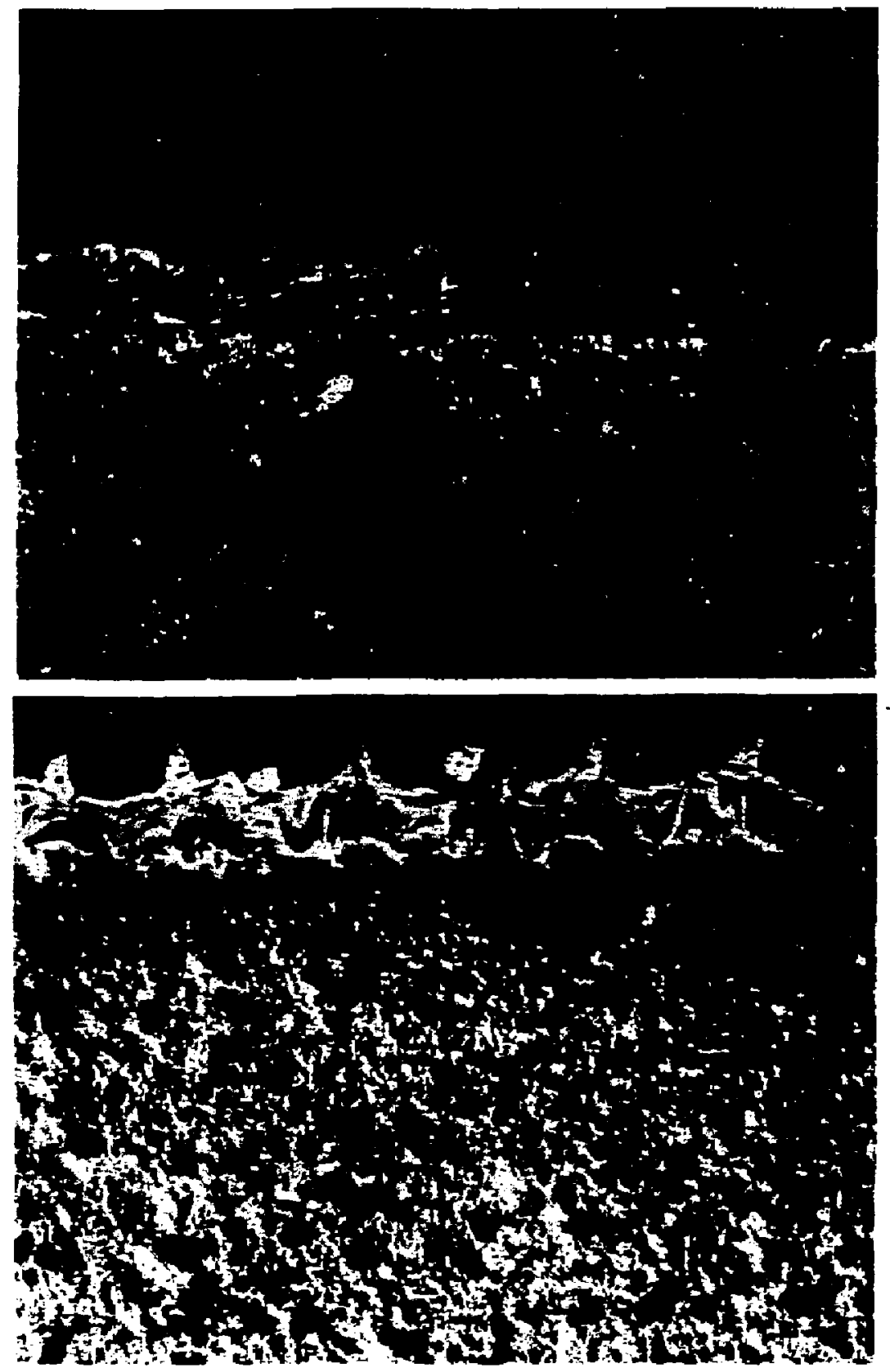

$50 \mu \mathrm{m}$

FIG 5.14. Cross-sections (horizontal and vertical) of the surface of a tile in the moderate deposition region near the midplane of the bumper limiter. 


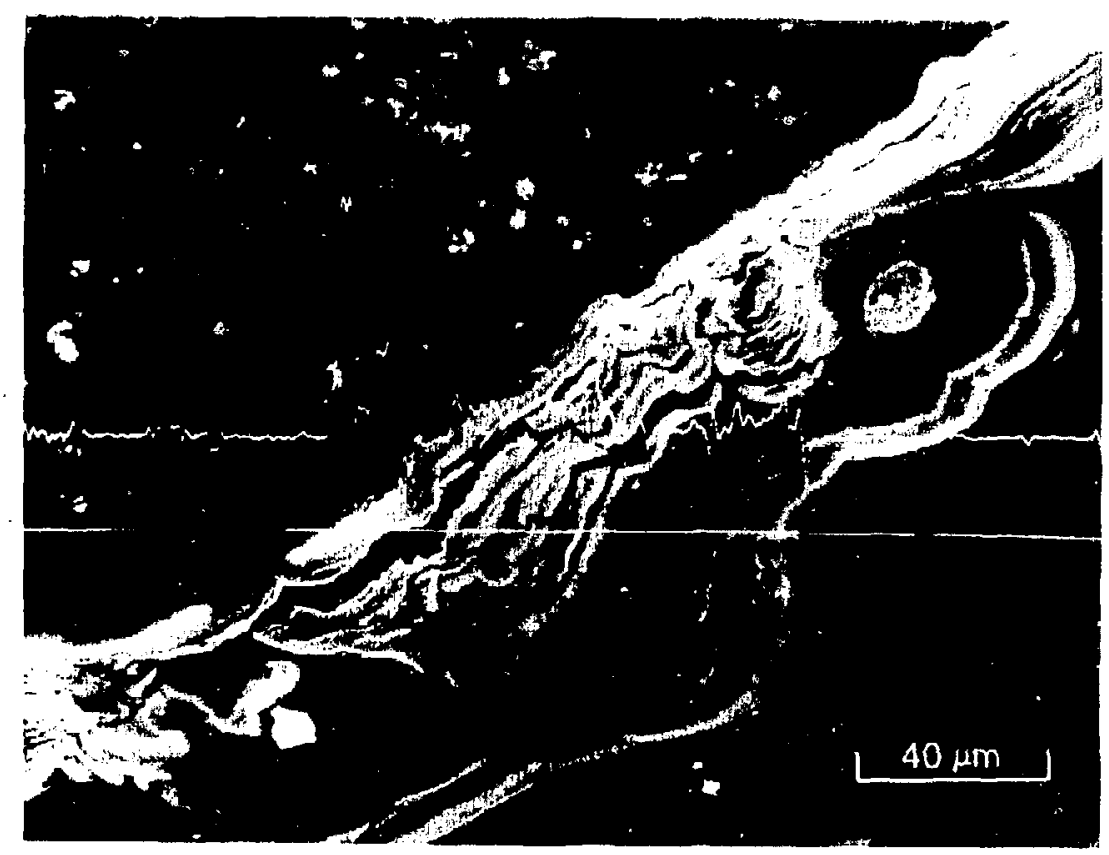

$\stackrel{\infty}{\oplus}$

FIG 5.15. An electron backscatter image with the trace of the backscatter signal along the 1ndicated line. These results show the differences in average $Z$ of the deposits laid down at different times on an edge of a tile in the moderate deposition region. 

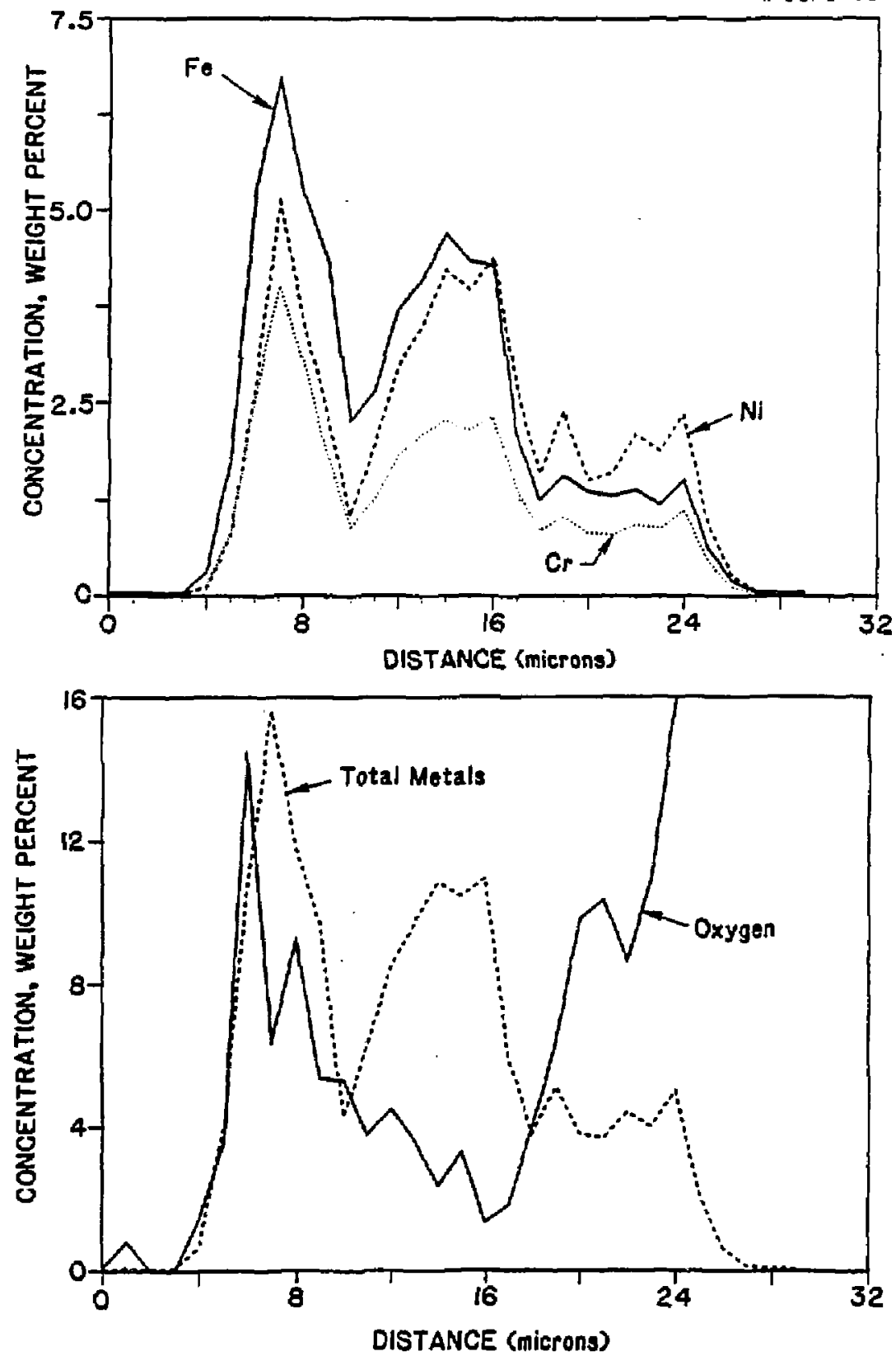

F18. 5.16. An electron microprobe trace across a cross-section of the layered deposited aterial on the side of a tile using a $15 \mathrm{kev}, 19.3 \mathrm{nA}$ electron beam and wave-length dispersive $x$-ray analysis. The tile-deposit interface is at about $5 \mathrm{~m}$, ; the deposit-potting material interface is at about $25 \mu m$. The potting material contains about 25\% oxygen. The top plot shows the 1ron (solid), nickel (dashed), and chromium (dotted) concentration as a function of distance from the interface ( $f . e$, machine time) which increases to the right. The bottom shows that the total metal content of the deposit (solid) is not always correlated with the oxygen content (dashed). The relative mix of trannsition metal components changes approximately as observed in the plasma impurity measurements during the 1985-87 operation period. 


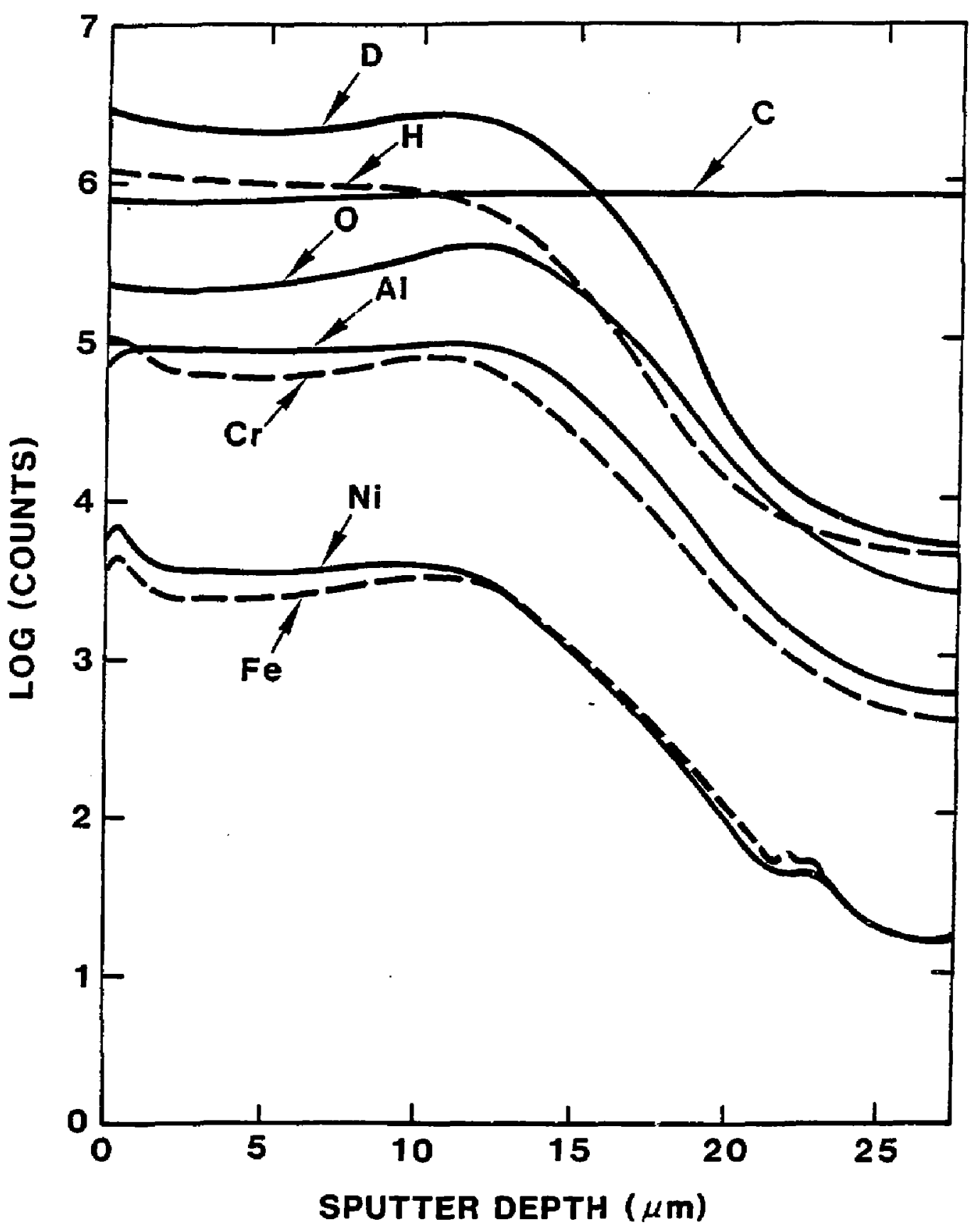

Fig. 5.17. Cesium SIMS depth profile of the plasma-facing surface of a tile in a moderate deposition region. Note that the deuterium, oxygen, and metal concentrations increase from the surface to the POCO graphite interface. 

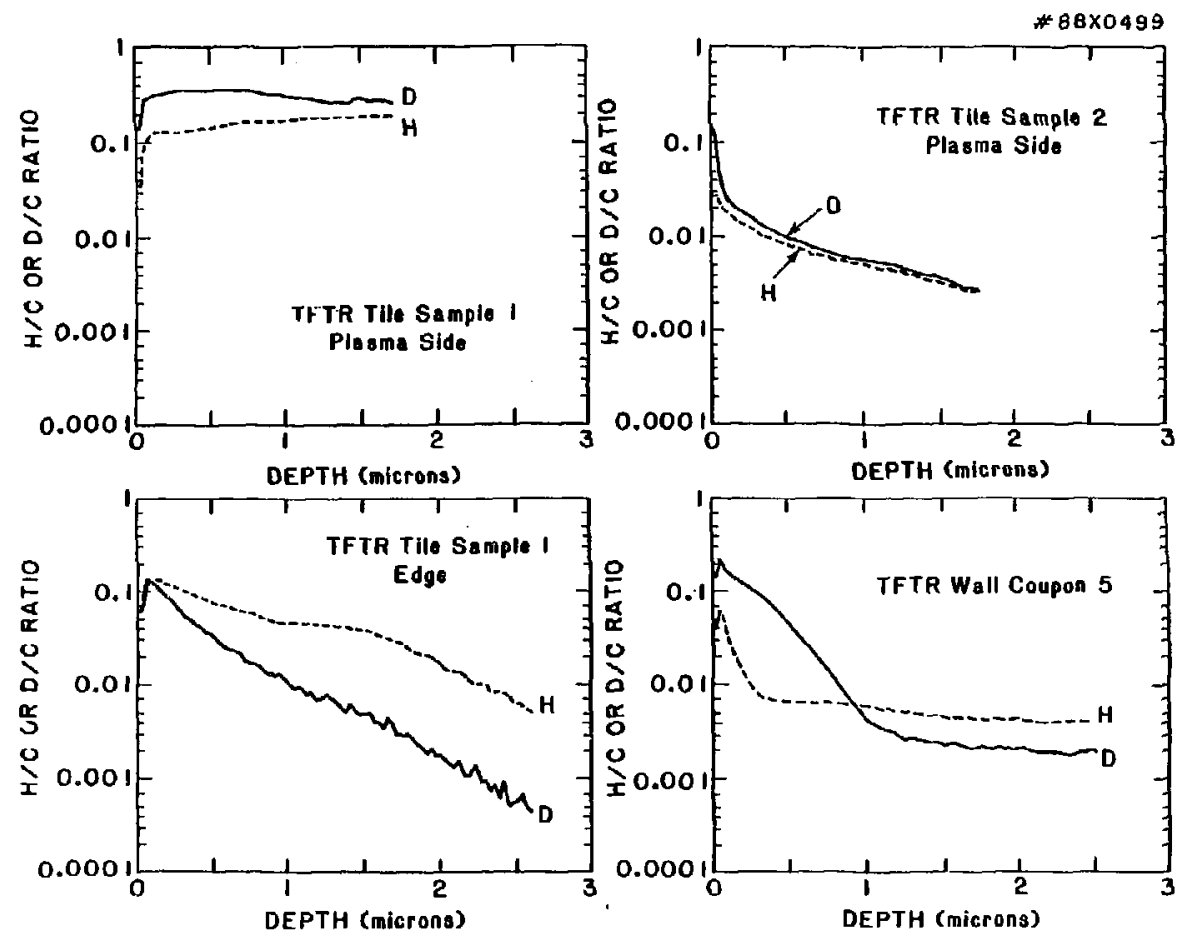

Fig. 5,18. Deuterium SiMs depth proflles of bumper limiter tiles. 


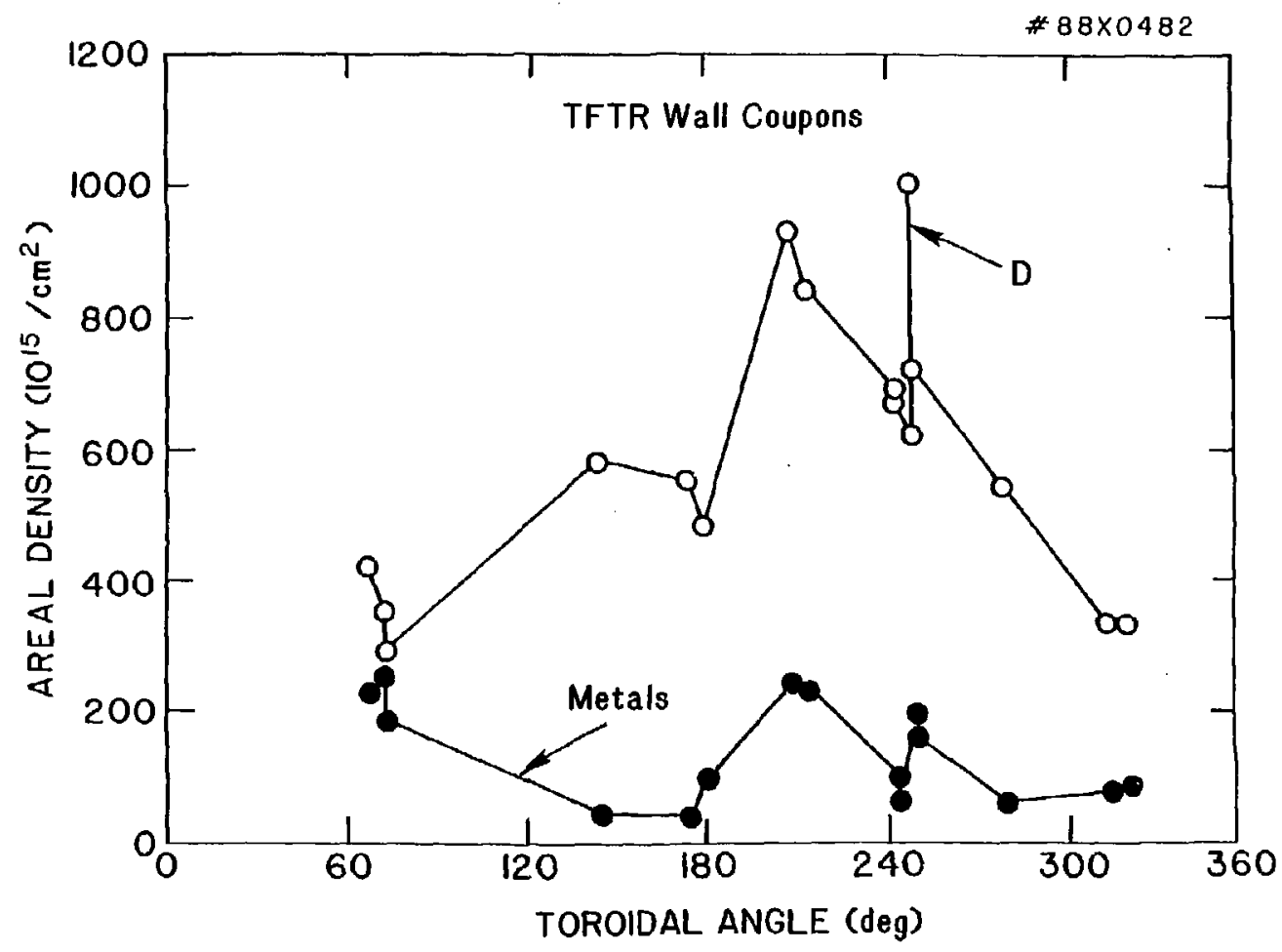

$\stackrel{\infty}{\substack{n \\ n}}$

Fig. 5.19. Toroidal yariation of the deuterium and metal deposition observed on the TFTR wall coupons exposed to the 1985-87 plasma operations. 


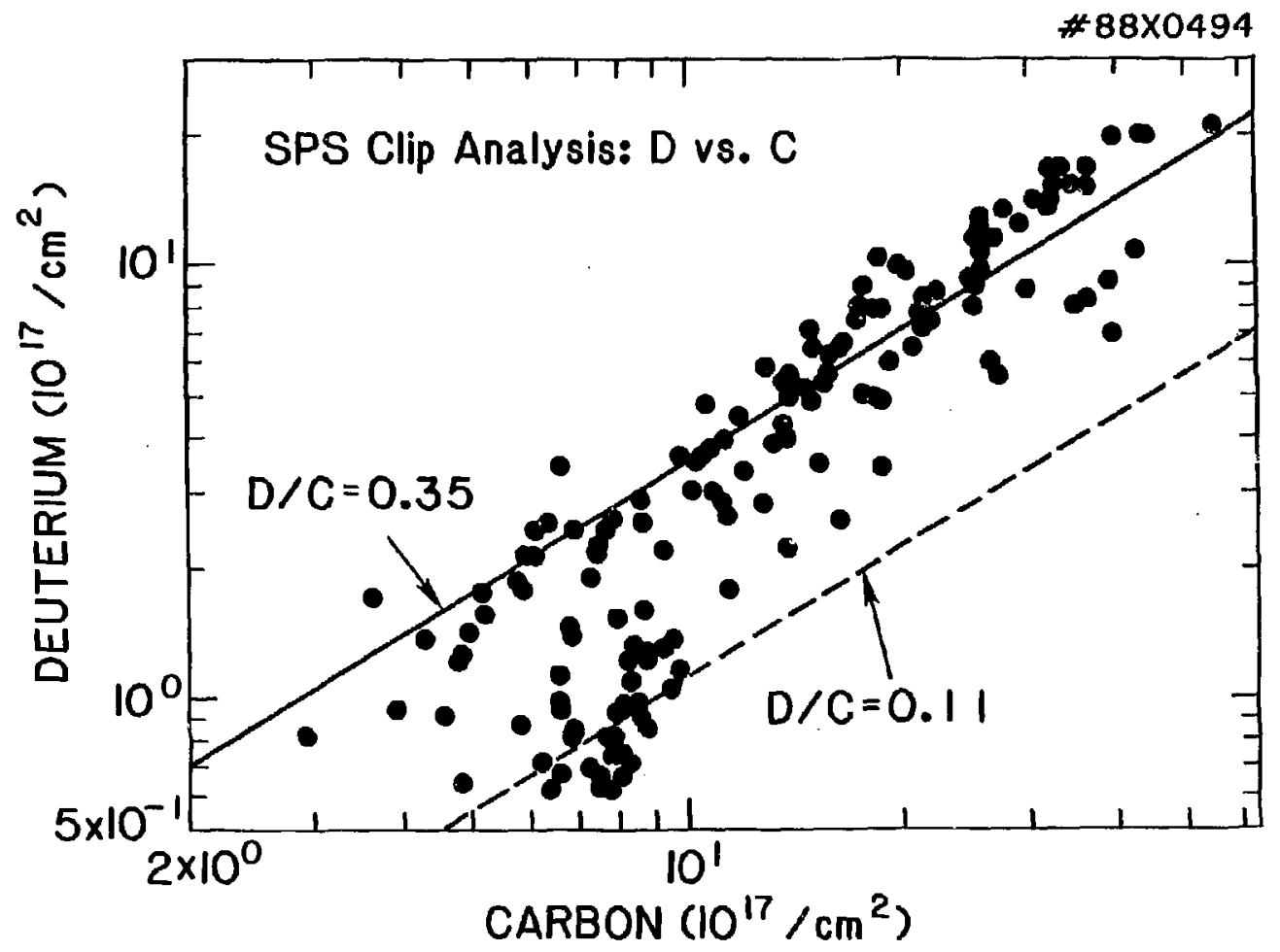

F1g. 5.20. Deuterium vs. carbon deposition as measured on the SPS clips which were exposed at vessel wall positions to the 1985-87 plasma operations. 


\subsection{MODELING OF D-T RETENTION}

Contributors: Modeling Working Group

R. T. McGrath, Chairman

\subsection{Introduction}

There are a number of important plasma-material processes which will affect the tritium operation of TFTR. The buildup of the in-vessel tritiun inventory results from: 1) codeposition of $T$ in hydrocarbon layers, 2) implantation of energetis $T$ in limiter (graphite) or first-wall surfaces, and 3) diffusion and trapping of $T$ into the bulk graphite. It is important to undergtand these processes to keep track of the in-vessel inventor; and to optimize procedures for recovery of the large near-surface ( $\leq 25 \mathrm{~nm}$ ) component through outgassing and isotope exchange. It is also important to understand the recycling processes taking place at the limiter. These processes influence particle and energy confinement times and D-T fueling ratios in the core plasma.

We describe here the development and results of several different modeling efforts aimed at providing understanding of the plasma-wall processes described above. Figure 6.1 shows the plasma-wall processes which must be considered and the various analytical models treating these processes.

The joint effort between Sandia, ANL, and PPPL has resulted in a combination of computer codes capable of predicting the fuel recycling rates, as well as permeation and inventory of hydrogen in first-wall components (see Fig. 6.1). An emphasis has been placed on including an accurate description of the device geometry, magnetic field structure and edge plasma conditions.

\subsection{Recyaling Studies on TFTR}

\subsection{1 $\cdot H_{a}$ Emission Studies}

$\mathrm{H}_{\mathrm{a}}$ is a useful Indicator of hydrogen ionization since the energy required to excite $\mathrm{H}$ to the $\mathrm{n}=3$ level is approximately the same as to ionize the hydrogen atom. $H_{\alpha}$ emission is a function of the electron density, $n_{e}$ and temperature $\mathrm{T}_{e}$, and the neutral hydrogen population. The neutral particle distribution can be inferred from a model for nestral atomic and molecular hydrogen transport in a fixed plasma. Together with a model describing $H_{\alpha}$ emission, other quantities can then be calculated from the distribution, such as ionization rate profiles, wall particle fluxes, and limiter particle retention rates. Since the neutral density depends on the neutral source distribution due to recycling plasma, the $H_{a}$ emission also contains information about the scrape-off plasma [1]. The following discussion will 
cover both the experimental observations and the analysis using the DEGAS neutral transport code [2].

\section{Diagnastics:}

There are two TFTR diagnostics useful for measuring $H_{a}$ emission. One is the $H_{\alpha}$ Interference Filter Array, HAIFA [3], which views the TFTR bumper limiter from the outside midplane. Five absolutely calibrated channels measure $H_{a}$ emission through views passing through a vertex at a major radius of $396 \mathrm{~cm}$ at angles $0,7.5,14,23$, and 30 from the midplane. Assuming up-down symmetry which is generally true, the HAIFA provides a measure of the total $\mathrm{H}_{a}$ enission in front of the bumper limiter, where all of the recycling occurs. $A$ second diagnostic which measures both the poloidal and toroidal $H_{\alpha}$ variation is a TV camera, filtered to observe light in the vicinity of the $H_{\alpha}$ line.

\section{$\underline{H}_{\mathrm{a}}$ observations:}

In order to determine functional dependencies of $\mathrm{H}_{a}$ emission, we have surveyed $H_{a}$ behavior in TFTR over the 16-day period from June 17 to July 2, 1987, during which over 500 bumper limiter discharges were made. DEGAS was used to examine in detail a representative subset of these discharges. From this study we determined variations with line-averaged density, $\vec{n}_{e}$, of the total $H_{\alpha}$ emission, the core recycling refueling, the particle scrape-off length, and average core particle confinement time.

A plot of the average $H_{a}$ emission in front of the inner limiter versus $\bar{n}_{e}$ is given in Fig. 6.2, for the survey of discharges. All useable discharges between June 17 and July 2, 1987, are shown including:

- Ohmically heated $(\mathrm{OH})$ discharges, where the $H_{\alpha}$ emission was measured during the current flat-top.

- Neutral beam injection (NBI) discharges, where the $H_{\alpha}$ was measured both during the initial $O H$ period, and during the density flattop typically occurring after $500-600 \mathrm{~ms}$ of beam injection.

Only dueteriun fueled discharges are included. In particuiar, helfum fueled "conditioning" discharges are excluded [4]. Fig. 6.2 shows that the $H_{\alpha}$ emission from small (minon radius, a, less than $0.70 \mathrm{~m}$ ), and large (a) $0.80 \mathrm{~m})$ discharges behave simllarly with $\bar{n}_{e}$.

A model for the emission:

The three-dimensional DEGAS neutral transport code was used to examine in detail selected discharges from the survey. The model faithfully reproduced the device geometry. Plasma flux surfaces were assumed to be circular. The 
most important neutral/plasma reactions are included in the calculation. The core plasma parameters were calculated by the SNAP program, which analyzes the data from plasma diagnostics, imposing particle and energy balances to compute a self-consistent picture of a discharge.

No direct measurements of the scrape-off plasma in the limiter region were included in this simulation. Scrape-off plasma density and temperature decay lengths, as well as particle decay lengths were inferred indirectly from a comparison between the measured and calculated $H_{\alpha}$ distribution. A decay length was assurned, from which an ion limiter flux was calculated. The calculated $H_{\alpha}$ profile was then compared to the measured profile, Fig. 6.3 , and the scrape-off length was adjusted until a reasonable fit was obtained.

\section{Calculated recycling rates:}

Results from the survey sampling using the DEGAS model are given in Table 6.1. We introduce in these tables the quantity $I$, defined as the ratio of calculated ionizations in the plasma core to the average $H_{\alpha}$. We may expect $I$ to be roughly constant, since the cross-sections for atomic hydrogen ionization vary with $n_{e}$ and $T$ similarly to the cross-section for excitation to the $n=3$ level. For the $O H$ discharges, the average value of $I$ is $I=2.72 \times$ $10^{7}\left(\mathrm{sr}-\mathrm{cm}^{2}\right) \mathrm{ph}^{-1}$. Since $I$ varies little for $\bar{n}_{\mathrm{e}}$ from 0.5 to $5.0 \times 10^{19} \mathrm{~m}^{-3}$, it can serve as a convenient measure of core refueling due to limiter recycling, as is customarily assumed [5]. Excluding discharge 31243, which is not well understood, $I$ is also relatively constant for NBI discharges, averaging $I=2.04 \times 10^{7}\left(\mathrm{sr}-\mathrm{cm}^{2}\right) \mathrm{ph}^{-1}$. As noted above, NBI-heated discharges, which have hotter edges, have higher average $\mathrm{H}_{a}$ emissions than $\mathrm{OH}$ discharges for a given $\bar{n}_{e}$, which may be the reeson for the lower $I$. The calculated particle scrape-off lengths which best reproduced the observed radiation varied from 2.5 to $8 \mathrm{~cm}$, decreasing with inereasing plasma current. The calculated $H_{\alpha}$ distribution was very sensitive to scrape-off iength.

\subsubsection{The Wall Loading Experiment}

The wall loading experiment described in Sec. 4.2.2 was used as a sample set of discharges to calculate changes in recycling from the $H_{\alpha}$ emission measurements. The experiment consisted of a conditioning sequence of seven 1.4 MA He discharges, followed by eleven 0.8 MA D fiducial discharges. These discharges were programmed to a density of $\mathrm{n}=1.25 \times 10^{19} \mathrm{~m}^{-3}$, at which time the deuterium gas feed was turned off to allow the density to decay to the recycling limit. The particle confinement time, ${ }^{\tau} p$, and global recycling coefficient, $R$, were calculated by solving the global particle balance equation: 


$$
\frac{d N^{+}(t)}{d t}=S+G-\frac{N^{+}(t)}{\tau_{p}}
$$

at time $t$. Here $N^{+}(t)$ is the total core ion population at time $t, G$ is the measured gas fueling rate, $S$ is the source in the core due to ionization of neutral particles, and $\tau_{p}$ is the average time that an ion stays in the core. Given $\mathrm{N}^{+}$and $\mathrm{dN}^{+} / \mathrm{dt}$, Eq. $(6.1)$ can be solved for $\tau_{p}$. Further, given the global density decay time, $\tau_{p}^{*}$, when the external sources are zero so that $d N^{*}(t) / d t=$ $\mathrm{N}^{+} / \tau_{\mathrm{p}}^{*}$, the global recycling coefficlent for deuterium, $R$, is determined from $R=1-\tau_{p} / \tau_{p}^{*}$.

The total deuterium ion population can be expressed as $N^{+}=f_{p^{+}}\left\langle n_{e}\right\rangle V$ where the $f_{D^{+}}$is the average ratio of the deuterium density, ${ }^{n}{ }^{+}$, $D^{+}$ver the
electron density, $\tilde{n}_{e}$, and is determined from spectroscopic data; $\left(n_{e}\right)$ is the volume-averaged electron density; and $V$ is the plasma volume. Assuming a parabolic density profile, then $\left\langle n_{e}\right\rangle$ is 0.75 times the measured line-averaged electron density. During the entire sequence $f_{p^{+}}=0.85$ and $\bar{n}_{e}=1.25 \times 10^{19}$ $\mathrm{m}^{-3}$, so that $\mathrm{N}^{+}=2.35 \times 10^{20}$. The density decay rate, $\mathrm{dN}^{+}(t) / \mathrm{dt}$, was calculated using this value of $\mathrm{N}^{+}$and the measured values of $\tau^{*}$ during the gas loading sequence (Fig. 6.4).

The remaining term in Eq. (6.1), the ion recycling source $S$, was calculated from analysis of $H_{\alpha}$ measurements using a three-dimensional DEGAS code as described in Sec. 6.2.1. The resulting values of $\tau_{p}$ varied from 0.16 to $0.18 \mathrm{~s}$. Using an average $\tau_{p}$ of $0.17 \mathrm{~s}$, the computed global recyciing coefficients varied from 0.61 at the beginning of the sequence to 0.82 at the end (Table 6.2). The calculated ion particle current $Q$ increased correspondingly from $2.17 \times 10^{21} \mathrm{D}^{+} / \mathrm{s}$ to $3.1 \times 10^{21} \mathrm{D}^{+} / \mathrm{s}$. The calculated limiter pumping efficiency, $p$, which is the fraction of particle flux removed by the limiter, decreased over the sequence from 0.085 to 0.025 .

\subsection{Carbon Transport in the TETR Edge Region}

Carbon impurity generation through sputtering on the limiter surface and the subsequent transport of carbon in the plasma edge region is being investigated using the Redep code [6-9]. The model includes a full threedimensional description of the bumper limiter geometry as well as the full structure of the magnetic field. This three dimensional description is an essential element of the analysis since the geometry leads to large shadowed areas on each of the bays of the inner bumper. The field line structure in TFTR is such that the upper left and lower right quadrants of each bay, as viewed from the plasma, receive direct incident particle flux. In these areas, the surface concentrations of deuterium are low, $0.2 \times 10^{18} \mathrm{D} / \mathrm{cm}^{2}$, and the graphite appears to have experienced net erosion (see sec. 5). On shadowed portions of the bays, upper right and lower left quadrants, 
connection lengths are only about $1 \mathrm{~m}$. In these regions, large accumulations of metallic impurities are observed, $100-200 \mathrm{~nm}$, as well as the buildup of a thick carbon layer rich with codeposited deuterium at areal densities of $2-3 \times 10^{18} \mathrm{D} / \mathrm{cm}^{2}$.

The observed surface conditions are consistent with the carbon and metal atom transport descriptions produced by Redep [8]. The calculations show that impurity atoms migrate from regions of high incident particle flux to regions of low flux. The migration takes place in a series of short range steps, described as follows. A sputtered neutral is ejected from the surface. It travels a short distance, only a few $\mathrm{mm}$, before undergoing electron impact. ionization. The impurity ion flows with the local plasma along the field lines, eventually returning to the limiter surface where it initiates selfsputtering. On the TFTR bumper limiter, impurities migrate to the boundaries of the unshadowed regions. From there neutral atoms ejected from the surface at shallow angies need only travel a short distance through the edge plasma before entering one of the shadowed zones where mean-free paths are wuch longer. Impurities deposited on one of the shadowed surfaces are trapped there since only charge exchange flux is available to further drive the migration process.

The Redep model requires an accurate description of the sputter erosion processes taking place on the limiter surface. This includes 1) the effects of simultaneous bombardment by hydrogen isotopes and impurity fluxes, 2) variations in carbon yields with changing surface hydrogen concentrations, 3 ) the effects of sheath structure and glancing incident magnetic field angle on the energies and angles of incident carbon and hydrogen ions. Items 1 and 2 are discussed below in Secs. 6.4 and 6.5. Information on the sheath and magnetic field geometry is provided using a self-consistent sheath model applied to TFTR edge plasma conditions and limiter geometry $[9,10]$. The sheath parameters and sheath acceleration of hydrogen ions and of carbon lons (primarily $\mathrm{c}^{+3}$ produced in the plasma edge reglon, and $\mathrm{c}^{+6}$ produced in the plasma core) are computed. These results are then used in the combined Redep/MEASTRI model, described below.

There is a strong evidence from laboratory experiments and some tokamaks that chemical erosion at graphite surfaces produces hydrocarbons. Therefore, in addition to the modeling of sputtered carbon discussed above we are developing a program to study carbon evolution from hydrocarbons (mainly methane) released at the edge in TFTR. We have assembled a data base for carbon and hydrocarbons interacting with a hydrogen plasma, and have begun development of a model of hydrocarbon transport at the edge of TFTR based on the neutral transport code DEGAS $[11,12]$. 
In contrast to the behavior of physically sputtered carbon, methane must be degraded by plasma reactions until carbon atoms and ions form, after which they can be followed as in the physically sputtered carbon case. The destruction process for hydrocarbons involves several stages in which ions can become neutrals and vice-versa. Therefore, it is necessary to treat both neutral and ion transport to model hydrocarbons at the edge. A complete code has to contain a wide variety of physical processes to model the hydrocarbon transport. It must include all plasma reactions and the dynamics of these reactions which change energy and momentum. Molecular Lons will undergo thermalizing collisions and they can be accelerated by electric fields, frictional and thermal forces, as well as subject to diffusion across field Iines and acceleration along field lines. At the present time we have modified the DEGAS neutral transport code to follow the breakdown of a complex hydrocarbon, and have included only the effects of the change in energy and momentum due to these reactions. At present the ionic forms of the hydrocarbon are not followed, being kept fixed at their creation point, but in the future we intend to develop algorithms to follow the ionic stage.

The hydrocarbon version of the DEGAS code has been used to model the DITE graphite probe experiments, and has recently been applied to model TFTR for an ohmic plasma. Preliminary results show that the carbon distribution is broader than that of methane, which is stopped very close to the limiter. The hydrogen atons produced from the destruction of methane have a different distribution from that of carbon, tending to penetrate further into tlie plasma. We expect these models to be useful in understanding impurity production in TFTR, but it is still too early to make any predictions. Coupling the DEGAS modeling with Redep should be Interesting as we will be able to compare the erosion and redeposition of physically sputtered and chemically released carbon in TFTh.

The large concentrations of deuterium in the codeposited carbon layers on the TETR first-wall (see Sec. 5) imply that fuel atoms follow trajectories similar to those of the sputtered carbon and are subsequently trapped in codeposited layers. A comparison of carbon transport predicted by Redep, which does not include hydrocarbons, with the results predicted by DEGAS is in progress. The results of both calculations will be used to investigate further the observed deposited layers on the inner bumper limiter. More detailed carbon impurity generation and transport will be estimated for a variety of representative TETR edge plasma conditions corresponding to different operational conditions, ie ohnic discharges at different plasma radi1, NBI shots at varlous power levels, etc. We have reproduced the erosion/redeposition patterns that have been observed on the inner bumper limiter. More detailed comparisons of these analytical results with the experimental measurements should provide a calibration of the parameters used in the code $[8]$. 


\subsection{MEASTRI: A Hybrid Analytical/Monte Carlo Code for Particle Transport in Solids}

The computer code MEASTRI has been developed to describe the evolution of near-surface composition and sputtered particle fluxes for a material exposed to an energetic D-T plasma containing impurities [13]. The code requires as inputs the incident plasma particle fluxes, their energy and angular distributions, and the initial sputtering coefficients. The near-surface concentration profiles are calculated by the code, including the effects of saturation and sotope exchange. The fluxes of sputtered, recycled, and reflected particles are predicted. Also calculated are the instantaneous inventories of deuterium, tritium, and the various impurities.

MEASTRI is currently being used in an interactive procedure with the Redep code to obtain an improved description of the effects of redeposition on tritium Inventory and limiter erosion and deposition [9]. For this application a subroutine YKI has been written for direct incorporation into Redep. The subroutine provides rapid and accurate evaluation of the sputtered particle fluxes over the entire limiter. The sputtered fluxes from the surface are conveniently described in terms of effective sputtering coefficients. For simultaneous carbon and hydrogen implantation into graphite the effective sputtering coefficients decrease with particle fluence since the implanted hydrogen interferes with the carbon-carbon sputtering, which provides the major contribution to erosion. Table 6.3 shows typical results for carbon and deuterium energies and fluxes characteristic of a central portion of the TFTR limiter. The tabulated effective sputtering yields show the decrease of $y$ with fluence, but an increase of $Y$ with incident angle.

The recent removal of limiter tiles from TFTR offers a unique opportunity to compare the predictions of Redep/MEASTRI with experimental measurements of carbon erosion/redeposition, and hydrogen inventory bulldup In these structures. We have used Redep (with YKI) to obtain representative, spatially dependent impurity fluxes on the limiter. Spatial and energy-dependent deuterium fluses to the surface are provided by the Flux 30 program which is callbrated against the avallable TFTR edge diagnostics. These fluxes are then used to obtain net erosion/redeposition over the life of the limiter, with some corrections for the He conditioning discharges that were periodically performed.

These fluxes are also be used as input to the full MEASTRI code. On the unshadowed portions of the limiter this calculation will estimate the recycling coefficient as a function of limiter conditioning, which depends on the number and nature of shots since the last He contiltioning sequence. This analysis will be carried out at a variety of positions on the limiter. The results obtained will be compared with estimates of the global recycling 
coefficient obtained in the $H_{\alpha}$ analysis described in Sec. 6.2. On both the shadowed and the unshadowed portions of the limiter, MEASTRI has been used to provide estimates of hydrogen (and impurity) concentrations in the nearsurface layer, with the spatial dependence again provided by Flux 3D and Redep [13]. Comparisons of these results with the experimental measurements provide a calibration of the parameter base which goes into these codes.

\subsection{Prelininary Results of the Redep/MEASTRI Model}

Initial results from the combined Redep/MEASTRI model provide some insight into a possible mechanism for the high plasma carbon concentrations in TFTR discharges following limiter conditioning. The calculations pr dict high carbon self-sputtering cascades due to near-unity carbon selr-sputtering coefficients in hydrogen-depleted carbon surface layers [9].

Initially the active surface area of the bumper limiter, that $r$ zeiving direct charged particle flux, has been depleted of near surface deiterium through He conditioning. The conditioning is followed by a ser es of identical ohmic discharges. The charged particle flux onto the - miter surface as a function of poloidal angle above or below the outboard midplane is shown in Figure 6.5. The flux varies with changing angle of incidence and with increasing distance from the last closed flux surface (plasma minor radius $=0.80 \mathrm{~m}$, bumper limiter minor radius $=1.0 \mathrm{~m})$. Also shown is the plasma temperature at the surface of the bumper. The calculations reported here are performed in a two-dimensional geometry, so deviations from full toroidal symmetry have not been included. "The flux and temperature values used here are roughiy consistent with estimbtes of the edge plasma conditions required to reproduce the observed $D_{\alpha}$ behavior on the bumper limiter (see See. 6.2.1).

Using the Redep/MEASTRI model, these fluxes are applied to the bumper limiter and the time dependence of the deuterium concentration in the near surface layer is calculated. Figure 6.6 shows the predicted time dependence of the ylelds for self and deuterium sputtering across the limiter surface. Near the center of the bumper limiter self-sputtering yields for carbon are very close to unity just after conditioning ( $t=3.7 \mathrm{~s}$ ). In fact, for a surface fu.:ly depleted of deuterium, MEASTAI predicts self-sputtering yields slightly in excess of one orl some portions of the liniter, and the Redep calculation is unstable. In reality the surfice is probably never completely depleted of deuterium and we begin the salculations with a few percent deuterium still resident in the carbon surface. As the discharges progress, deuteriun builds up in the near-surface layers, and the sputtering $y$ ields decrease as described in Sec. 6.4. The spatial profiles for this build up are shown in Figure 6.7 . 
The local deuterium concentrations are averaged over the poloidal extent of the limiter and the averaged values as a function of plasma exposure time, are shown in Figure 6.8. In these calculations the near surface $D$ inventory increases rapidly, then levels of to a steady state value of about $28 \%$ after about 25 plasma-seconds (four, 6 sec discharges). The level of saturation is consistent with NRA measurements of the near-surface $D$ concentration made on tile samples removed from the machine (see Sec. 5). In the Redep calculation, we also follow the $C$ impurity concentration in the core plasma. Figure 6.8 also shows that the initial $c$ concentration $\left(n_{c} / n_{D}\right)$ in the plasma is calculated to be almost $20 \%$. On successive discharges the core plasma carbon concentration decreases as the carbon sputtering yields decreases. The core plasma carbon concentration reaches a steady state level of $7 \%$ after about 25 plasma seconds. This time dependence is reasonably consistent with the observed rate of change of z-effective reported by Ramsey [14] for a deconditioning sequence of ohnic discharges (Fig. 6.9). Additional work needs to be completed to determine if the deuterium recycling behavior (rate of limiter saturation) predicted by the model is consistent with the observed increases in electron density and $D_{\alpha}$ brightness that occur during these deconditioning sequences.

\subsection{The FDTD Mode1}

Figure 6.10 shows results from an example calculation of a $1.4 \mathrm{MA}$, ohmically heated discharge on the moveable limiter in TFTR using the DEGAS/DIEFUSE combination. The evolution of the particle population was calculated at a number of representative sites on the limiter and vacuum vessel wall, during and between a number of cycles of ohmic discharges. (Fig. 6.10). The moveable limiter saturated quickly during each discharge, reaching 100 f recycle within $0.5 \mathrm{~s}$. The first wall received a much smaller ion flux than did the limiter, and acted as a sink during the entire discharge. However, after a large number of cycles the wall retalnet approximately as many particles as the limiter.

A bumper limiter discharge, with a similar 1.4 MA ohmic plasma, was also modelled. Figure 6.10 shows a comparison of the calculated overall recycling for the bumper limiter and for the moveable limiter. The bumper limiter recycling is substantially less.

Some of the analysis discussed in the earlier sections could be used to improve the FDTD model. For instance, EDTD currently uses the Local Mixing Model to estimate near-surface retention. This should be replaced by the more sophisticated MEASTRI model. FDTD is most appropriate for high temperature limiter operation $\left(700^{\circ} \mathrm{C}\right.$ or greater): It is most applicable then to operation of the TFTR moveable limiter (which has been removed from the machine) or to 
the inner bumper iimiter on I'FTh when full input power ( $>30 \mathrm{MW}$ ) is reached. Presently, our efforts are concentrating on understanding the operation of the inner bumper 1 imiter on TFTR where surface temperatures are below $300^{\circ} \mathrm{C}$ (characteristic of the 1985-87 operations period). Therefore, no improvements in the EDTD model are scheduled for the immediate future, 


\section{REFERENCES}

[1] D. B. Heifetz, Physics of Plasma Hall Interactions in Controlled Fusion, D. Post and R. Behrisch, Eds. (Plenum, New. York, 1986) pp. 695-772.

[2] D. B. Heifetz et al., J. Comp. Phys. 46 (1982) 309.

[3] A. T. Ramsey et al., Rev. Sci. Instrum. 58 (1987) 1211.

[4] H. F. Dylla et al., Nucl. Fusion $\underline{27}$ (1987) 1221.

[5] E. S. Marmar, J. Nucl. Mater. 76-77 (1978) 56.

[6] J. N. Brooks, Nucl. Tech. Fusion 4 (1983) 33.

[7] R. T. McGrath et al., J. Nucl. Mater. 145-147 (1987) 660 .

[8] R. T. MeGrath and J. N. Brooks, in Proc. 8th Intern. Conf. on Plasma Surface Interactions in Controlled Fusion Devices, 1988; J. Nucl. Mater., submitted.

[9] J. N. Brooks et al., in Proc. 8th Intern. Conf. on Plasma Surface Interactions in Controlled Eusion Devices, 1988; J. Nucl. Mater., submitted.

[10] B. Dewald et al., Phys. Fluids 30 (87) 267.

[11] A. B. Ehrhardt et al., Princeton Plasma Physics Laboratory Report No. 2477 (1987).

[12] W. D. Langer et al., Nuci. Technol. (1988) submitted.

[13] D. Brice, in Proc. 8th Intern. Conf. on Plasma Surface Interactions in Controlled Fusion Devices, 1988; J. Nucl. Mater., submitted.

[14] A. T. Kamsey et al., Bull. Am. Phys. Soc. 32 (1987) 1809. 
TABLE 6.1

Calculated Confinement Times and Scrape-off Lengths

Shot No.

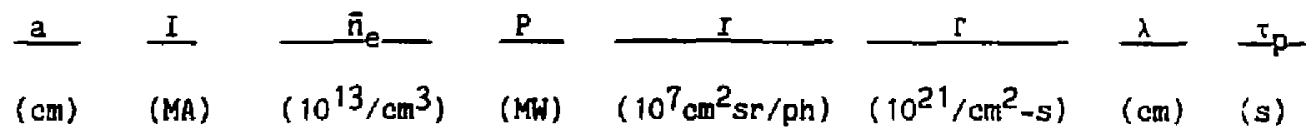

Ohnic Discharges

$\begin{array}{lllllllll}31452 & 81 & 0.91 & 0.48 & 0.61 & 2.36 & 0.14 & 7.5 & 0.43 \\ 31456 & 81 & 0.91 & 0.55 & 0.64 & 2.68 & 0.25 & 7.5 & 0.70 \\ 31475 & 81 & 1.01 & 0.72 & 0.66 & 2.38 & 0.30 & 7.0 & 0.37 \\ 31362 & 66 & 1.00 & 1.00 & 0.67 & 2.56 & 0.34 & 5.0 & 0.24 \\ 31526 & 81 & 1.01 & 1.29 & 0.58 & 2.12 & 3.43 & 6.0 & 0.07 \\ 31835 & 71 & 1.21 & 1.82 & 0.72 & 2.82 & 4.67 & 6.2 & 0.11 \\ 31919 & 71 & 1.61 & 2.23 & 1.41 & 3.24 & 14.8 & 4.0 & 0.07 \\ 31817 & 71 & 1.20 & 2.51 & 0.75 & 2.50 & 9.45 & 4.0 & 0.11 \\ 31922 & 71 & 1.61 & 3.11 & 1.22 & 2.88 & 11.4 & 5.0 & 0.10 \\ 31921 & 71 & 1.61 & 3.68 & 1.38 & 3.54 & 28.4 & 4.0 & 0.07 \\ 31930 & 71 & 1.61 & 4.38 & 1.40 & 2.86 & 20.9 & 2.5 & 0.14\end{array}$

Neutral Beam Discharges

$\begin{array}{rrrrrrrr}31243 & 80 & 0.60 & 1.05 & 2.87 & 5.44 & 2.92 & 8.0 \\ 31440 & 80 & 0.80 & 1.32 & 7.2 & 2.14 & 4.89 & 6.0 \\ 31478 & 81 & 1.01 & 1.60 & 7.3 & 2.26 & 8.28 & 5.5 \\ 31531 & 81 & 1.01 & 1.95 & 7.9 & 2.50 & 13.0 & 5.5 \\ 31700 & 81 & 1.81 & 3.04 & 7.4 & 2.18 & 33.3 & 5.0 \\ 31614 & 81 & 1.81 & 3.47 & 9.3 & 1.48 & 58.9 & 5.0 \\ 31613 & 81 & 1.81 & 4.08 & 7.7 & 1.68 & 103.0 & 5.0\end{array}$


TABLE 6.2: Gas Loading Results

\begin{tabular}{|c|c|c|c|c|c|c|}
\hline SHOT & $\left(10^{20} / \mathrm{s}\right)$ & $\begin{array}{c}G \\
\left(10^{20 / 5}\right)\end{array}$ & $\begin{array}{l}\tau_{p}^{*} \\
(s)\end{array}$ & 凡 & $\begin{array}{c}\Gamma^{+} \\
\left(10^{21 / s}\right)\end{array}$ & p \\
\hline 27634 & 8.2 & 4.8 & 0.44 & 0.61 & 2.17 & 0.085 \\
\hline 27637 & 11.6 & 1.9 & 0.69 & 0.75 & 2.81 & 0.043 \\
\hline 27645 & 13.2 & 1.5 & 0.94 & 5.82 & 3.10 & 0.025 \\
\hline
\end{tabular}

All quantities are at the moment before gas cutoff ( $t=2 \mathrm{~s}$ ). The recycling coefficient $R$ was calculated using $\tau_{p}=0,17$. 
TABLE 6.3: Test Calculations of effective sputtering yields for the exposure of graphite to $D+C$ plasma

Alpha $=0$. degrees

\begin{tabular}{rrrrr} 
Time & yce & ycd & yde $y d d$ \\
\cline { 2 - 3 } 0.01 & 0.5897 & 0.0002 & 0.02000 .0000 \\
0.10 & 0.5871 & 0.0021 & 0.01990 .0001 \\
1.00 & 0.5609 & 0.0211 & 0.01880 .0007 \\
2.00 & 0.5338 & 0.0484 & 0.01720 .0014 \\
3.00 & 0.5134 & 0.0546 & 0.01520 .0019 \\
4.00 & 0.5012 & 0.0631 & 0.01330 .0022 \\
5.00 & 0.4947 & 0.0676 & 0.01190 .0023 \\
6.00 & 0.4911 & 0.0701 & 0.01100 .0024 \\
8.00 & 0.4870 & 0.0728 & 0.01010 .0025 \\
10.00 & 0.4851 & 0.0741 & 0.00970 .0625 \\
15.00 & 0.4800 & 0.0776 & 0.00890 .0027 \\
20.00 & 0.4801 & 0.0776 & 0.08890 .0027 \\
25.00 & 0.4799 & 0.0776 & 0.00890 .0027 \\
30.00 & 0.4799 & 0.0776 & 0.00890 .0027 \\
40.00 & 0.4799 & 0.0776 & 0.00890 .0027
\end{tabular}

\section{Alpha $=$ 80. degrees}

\section{Time}

0.01

0.10

1.00

2.00

3.00

4.00

5.00

6.00

8.00

10.00

15.00

20.00

25.00

30.00

40.00

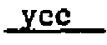

1.1869

1. 1607

0.9858

0.9025

0.8584

0.8389

0.8122

0.7993

0.7830

0.7737

0.7609

0.7649

0.7546

0.7546

0.7546 yed

0.0022

0.0212

0.1443

0.1998

0.2282

0.2458

0.2578

0.2667

0.2779

0.2829

0.2981

0.2935

0.2933

0.2933

0.2933 yde ydd

0.04020 .0001

0.03890 .0007

0.02880 .0049

0.02320 .0069

$\begin{array}{lll}0.0200 & 0.0079\end{array}$

$0.0193 \quad 0.0085$

0.01860 .0089

0.01810 .0092

0.01750 .0098

0.01720 .0098

0.01680 .0104

0.01670 .0102

0.01670 .0102

0.01670 .0102

0.01670 .0102 


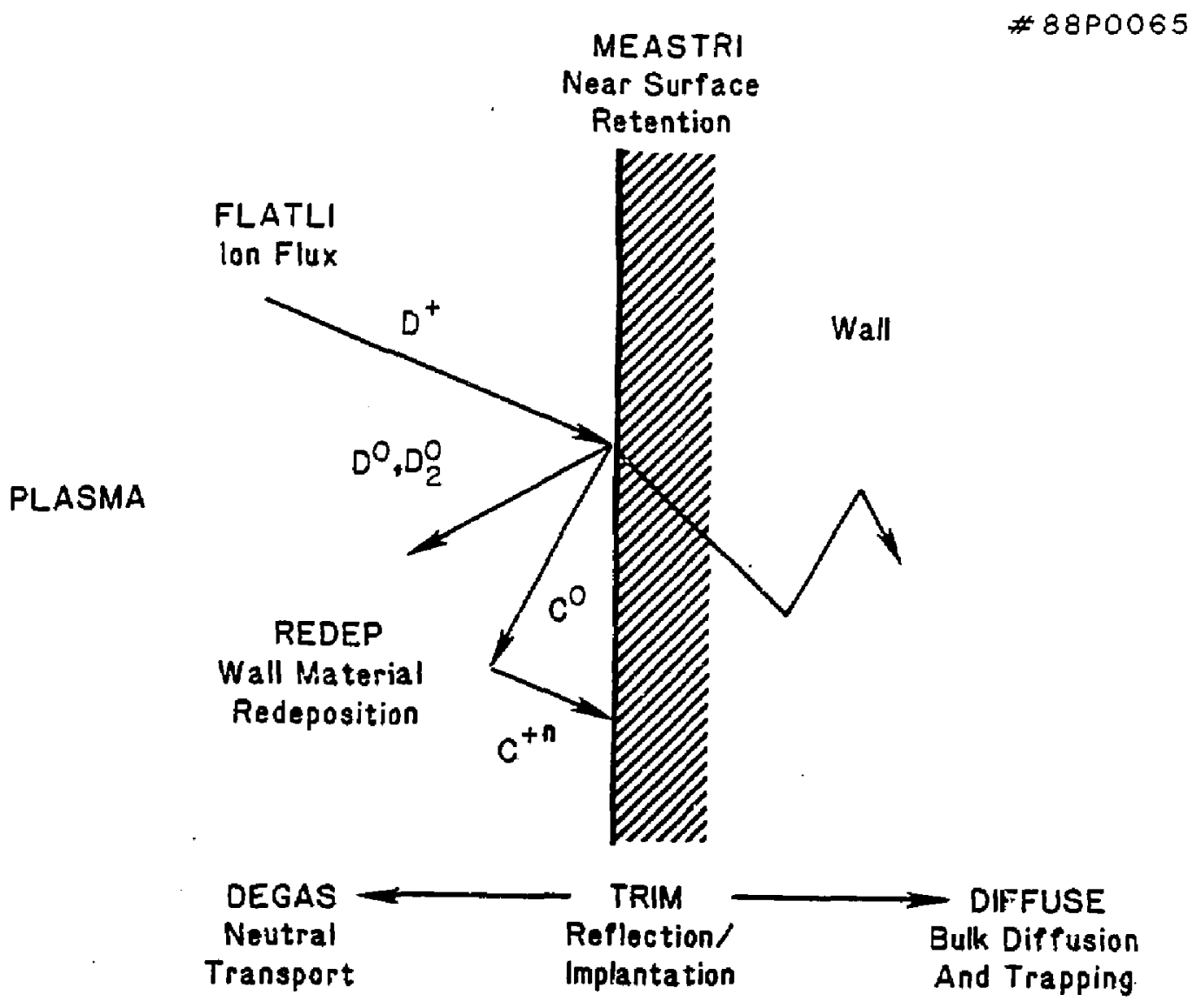

Eig. 6.1. Processes influencing plasma-wall interaction and the analytical model developed to investigate each process. : 


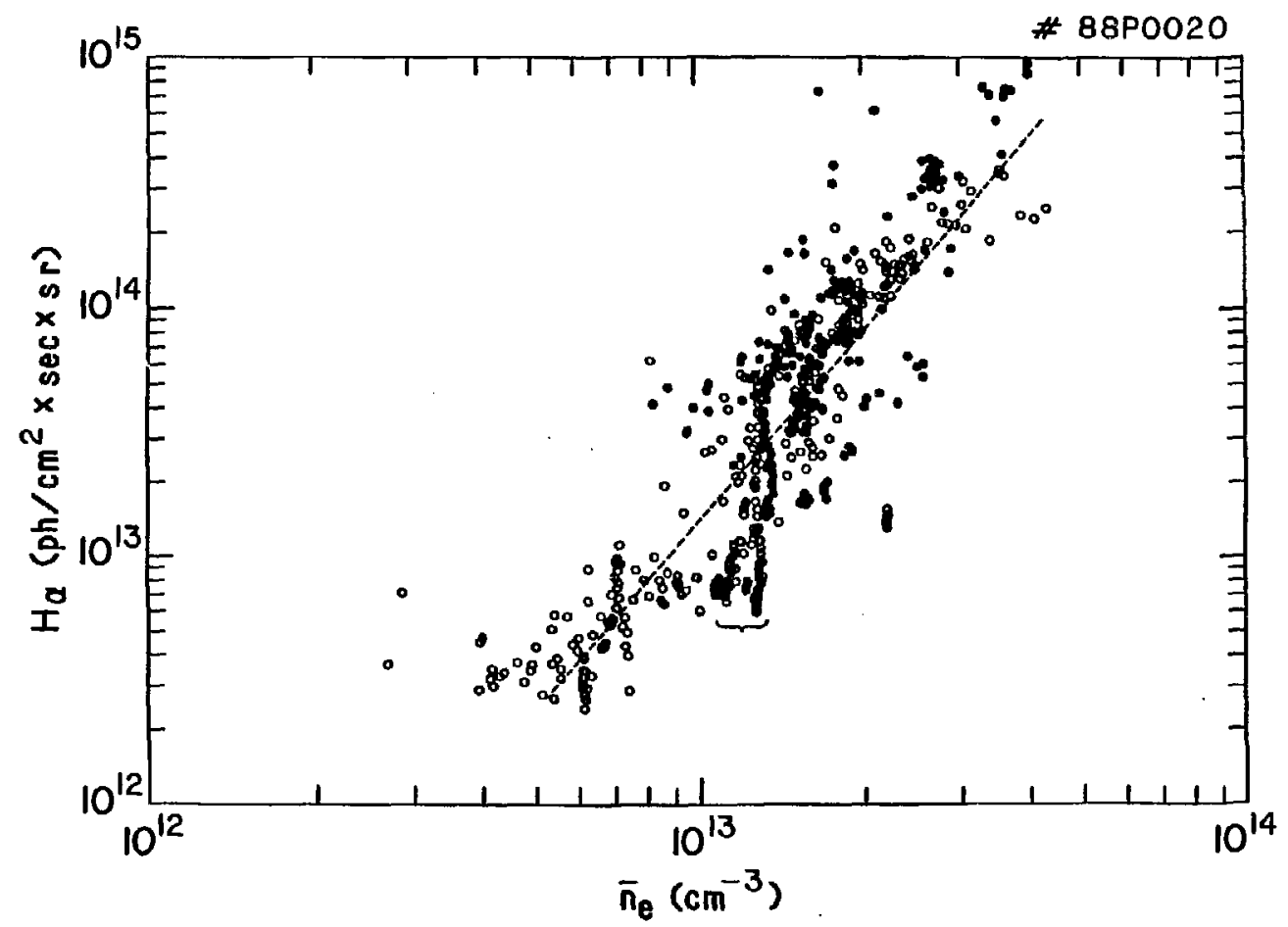

Fig. 6.2. Average of $\boldsymbol{H}_{\alpha}$ emission across the TFTR inner limiter versus $\overline{\mathbf{n}}_{e}$ for the deuterium-fueled discharges during the period June 17 to July 2, 1987. Open eircles are $\mathrm{OH}$ discharges, and filled circles are NBI discharges. 


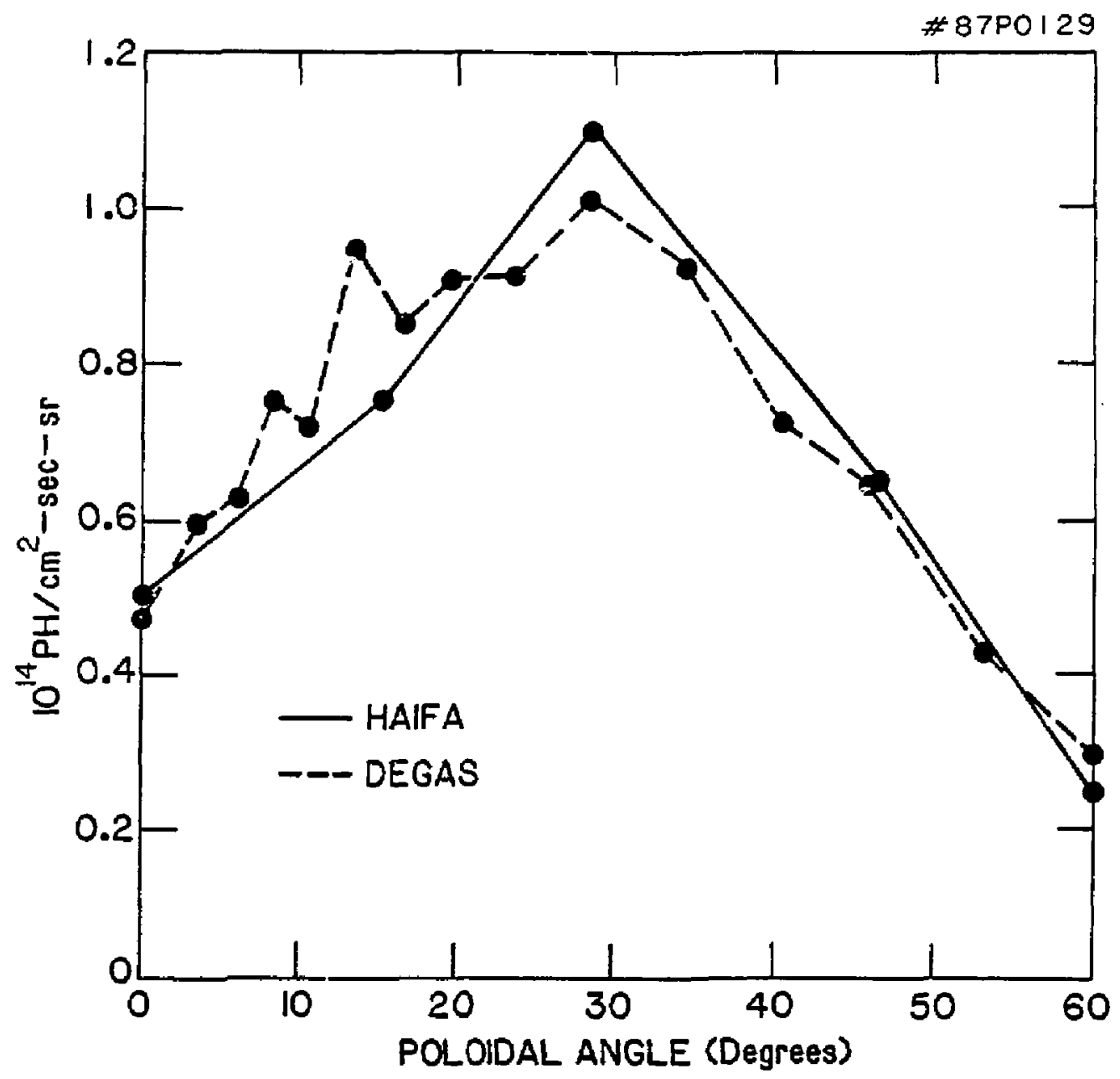

Fig. 6.3. Comparison between toroidally ayeraged $H_{\alpha}$ emfssion for discharge 31613 , as measured by the HAIFA and as calculated by DEGAS. A scrape-off length of $5 \mathrm{~cm}$ is assumed. The measured values have been reduced by a factor of 0.9 to account for toroidal asymmetries observed with the IV H-alpha monitor. 


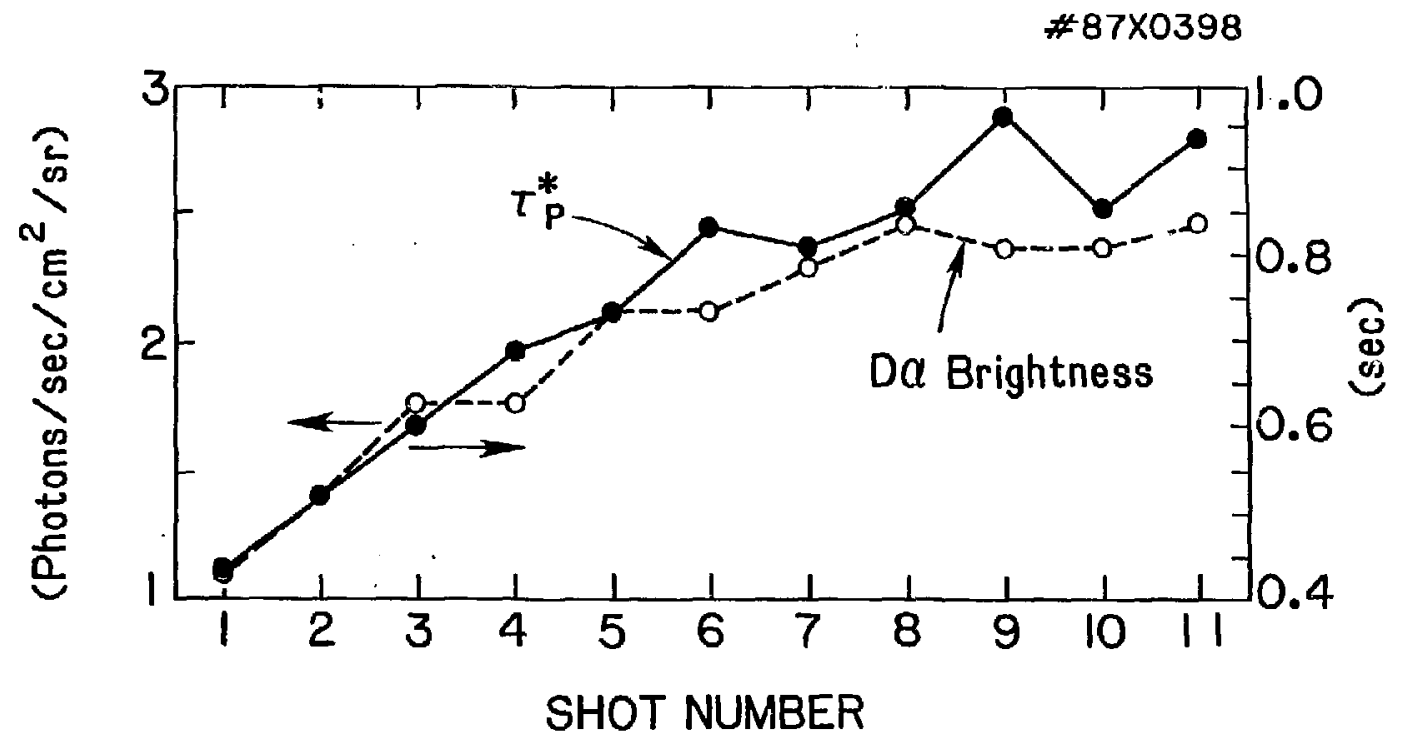

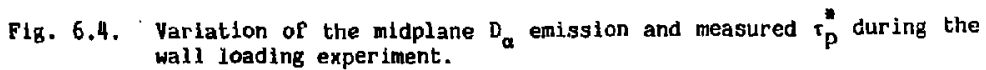




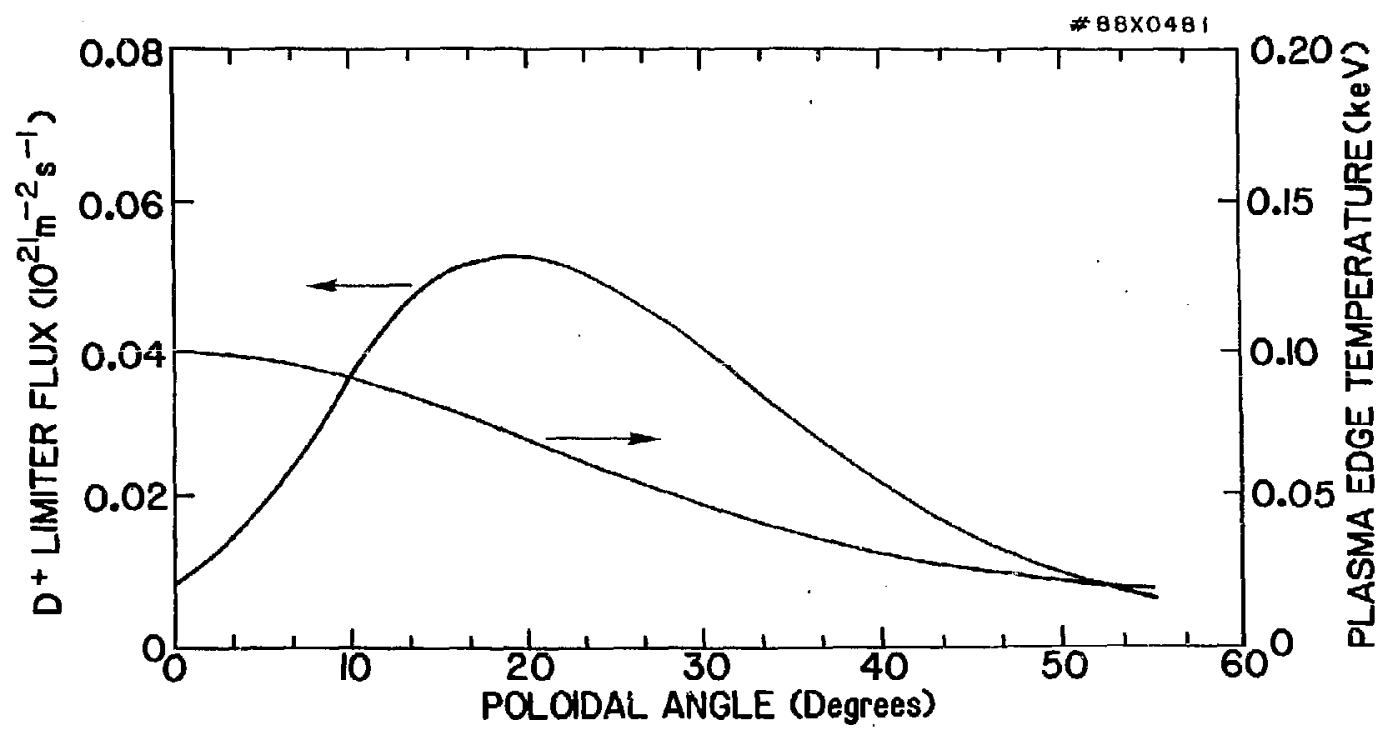

FIG. 6.5. Poloidal varlation of Incident flux and plasma temperature at the surface of the inner bumper 1 imiter. 
* $88 \times 0495$

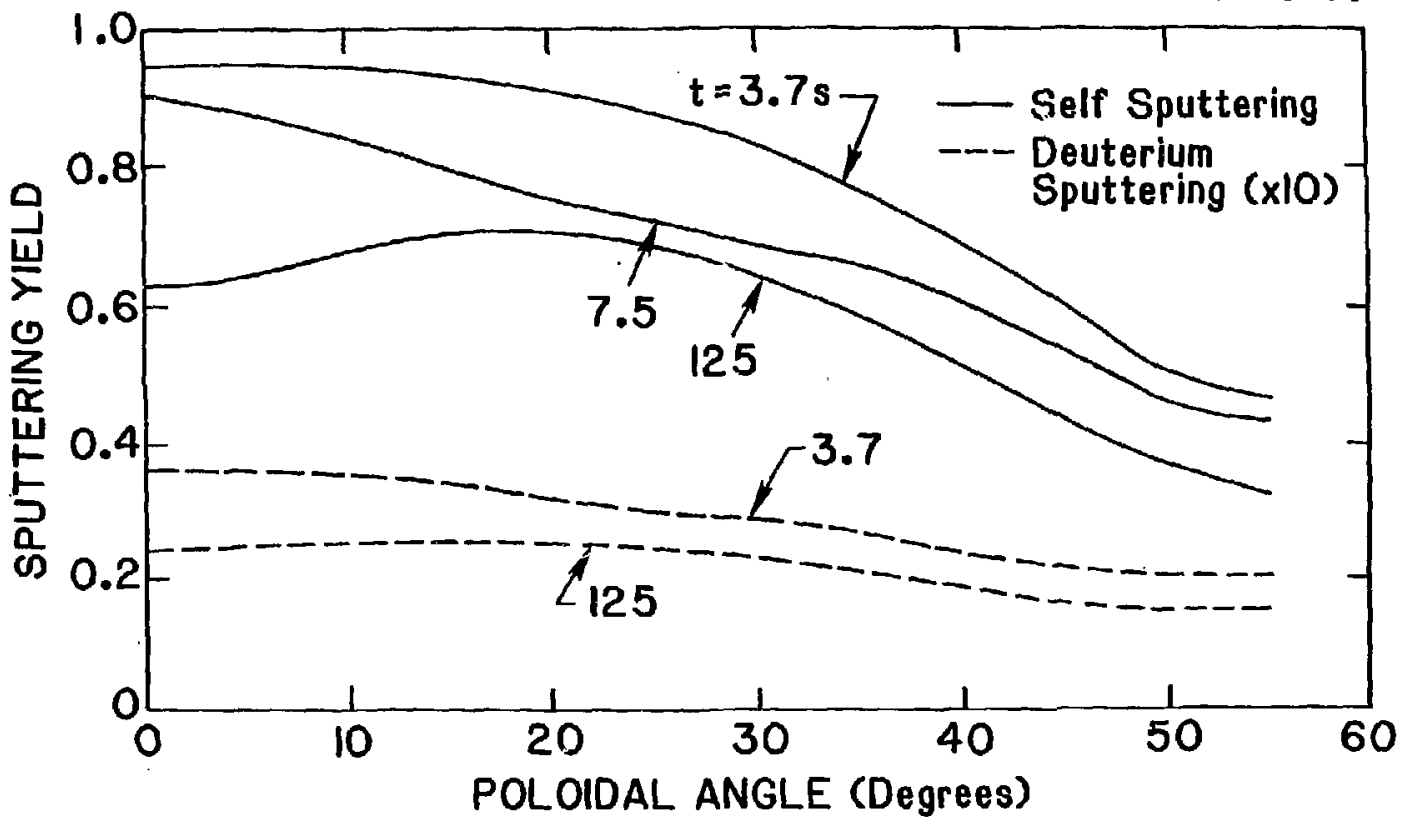

FIG. 6.6. Sputtering yields across the surface of the inner bumper limiter paramoterized by plasma exposure time after He conditioning. 


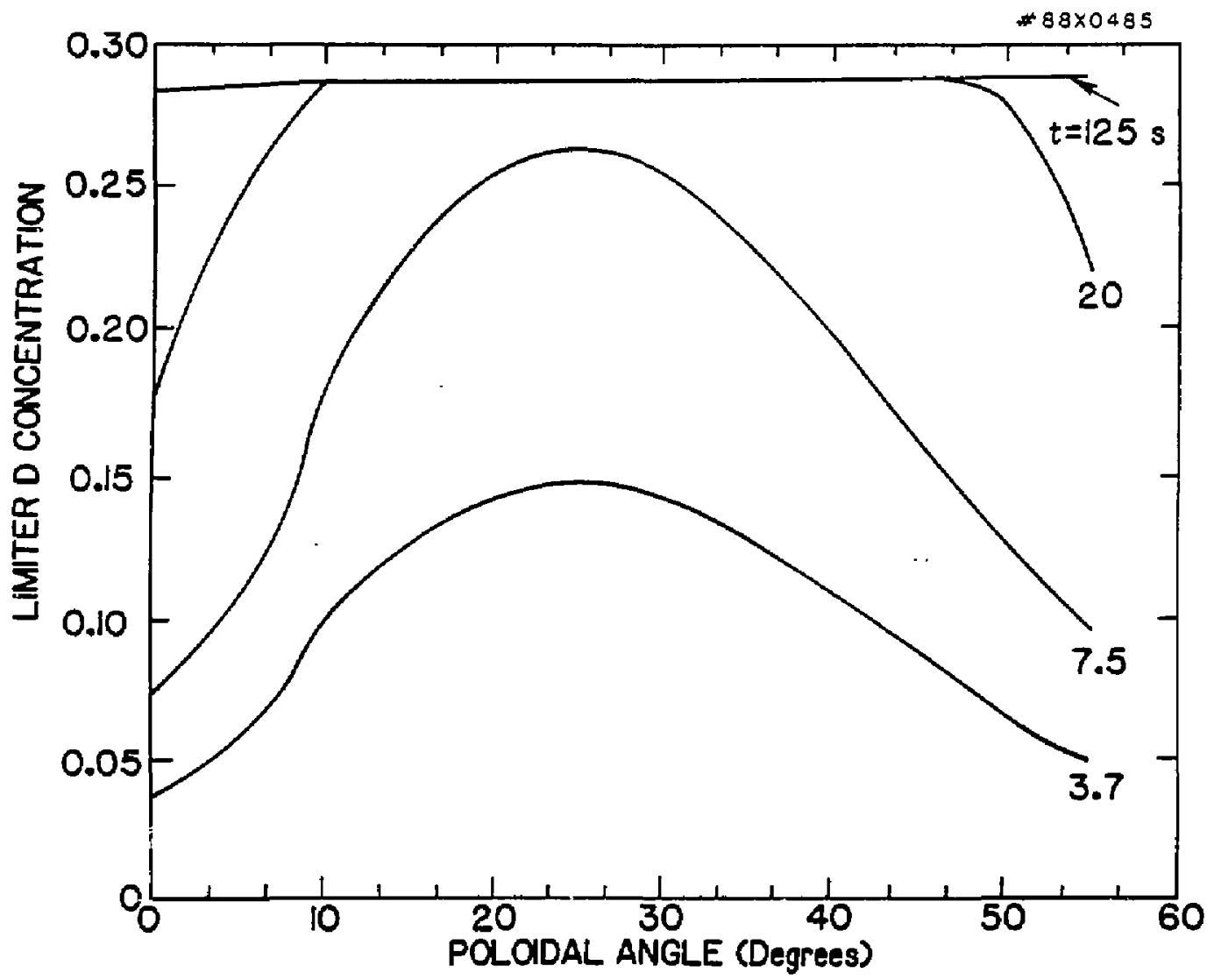

FIG. 6.7. Spatial profiles of delterium concentration in the graphite near surface layers parameterized by plasma exposure time after He conditioning. 


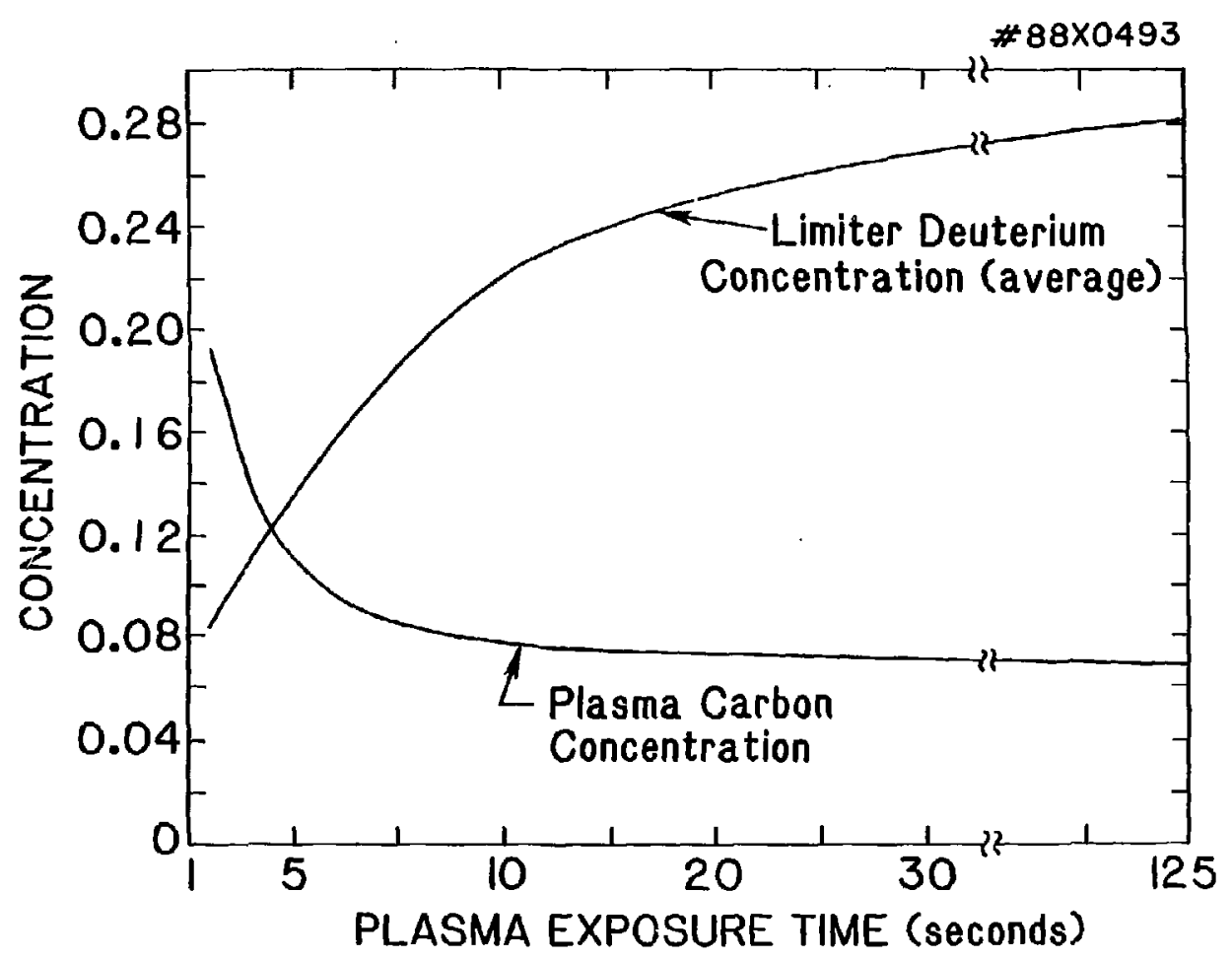

FIG. 6.8. Average deuterium concentration in the near surface layers of the inner bumper and core plasma carbon concentration $\left(n_{c} / n_{i}\right)$. 


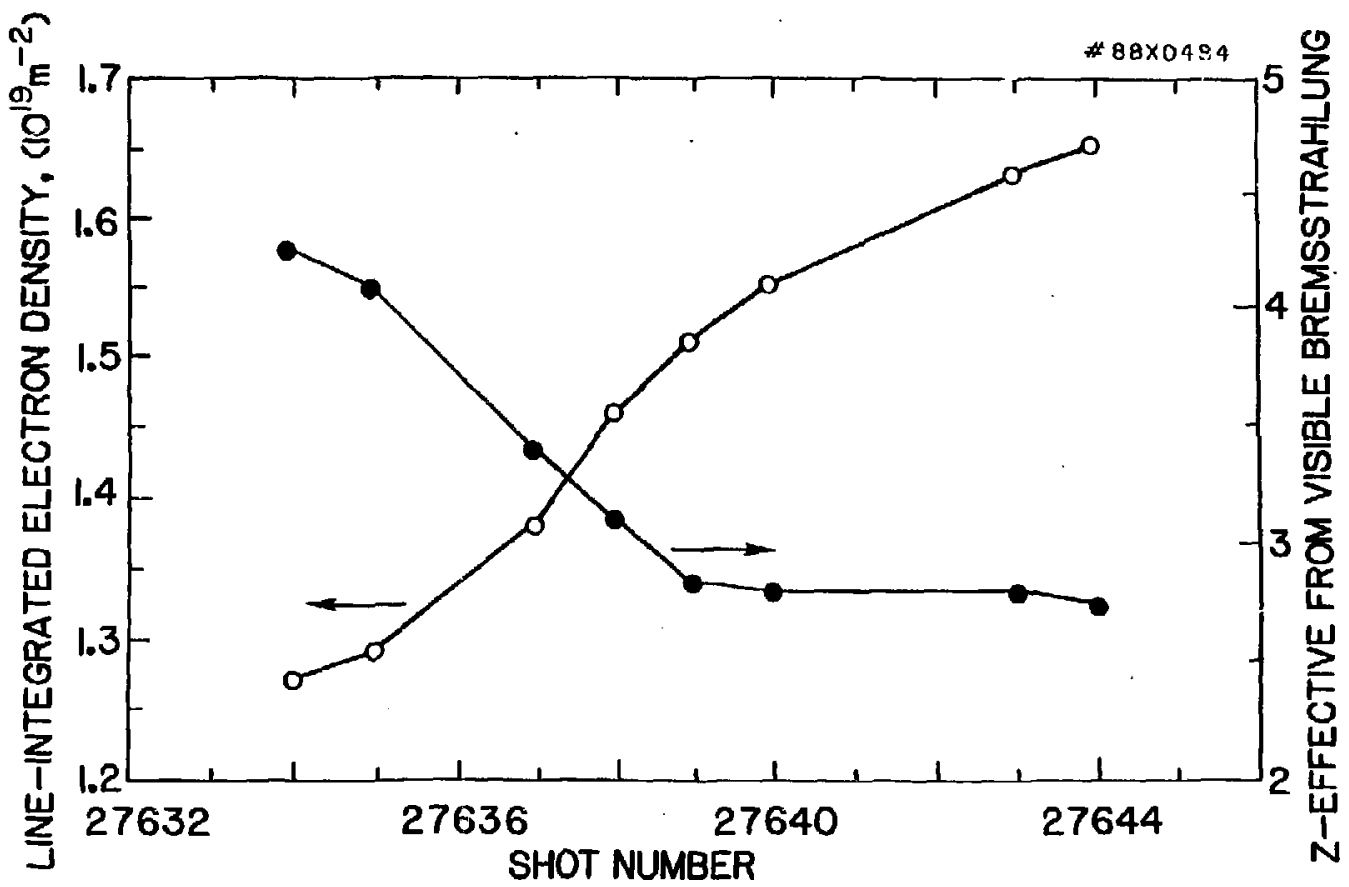

FIG. 6.9. Z-effective and line integrated electron density during a sequence of deconditioning ohmic discharges. Pulse length is 6 seconds for each shot $[12]$. 



FIG. 6.10. (a) Total predicted particle population in the noveable limiter during a sequence of 24 1dentical $1.4 \mathrm{MA}$ of discharge cycles, The dashed curve is a fit which varies as the square-root of the discharge cycle number. (b) Ratlos of the total particle outflux over the total flux on to the moveable and inner limiters during the model $1.4 \mathrm{MA}$ OH discharge. At the moveable limiter, this ratio reaches almost unity in less than 1 sec, while at the bumper limiter it peaks at only 0.9 . 


\subsection{ESTIMATES OF TRITIUM INVENTORY}

Contributors: Tritium Inventory Working Group

A. E. Pontau, Chairman

\subsection{Introduction}

He estimate the total tritium inventory in TFTR using two methods. The first method involves estinating total tritium in each TFTR component separately, and then suming the individual estimates. For example, for the bumper limiter we (a) measure the total deuterium present in TFTh following the 1985-87 operations perfod which exposed the first-wall components to 9922 high power, deuterium-fueled discharges, numerous disruptions, and various wall conditioning campaigns (Sec. 5), and then (b) scale this deuterium inventory to obtain a tritium total. Both steps (a) and (b) are difficult. The final series of discharges in the 1985-87 run period were deuterium pellet fueled. It is belleved that these high-density discharges left the limiter surfaces saturated with deuterium. The distribution of deuterium is different on each bumper limiter tile; only a small subset can be measured for determination of total deuterium retained. Once we establish the total deuterium retention, scaling to tritium operation is still not obvious. We have elected to use total hydrogenic fueling as our scaling factor for the dominant codeposition process on all in-vessel components, as opposed to other possibilities such as the number of discharges or number of disruptions. This assumption of linearity is based on wall coupon data, which showed about $10^{17}$ $\mathrm{D} / \mathrm{cm}^{2}$ for 1770 discharges and $6 \times 10^{17} \mathrm{D} / \mathrm{cm}^{2}$ for 9922 similar discharges, averaging about 10 torr-liters of fueling per discharge (Sec. 4). We conduct our analysis on a baseline case of $600 \mathrm{D}-\mathrm{T}$ neutral-beam-fueled discharges. For each of these discharges, practically all of the plasma fueling is provided by two deuterium and two tritium $120 \mathrm{keV}$ neutral beams of $2 \mathrm{~s}$ duration. The 600 discharges are nearly twice the maximum number of allowed high-Q discharges based on neutron activation limits (Sec. 2). This should allow for some operational flexibility to select lower $Q$ discharges. More fueling will be necessary for these high-power discharges than for previous run periods - about 66 torr-liters $\left(D_{2}+T_{2}\right)$ per discharge (see Table 2.1). We require as-yet unverified assumptions for our final tritium inventory estimate that 1 imit its accuracy to the order of a factor of two.

Our second method for estimating the tritium inventory is based on a particle accounting study involving a small number of high power NB-fueled deuterium discharges (Sec. 2.3). We use estimates of the total fraction of tritlum retained to predict the shot-to-shot evolution of the inventory in support of the proposed operating scenario (Sec. 2.0). Uncertainties in this analysis result from the limited data base used. 


\subsection{Estimate of TETR Tritium Inventory by Component}

In this section, an outline of our tritium inventory estimate is given for each component exposed to tritium plasma or gas.

\subsection{Bumper Limiter $1.4 \mathrm{gT}$}

The Bumper Limiter ( $B L$ ), is composed of about two tons of POCO AXE-5Q graphite. The $\mathrm{BL}$ is the primary source of plasma-eroded carbon, which redeposits throughout the machine, and will serve as the predominant reservoir for tritium retention in TFTR. We will treat the BL in three parts: plasmafacing surfaces, protected surfaces, and the graphite bulk.

We divide the BL plasma-facing surface into two regions based on beta backscattering and Nuclear Reaction Analysis (NRA) measurements of TFTR BL tiles following 9922 mostly D-fueled discharges (Sec. 5.3.1). A relatively "clean" region makes up approximately 1/3 of the limiter surface area. Here plasma contact was intense and net erosion occurred; a low amount of metallic impurities and deuterium (averaging $3 \times 10^{17} \mathrm{D} / \mathrm{cm}^{2}$ ) was observed. The other $2 / 3$ of the limiter surface area showed significant deposition of carbon and metallic impurities, codeposited with about $6 \times 10^{18} \mathrm{D} / \mathrm{cm}^{2}$. In this region, NRA depth profiles of deuterium on two tiles indicated that deuterium did not extend beyond a depth equivalent to $1.4 \mathrm{mgC} / \mathrm{cm}^{2}\left(8 \mu \mathrm{m}\right.$ for $1.8 \mathrm{~g} / \mathrm{cm}^{3}$ carbon), but optical and SEM observations of other tiles showed much thicker deposits (30 um or more) where deuterium could be trapped (Sec. 5.3). We do not fully understand the conflicting indications. The different apparent thickness may be due, in part, to an extended NRA range in low-density carbon/deuterium deposits.

\subsubsection{Bumper Limiter Plasma-Facing Surfaces: $0.8 \mathrm{gT}$}

For tritilum operations, the same areal ratio (1:2) between low-deposition and high-deposition regions on the BL should be produced. In the lowdeposition area, tritium will build up in a few discharges to $1.5 \times 10^{17} / \mathrm{cm}^{2}$ and remain at that level [equivalent to $1 / 2$ of the $3 \times 10^{17} \mathrm{D} / \mathrm{cm}^{2}$ observed during the 1985-87 D-D operations accounting for 50/50 D-T fueling] (Sec. 5.3.1). This tritiun will be contalned in a saturated near-surface layer allowing exchange with the plasma during dischargs:s. In high-deposition regions, only $1 / 6$ as much codeposited tritium will build up during $D-T$ operations, as deuterium did during D-D operations because of the lower total fuel load and because only half of the D-T buildup will be tritium. Therefore, $10^{18} \mathrm{~T} / \mathrm{cm}^{2}$ is expected on the high-deposition area. Even if the amount of deposited tritium were more, it should be removable (possibly using $\mathrm{H}$, $\mathrm{D}$, or $\mathrm{He} / \mathrm{O}_{2}$ glow discharge cleaning). This assumption means that the possibility of heavier D-T deposits implied by microscopy should not be a 
problem. Multiplying these average tritium levels by the BL surface area gives the following contributions to the inventory: low-deposition area $=0.06$ $\therefore$ high-deposition area $=0.73 \mathrm{gT}$.

\subsubsection{Bumper Limiter Hidden Surfaces: $0.55 \mathrm{gT}$}

It is more difficult to estimate the amount of deuterium on the sides of tiles than on the front face because of the steep gradient in deuterium levels observed as a function of distance from the front face, and because different sides of each measured tile have different deuterium levels. An area of relatively thick deposition exists on the side surfaces on nearly half of the BL tiles. This area is as much as $100 \mu \mathrm{m}$ thick at the tile front edge and becomes thinner than a few $\mu \mathrm{m}$ within about $8 \mathrm{~mm}$ of the tile front. At points 2-4 mm or more from the tile front edge, deuterium was directly measurable using NRA depth profiles. Nearer the front edge, micrographs of the deposit thickness and NRA measurements of the deuterium loading vs. depth in typical deposits $(\sim 0.1 \mathrm{D} / \mathrm{C})$ are used to estimate the maximum deuterium deposition occurring on the tile surfaces. Our best estimate of the average amount of deuterium occurring on the side surfaces of tiles is $1.7 \times 10^{20} \mathrm{D} / \mathrm{tile}$, or $6.3 \times 10^{23}$ deuterium for all of the $\sim 1920 \mathrm{BL}$ tiles. The same scaling assumptions as above for codeposited layers are used to calculate the tritium inventory. It will be much more difficult to remove codeposited tritium from protected surfaces than from the front face of tiles.

\section{2 .1 .3 Bumper Limiter Bulk: $0.1 \mathrm{gT}$}

Tritium Plasma Experiment (TPX) measurements, where there is a 5 mtorr neutral gas pressure, indicate that, at elevated temperature, it is possible to get $10-15 \mathrm{ppm}$ D-T into carbon [1] especially into carbon which has been conditioned by exposure to TFTR plasmas [3]. Howeyer, NRA of one sectioned tile gave a low bulk inventory $(0.4 \pm 0.2$ ppm $D-T)$ (Sec. 5.3.1). The gas pressure with the plasma may be required to obtain the larger bulk inventory. Using Secondary Ion Mass Spectrometry (SIMS) and NRA, up to 1\% $H$ Is observed in bulk graphite (Sec. 3). Experimentally, it has not been possible to exchange tritium or deuterium with the $H$; therefore, this level of exchange should not occur in TFrR. For our inventory estimate, we assume that $0.6 \mathrm{ppm} D-T$ will be retained in the BL bulk.

On the other hand, if the bulk of the tiles are heated (perhaps, during discharge cleaning), D-T could transport into the graphite to a 10 ppm level. Tritium retention at $5 \mathrm{ppm}$ for the entire BL would be equivalent to i.6 $\mathrm{g} . \mathrm{T}$. 


\subsubsection{Vacuum Vessel Wall: $0.37 \mathrm{gT}$}

NRA of codeposited layers on wall coupons indicated an average of about $6 \times 10^{17} \mathrm{D} / \mathrm{cm}^{2}$ after the 9922 discharge exposure (Sec.5.3.2). A similar average was found for hundreds of measurements on surface pumping system ( $\mathrm{Zr}$ Al getter) fixtures on the wall. Several beta backscattering measurements and $v$ isual observations indicate that the deposits inay be somewhat thicker on the top and bottom of the machine than near the midplane where many of the wall samples were located. It appears that deuterium levels scale with deposit thickness at different geometric positions. As indicated above, they also seen to scale with a number of discharges for a given position (Sec. 5.1).

We assume that the appropriate surface area to use for wall deposition is the $110 \mathrm{~m}^{2}$ projected area even though there are pump ducts and other geometrical varlations in the vessel. The $6 \times 10^{17} \mathrm{D} / \mathrm{cm}^{2}$ retention observed from the last run period is scaled for the $D-T$ phase by the ratio of total fueling. Discharge cleaning techniques should be effective in minimizing these deposits.

\subsubsection{TiC-Coated Neutral Beam Arwor: $0.2 \mathrm{gT}$}

The codeposition process over the armor surface area will contribute 0.05 $\mathrm{gT}$ to the inventory. Erom accelerator experiments, the behavior of tritium in TiC is similar to tritium in C [3]. TRIM code [4] calculations give a value of $-0.8 \mu \mathrm{m}$ range for $120 \mathrm{keV}$ tritium normally incident onto $T i C$. If tritium beams strike half of the armor surface with a maximum T/TiC loading ratio of 0.25 in the coating, the total near-surface capacity is $0.27 \mathrm{gT}$; but this capacity will not be totally filled.

For the portion of the armor with maximum NB shinethrough, temperatures will exceed $700^{\circ} \mathrm{C}$ and tritium will be transported into the bulk carbon. However, the maximum bulk level is no more than $1.5 \times 10^{18} \mathrm{~T} / \mathrm{cm}^{3}$ for the carbon substrate [1], and the hot area is $1250 \mathrm{~cm}^{2}$ total for two tritium beams. Even if the total carbon volume in these hot zones fills to the saturation level, there will be only $0.03 \mathrm{gT}$ in the bulk.

For the area not heated to such high temperatures, we assume that all incident $120 \mathrm{keV}$ tritium is retained. The flux to this cooler part of the tritium-beam armor area averages as much as $0.1 \mathrm{kw} / \mathrm{cm}^{2}$ over $-4000 \mathrm{~cm}^{2}$. This tatal amount of tritium is equivalent to about $0.12 \mathrm{gT}$, which is implanted in the near-surface region of the $\mathrm{TiC}$ coating. 


\subsubsection{Neutral Beamline Surfaces: $0.2 \mathrm{gT}$}

The total surface area for each of the four neutral beamlines is $1641 \mathrm{~m}^{2}$ of which $423 \mathrm{~m}^{2}$ is painted with a black paint for high emissivity. Most of these areas constitute cryopanels at liquid nitrogen (LN) or liquid helium (LHe) temperature. The deuterium beamlines will adsorb negligible amounts of tritium gas. He anticipate separately warming each set of TNB LHe panels to LN temperature periodically to retrieve tritium gas. For 600 D-T discharges, each TNB line will be exposed to a total of about 1.1 torr-hour of $T_{2}$. In laboratory studies, exposure of most beamline materials to 1 torr-hour of $\mathrm{T}_{2}$ gas at room temperature ylelded $2 \times 10^{14} \mathrm{~T} / \mathrm{cm}^{2}$ for unpainted surfaces, and $2 \times 10^{15} \mathrm{~T} / \mathrm{cm}^{2}$ or less for painted surfaces (Sec. 3.2.1). An integrated tritium level of $0.05 \mathrm{gT}$ per beamline results, which we multiply by four to allow for the possibility of fueling any of the beamlines with tritium.

We assume that tritium in the tritium AB sources will be negligible since they are relatively small in size $\left(0.1 \mathrm{~m}^{2}\right.$ per source). There is still considerable uncertainty about tritium behavior in the neutral beam area because 1) the presence of extra atomic tritium from the source, 2) the large surface area at LN temperature, or 3) the possibility of conversion of $\mathrm{T}_{2}$ gas to tritiated water or hydrocarbons could result in increased adsorption or condensation on surfaces. These issues may affect operating scenarios by requiring more frequent regeneration of LN cryopanels, but are not expected to adversely impact the ultimate tritium inventory.

\subsubsection{Copper Ion Dumps and Calorimeters: $0.15 \mathrm{gT}$}

Detailed calculations of tritium retention in TFTR NB ion dumps and calorimeters were performed using the DIFFUSE code [5]. The calculations predicted a total tritium retention of $4.8 \times 10^{20}$ atoms for ten $0.5-\mathrm{sec}$ discharges five minutes apart on a total of 12 ion dumps and calorimeters for two tritium neutral beams. This estimate was based on NB test stand studies and laboratory experiments on $\mathrm{Cu}$. The calculation is scaled up linearly to estimate tritium inventory for 600 2-sec D-T discharges spaced at hourly intervals (Sec. 2.0). The calculations predicted that tritium retention will' scale with (number of discharges) ${ }^{1 / 2}$ up to to discharges, so using linear scaling is somewhat conservative.

\subsubsection{Carbon-Carbon Antenna Limiter: $0.1 \mathrm{gT}$}

The antenna limiter surface will behave (at worst) like the wall and have negligible tritium retention for its small surface area. The bulk should heat up and allow tritium retention to a 5 ppm level [6]. 


\subsubsection{Tritiun Handling Systems: $0.83 \mathrm{gT}$}

The inventory in the TFTR gas delivery and recovery systems [7] is estimated to be $0.83 \mathrm{~g}$ based on minimum operating pressures in system volumes and one monolayer of adsorbed tritium on all the stainless steel surfaces of the system hardware and piping.

7.2.8 Summary of Component Contributions

The contributions of each component can be sumarized to arrive at the total expected tritium inventory of $3.2 \mathrm{~g}$ shown in Table 7.1 . We somewhat arbitrarily assign a factor of two uncertainty level to our tritium inventory estimates. Because of the limitations of the experiments and the numerous assumptions required, we cannot guarantee that the total inventory will fall in this range. Our greatest uncertainties are in the bumper limiter and neutral beam areas. The codeposited layers on bumper limiter tile edges are difficult to characterize. All of the neutral beam material analysis to date has been conducted at room temperature instead of the lower operating temperatures (77K) where more tritium could be retained. Eurther studies of the formation and removal of codeposited layers, and tritium adsorption at cryogenic temperatures are planned.

\subsection{Estimate of Tritium Inventory From Particle Balance}

The second method of estimating the tritum inventory involves the use of particle balance measurements. Using fueling predictions shown in Table 2.1 for every TNB discharge, 672 torr-liters of $\mathrm{T}_{2}$ will be injected into the $\mathrm{NB}$ systems whereas only a smaller quantity -33 torr-liters $T_{2}$ will reach the torus directly as high-energy beam fueling. The inventories in the torus and beamlines will evolve per discharge by the product of the above input and a respective retention factor. The retention factors can be estimated from the data and analysis given in Sec. 7.2. With regard to the torus inventory, three retention mechanisms are identified: surface saturation, bulk diffusion, and codeposition. The in-vessel retention is dominated by codeposition, which is linear with the number of discharges. The surface saturation of the high-flux areas of the limiters represents a relatively small $(<500 \mathrm{CI})$ increment to the retention after the first few discharges, and the contribution due to bulk retention is negligible.

A measure of the total in-vessel retention per discharge is avallable from particle balance measurements, which yielded an average retention factor of $-(35 \pm 22) \%(\mathrm{sec} .4 .2 .3)$. These data were collected for 41 high-power NB discharges withil 80 seconds after the end of each discharge. Note that this factor would yield a cotal in-vessel tritium retention value for 600 discharges of $2.3 \pm 1.5 \mathrm{gT}$, in very good agreement with our Sec. 7.2.8 predicted in-vessel inventory of $2.1 \mathrm{gT}$. The retention factor for the neutral beamline exposure to tritium should be much lower because it is primarily a 
gas phase exposure of tritium to the large surface area of the beamlines. Since the TNB operational scenario (Table 2.2) includes twe hours of beam conditioning in $\mathrm{D}_{2}$ prior to TNB operation, all beamline ambient temperature and $77 \mathrm{~K}$ surfaces should be saturated with approximately monolayer quantities $\left(10^{14}-10^{15} \mathrm{~cm}^{-2}\right)$ of deuterium. Therefore, it is likely that the subsequent adsorption of tritium during a TNB discharge will be characterized by weak physical bonding to these surfaces. Most of the input tritium should be reversibly cryosorbed to the He-cooled surfaces of the NB cryopanels. Upon regeneration of the He cryopanels the retention factor for tritium on the $\mathrm{LN}_{2}$ cryopanels and ambient temperature surfaces should be small. The tritium adsorption data for the $\mathrm{LN}_{2}$ oryopanel material shown in Fig. 3.8 implies a retention factor of less than $0.3 \%$ at room temperature for pure tritium exposures. Using the Fig. 3.8 adsorption data as characteristic of the kinetios for tritium retention in the beamlines, the shot-to-shot evolution of the beamline inventory can be calculated (Fig. 7.1). Comparison with the linear evolution of the vacuum vessel inventory (Fig. 7.1) shows that the beamline inventory is small $(\sim 0,1 \mathrm{~g}$ for 2 TNB $)$ relative to the in-vessel inventory $(\sim 2.3 \mathrm{~g}$ ) after 75 regeneration cycles (or the equivalent of 600 full power discharges). The estimated retention in neutral beamlines will be checked by $D_{2}$-particle balance measurements in TFTR beamlines during the 1988 run period, and by additional laboratory adsorption-deposition experiments with tritium on neutral beamline materials.

\subsection{Conclusions}

There are two major impacts of these studies. First, it appears that TFT could operate within the 5 gram administrative limit of on-site tritium, but this limit would constrain operational flexibility. Second, most of the tritium retention in TFTR will be on limiter, vacuum vessel, and neutral beam surfaces; bulk retention is negligible. The major uncertainties in our tritium inventory estimates are: 1) Measuring codeposited D/C layers on the nonplasma-facing surfaces (sides and edges) of bumper limiter tiles and extrapolating these measurements to tritium operations is difficult. 2) The analysis of tritiun retained on neutral beam materials to date has been conducted only at room temperature. We have assumed that tritium adsorbed on cryopanels will be released at temperatures as low as $80 \mathrm{~K}$ enabiing rapid cycling of discharge sequences. Detailed studies of tritium adsorption/desorption phenomena are continuing to ensure optimal TFTA operating procedures during the D-T phase. 


\section{REFERENCES}

.[1] R. A. Causey, M. I. Baskes, and K. L. Wilson, J. Vac. Sci. Technol. A3 (1986) 1189.

[2] A. E. Pontau, R. A. Causey, and J. Bohdansky, J. Nucl. Mater. 145/147 775.

[3] B. L. Doyle, H. R. Wampler, and D. K. Brice, J. Nucl. Mater. 103/104 513.

[4] J. P. Blersack and L. G. Haggmark, Nucl. Instrum Meth. 57 (1980) 257.

[5] K. L. Wilson et al., J. “iac. Sc1. Technol. A5(4) (1987) 2210

[6] R. A. Causey et al., in Proc. 12th Sym. on Fusion Engineering, Monterey, CA, 1987, to be published.

[7] J. T. Gill, B. E. Anderson, R. A. Watkins, and C. W. Plerce, J. Vac. Sci. Technol. A1 (1983) 856 . 
TABLE 7.1

TFTR COMPONENT DIMENSIONS AND TRITIUM INVENTORY ESTIMATES

\begin{tabular}{|c|c|c|c|}
\hline & Surface Area & Volume & Tritiun \\
\hline Component & $\left(m^{2}\right)$ & $\left(m^{3}\right)$ & (grams) \\
\hline Bumper Limiter & 22 & 0.74 & 1.4 \\
\hline Tritium Handling Systems & -- & -- & 0.8 \\
\hline Vacuum Vessel Wall & 110 & - & 0.4 \\
\hline Neutral Beam Lines & 6564 & 184 & 0.2 \\
\hline NB Protection Armor & 10.9 & 0.36 & 0.2 \\
\hline NB Ion Dumps and Calor imeters & -- & - & 0.1 \\
\hline RF Antenna Limiter & 5.0 & 0.05 & 0.1 \\
\hline \multicolumn{3}{|c|}{ TOTAL } & 3.2 G Tritium \\
\hline & & & $\begin{array}{l}\text { Estimated } \\
\text { uncertainty }\end{array}$ \\
\hline & & & factor: 2 \\
\hline
\end{tabular}


\#88x0503

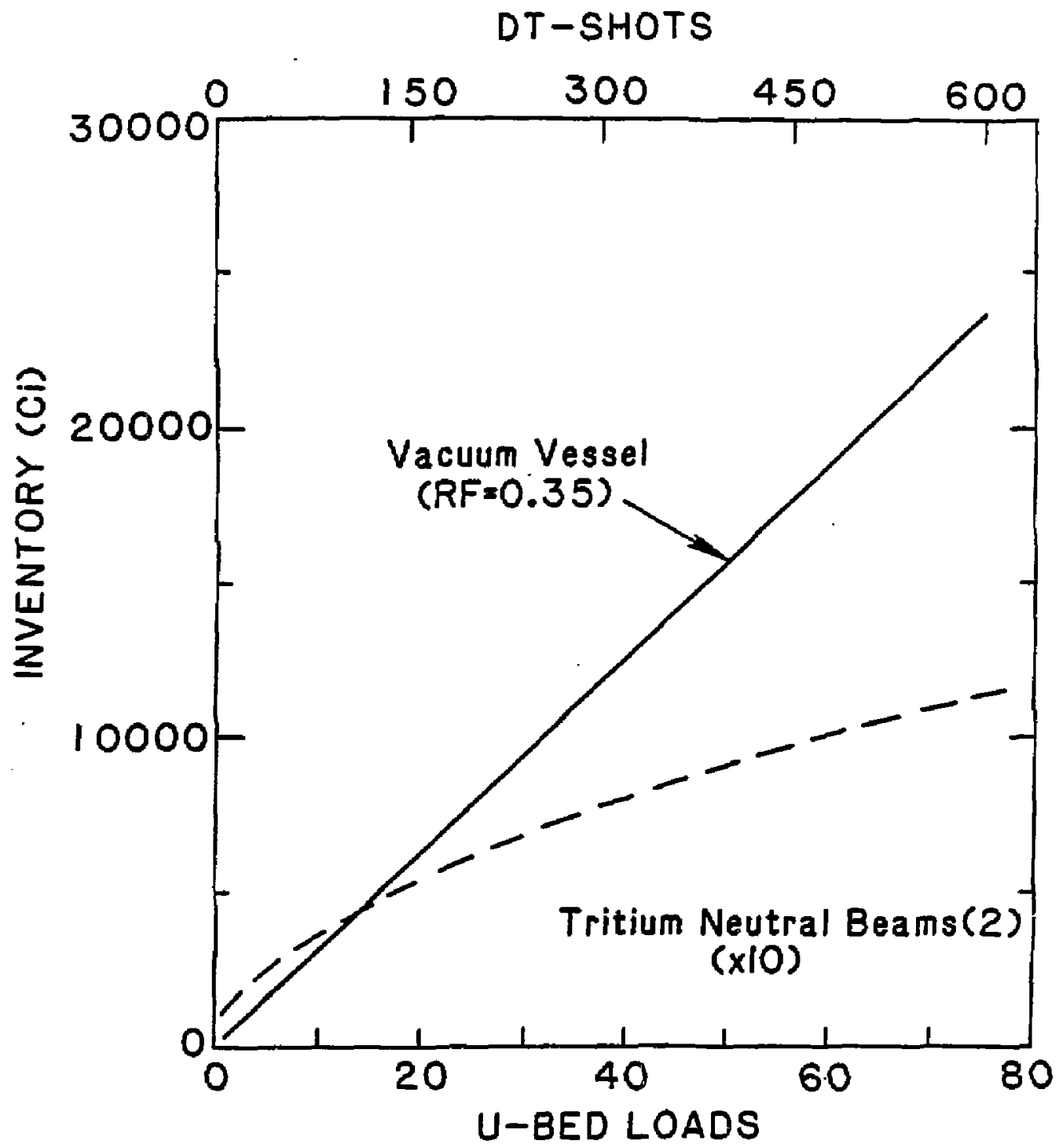

F1g. 7.1. Predicted dependence of the tritium inventory in the TFTR vacuum vessel and tritium-fueled neutral beamlines vs. number of full power (-30HW) D-T discharges. 


\subsection{SUMMARY}

The tritium retention studies described in this report have identified three distinct mechanisms for the retention of tritium within the TFTR vacuum vessel: 1) surface saturation of the plasma contacting first-wall components (i.e., limiter tiles), 2) diffusion into the bulk regions of graphite firstwall components, and 3) redeposition of carbon eroded from high-flux areas onto low-flux areas with incorporation of tritium into the deposited film.

The first mechanism, the surface saturation of graphite subjected to hydrogenic bombardment, is well understood on the basis of numerous laboratory experiments and a simple model (the Local Mixing Model) of $\mathrm{H}-\mathrm{C}$ interactions. All forms of nuclear-grade graphites that have been incorporated in TFTR first-wall structures [1.e., small grain-isotropic (POCO AXF-5Q) and carboncarbon composites] have nearly identical surface saturation levels when subjected to hydrogenic bombardment: carbon surfaces (at room temperatures) will saturate at atomic loadings of $\mathrm{T} / \mathrm{C}=0.4$ to a depth consistent with the range of the incident hydrogenic species. Because of the relatively low energy $(<300 \mathrm{eV})$ and high flux $\left(>10^{16} \mathrm{~cm}^{-2}\right)$ of hydrogenic species on the bumper limiter, the surface regions should rapidly saturate (i.e., within less than one discharge on high flux areas). The resulting low level of tritium retention $(\leq 0.05 \mathrm{~g})$ has a minor impact on total TFTR tritium inventory.

The second mechanism for tritium retention is diffusion of tritium from the saturated surface layer to the bulk of the graphite first-wall components. Diffusion of hydrogenic species is a complicated process in graphite because of the complex microstructure. Bulk tritium retention is assumed to occur uniformly throughout the carbon tiles in TFTR (in the bumper limiter, RF limiter, RF antennae, and protective plates) by the processes of surface diffusion and permeation along internal pores followed by incorporation in the lattice by trans-granular diffusion and trapping. Diffusion along the surface of interconnected pores has a low activation energy $(\sim 0 . \dot{9} \mathrm{eV})$ and trans-granular diffusion is characterized by a fairly high activation energy $(\sim 2.8 \mathrm{eV})$. Because of these activation energies, diffusion is negligible at low graphite temperatures $\left(<350^{\circ} \mathrm{C}\right)$ and retention peaks at bulk temperatures on the order of $1200^{\circ} \mathrm{C}$.

Measurements of the bulk retention of deuterium in TFTR moveable limiter tiles which were removed in 1985 (after exposure to 2700 discharges) showed a variable retention of $5-13 \mathrm{ppm} D$ with significant uncertainty ( $\pm 5 \mathrm{ppm}$ ) in the measurements. These tiles experienced bulk temperature excursions during plasma exposure exceeding $500^{\circ} \mathrm{C}$.

Based on detailed laboratory tritium retention measurements on 2-D carbon-carbon composites used for the TFTR RF antenna limiter material, a 
maximum retention of $-10^{18} \mathrm{D}-\mathrm{T} / \mathrm{cm}^{3}$ (10 appm) D-T is predicted for operating temperatures $1200 \mathrm{~K}$ to $1500 \mathrm{~K}$. Measurements of the bulk retention in TFTR bumper limiter tiles removed in 1987 after exposure to 9,922 discharges showed negligible deuterium bulk retention $(0.4 \pm 0.2 \mathrm{ppm})$, consistent with the low bulk temperature $\left(<350^{\circ} \mathrm{C}\right)$ of these tiles.

The third and most important source of tritium retention in TFTh arises from the buildup of tritium incorporated into redeposited carbon films on all plasma-exposed surfaces. This process has been observed in all tokamaks using graphite 1 imiters and in laboratory simulations for first-wall processes when graphite samples are exposed to hydrogen plasmas.

Following the 1985-1987 FFTh operations period the amount of deuterium on 33 of the 1920 bumper-limiter tiles and on several hundred wall samples was measured by nuclear reaction analysis. In addition, global patterns of deposition and erosion on the bumper limiter were mapped in-situ by beta backscattering. Based on these measurements the total anount of deuterium remaining in the TETR first-wall structure after exposure to 9,922 discharges (with an average fueling of 10 torr-liters each) was estimated to be about $2 \times 10^{24}$ deuterium atoms with an uncertainty of about $\pm 1 \times 10^{24}$ deuterium atoms.

The amount of tritium which will be retained in redeposited material during the proposed $D-T$ phase can be estimated from the amount of deuterium which was retained during the 1985-1987 deuterium plasma operation. Assuming that the deuterium (or tritium) accumulation scales linearly with the amount of fuel used to make the plasmas, then the amount of tritium retained in the first-wall after 600 full power discharges (with 66 torr-liters of $\mathrm{D}_{2}+\mathrm{T}_{2}$ per discharge) will be $4 \times 10^{23}$ tritium atoms or $(2 \pm 1)$ grams.

Particle balance measurements of neutral-beam-fueled discharges also indicate that the deuterium remaining in TFTR scales roughly with fueling. The amount of deuterium remaining. In the machine was found to be $(35 \pm 22) \%$ of the amount used to fuel the plasmas. This provides a second method of estimating the in-vessel tritium inventory. Corresponding to $(2.3 \pm 1.5)$ grams of tritium for 600 D-T discharges each with 66 torr-liters of D-T fueling, this is in good agreement with the estimate from the first method.

In addition to considering in-vessel components, a full accounting of the TFTR tritium inventory must include the neutral beamlines and the tritiunt handling systems. The inventory in the tritium gas delivery and recovery systems is made up of the minimum operating pressure in the delivery volumes and surface retention on the system piping, which sums to $\sim 0.8 \mathrm{~g}$. The neutral beamlines must be included in the inventory analysis because they are exposed to thermal tritium gas as the beamline cryopumps pump the plasma exhaust, and 
in addition, are exposed to energetic tritium as a result of tritium neutral beam operation. Estimates of the neutral beam retention have been made from tritium adsorption measurements on beamline component materials and detailed calculations of retention in $\mathrm{Cu}$ ion dumps and calorimeters. The present total beamline inventory estimates $(\leq 0.2 \mathrm{~g}$ ) are not large. However, considerable uncertainty exists because of the extrapolations necessary to scale to the large beamline surface areas $\left(>6000 \mathrm{~m}^{2}\right)$ and the lack of tritium adsorption/desorption measurements at the $77 \mathrm{~K}$ cryopanel temperatures.

The total tritium inventory estimate itemized by component is given in Sec. 7.0 and gives a most likely value of $3.2 \mathrm{~g}$. Because of the limitations of the experimental measurements and the assumptions that were incorporated in this estimate, a statistical analysis cannot be performed to provide confidence limits relative to these values, and we have assigned somewhat arbitrarily a $+100 \% /-50 \%$ uncertainty level to the inventory estimate. Given the available information on hydrogenic retention in graphite, the TFTR machine configuration and the proposed D-T operational scenario, the estimates shown in Table 7.1 represent the best efforts to date and are not inikely to change significantly prior to D-T operation of TFTR.

If the most likely estimate $(3.2 \mathrm{~g})$ is assumed, the present on-site inventory $1 \mathrm{imit}$ of $5.0 \mathrm{~g}$ does not impose a serious constraint to TFTR D-T operations. Considering the uncertainty in this estimate, it would be prudent to consider a doubling of the present limit to $10 \mathrm{~g}$ in order to minimize any possible constraints of tritium inventory on TFTR operations.

Optimized techniques for removal of in-vessel tritium are being developed and tested both in laboratory simulations and during D-D operation of TETR in 1989-90. The use of in-vessel inventory reduction techniques (i.e., discharge cleaning) is a prudent procedure following each D-T cycle of machine operations (see Table 2.1), which corresponds to an input of approximately 1.8 g of tritium per 9-hour shift of tritium neutral beam operation. Such an operational mode will insure the maintenance of minimal tritium inventory within first-wall materials in order to minimize the consequences of loss-ofvacuum accidents. 


\subsection{Bibliography}

1987

R. Beutler et al.

D. K. Brice et al.

j. W. Davis et al.

J. W. Davis et al.

J. W. Davis et al.

H. F, Dylla et al.

H. F. Dylla et al.

H. F. Dylla et al.

D. M. Goebel et al.

A. A. Heasz et al.

A. A. Haasz et al.
"Pyrolytic Graphite Inherent H-Eontent and Trapping of sub-eV D० Atoms"

J. Nucl. Mater. 145/147 (1987) 280

"Simultaneous gas- and plasma-driven hydrogen transport in solids"

J. Vac. Sci. Technol. A5 (1987) 2311

"Hydrocarbon Formation due to Combined $\mathrm{H}^{+} \mathrm{Ion}$ and $\mathrm{H}^{\circ}$ Atom Impact on Pyrolytic Graphite"

in Proc. 3rd Intern. Conf. on Fusion Reactor Materials, Karlscuhe, 1987

J. Nucl. Mater. (in press)

"Hydrocarbon Formation due to Hydrogen Ion Impact on Amorphous Hydrogenated Carbon Films"

J. Nucl. Mater. 149 (1987) 349

"Flux and Energy Dependence of Methane Production from Graphite de to $\mathrm{H}^{+}$Impact"

J. Nucl. Mater. 145/147 (1987) 417

"Conditioning of the graphite bumper limiter for enhanced confinement discharges in TFTR"

Nucl. Fusion $\underline{27}$ (1987) 1221

"Wall pumping and particle balance in TFTR"

in Proc. 14th European Conference on Controlled

Eusion and Plasma Physics, Madrid, 1987

(European Physical Society, 1987) Vol. IID, p. 698

"Materials behaviour and materials problems in TFTa"

in Proc. 3rd Intern. Conf. on Fusion Reactor Materials, Karlsruhe, 1987

J. Nucl. Hater., in press

"Erosion and redeposition experiments in PISCES"

J. Nucl. Mater. 145/147 (1987) 61

"Flux and Energy Dependence of Radiation-Enhanced Sublimation of Graphite"

J. Nucl. Mater. 151 (1987) 77

"Synergistic Methane Formation on Pyrolytic Graphite due to Combined $\mathrm{H}^{+}$Ion and $\mathrm{H}^{\circ}$ Atom Impact"

J. Nucl. Mater. 145/147 (1987) 412 
צ. Hirooka et al.

H. L. Hsu et al.

R. A. Langley

K. L. Wilson et al.

R. Bastasz

A. A. Causey et al.

R. E. Clausing et al.

D. M. Goebel et al.

D. M. Goebel et al.

D. B. Heifetz et al.

Y. Hirooka et al.

R. A. Langley
"Materials surface modification by plasma bombardment
under simultaneous erosion and redeposition
conditions"
J. Nucl. Instrum. and Methods B23 (1987) 458

"Pumping of hydrogen during plasma-graphite interaction"

J. Vac. Sci. Technol. A5 (1987) 2768

"Retention of hydrogen in graphite"

J. Vac. Sci. Technol. A5 (1987) 2205

"Hydrogen isotope retention and release from copper" J. Vac. Sci. Technol. A5 (1987) 2319

\section{8}

"Residual hydrogen concentrations in graphite" in Proc. 34th National Symposium of the American Vacuum Society, Anaheim, CA, 1987

J. Vac. Sci. Technol. A6 (1988) in press

"Performance tests of carbon-carbon composites as plasma facing materials for fusion reactors"

in Proc. 34th National Symposium of the American Vacuum Society, Anaheim, CA, 1987

J. Vac. Sci. Technol. A6 (1988) in press

"Hydrogen recycle from graphite"

ibid

"Erosion of graphite by high flux hydrogen plasma bombardment in the PISCES facility"

Nucl. Fusion, in press

"Plasma erosion and redeposition studies of graphite in the PISCES facility"

Nucl. Technol., submitted

"H-alpha studies in TETR"

in Proc. 34th National Symposium of the American

Vacuum Society, Anaheim, $\mathrm{CA}, 1987$

J. Vac. Sci. Technol. A6 (1988) in press

Hydrogen pumping and release by graphite under high flux plasma bonbardment"

J. Vac. Soi. and Technol.A, in press

"Ion-induced release of hydrogen from graphite"

in Proc. 34th National Symposium of the American

Vacuum Society, Anaheim, CA, 1987

j. Vac. Soi. Technol. A6 (1988) in press 
W. K. Leung et al.

H. Hsu

J. E. Simpkins et al.

M. Ulrlckson et al.

W. R. Wampler et al.

A. E. Pontau et al.

P. L. Andrew et al.

A. B. Automazzi et al.

D.K. Brice

J. N. Brooks et al.

D. Buchenauer et al.

R. A. Causey
"An in-situ spectroscopic erosion yield measurement and its application as a surface morphology diagnostic"

J. of Vac. Sci. and Technol. A, to be published

"The interaction of hydrogen with graphite: a summary of the database accumulated from fusion research"

in Proc. 34th National Symposium of the American Vacuum Society, Anaheim, CA, 1987

J. Vac. Sci. Technol. A6 (1988) 1r: press

"Outgassing properties of various graph1tes" ibid

"Particle balance in TFTR"

ibid

"Deposition of carbon, deuterium and metals on the walls and limiters of TFTR"

ibid

"TFTR tritium inventory analysis"

in Proc. Ist Intern. Conf. on Fusion Nuclear Technolagy, Tokyo, 1988

Fusion Engineering Design (in press)

"Measurement of Inherent Hydrogen and Oxygen in graphite Using Laser Release Analysis"

in Proc. 8th Intern. Conf. on Plasma Surface Interactions in Controlled Fusion Devices, Julich, $19 \mathrm{~g} ;$;. Nucl. Mater., subuitted.

"The Effect of Adsorbed Carbon and Sulphur on Hydrogen Permeation Through Palladuim"

ibid

"MEASTRI: A hybrid analytical/Monti Carlo code for particle transport in solids"

ibid

"Erosion/redeposition modeling and calculations for carbon"

ibid

"Particle balance and wall pumping measurements in TFTR"

ibld

"The interaction of tritium with graphite and its impact on tokamak operation

ibid 
B. L. Doyle et al. Deuterium and metal deposition on the limiters and
walls in TFTR"
ibid

H. E. Dylla

"First-wall conditioning for enhanced confinement discharges in TFTR"

ibid

A. Ehrhardt et al.

"Modeling $D_{\alpha}$ emission in TFTR"

ibid

E. Eranconi et al.

"Erosion and redeposition behavior of $C+S i C$, $C F+S I C, C F$ and isotropic graphite under '-D plasma bombardment in PISCES"

Ibid

A. A. Haasz et al.

"Angle of Incidence Dependence of Light Ion Physical sputtering of carbon"

Ibid

Y. Hirooka et al.

"Spectroscopic Measurements of Hydrogen Recycling and Erosion of Graphite Materials in PISCES" ibid

S. J. Kilpatrick et al. "Collector probe measurements of ohmic conditioning discharges in TFTR"

ibid

H. Langer

"Modeling in carbon and methane impurity transport in tokamaks"

ibid

R. Langley

"Deuterium and helium ion-induced release of hydrogen from graphite"

ibid

D. M. Manos et al.

"Probe measurements of TFTR edge plasmas at neutral beam powers up to $20 \mathrm{MW"}^{\prime \prime}$

ibid

R. T. MaGrath et al. "Transport of sputtered impurities and deuterium in the vicinity of the TFTR inner bumper limiter"

ibid

B. E. Mills et al.

"Distribution, composition, and morphology of deposition and erosion of material on the Iimiter and wall of TFTR"

ibid 